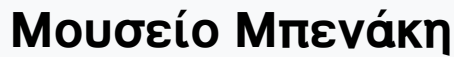

Tóp. 8, Ap. 8 (2008)

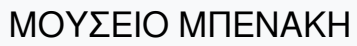

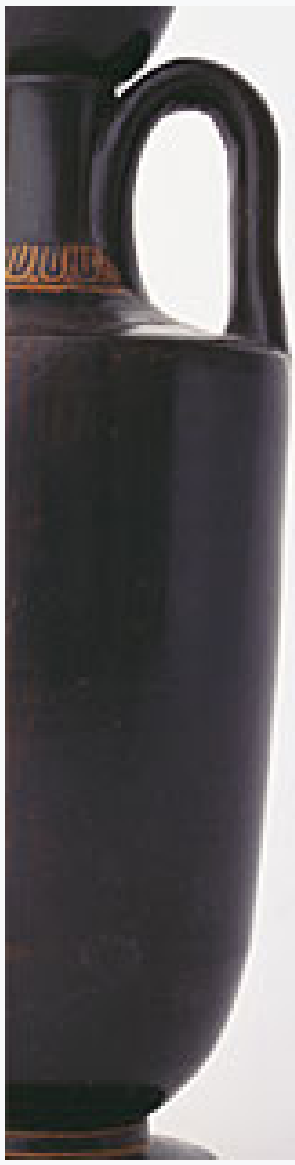

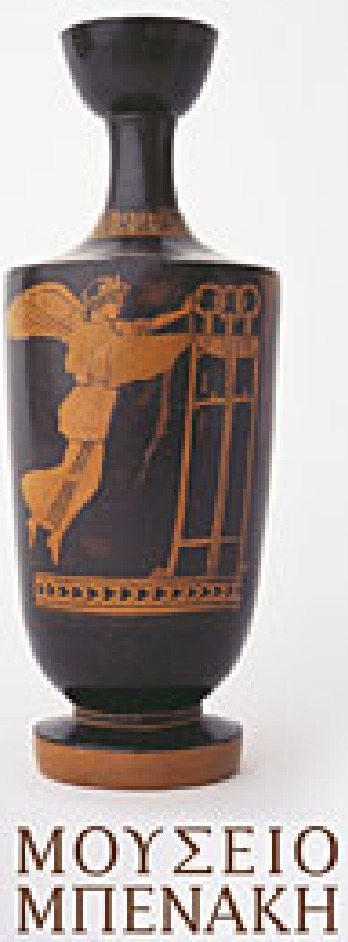

8,2008

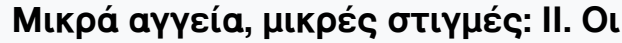

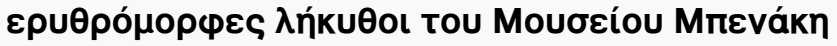

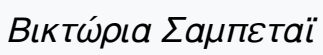

doi: $10.12681 /$ benaki.14

\section{Bıß入ıорачıкń avaчорá:}

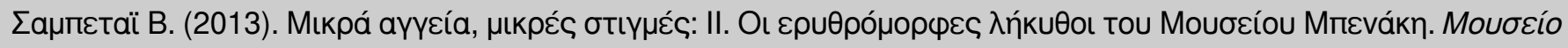
Мпєvákn, 8(8), 63-89. https://doi.org/10.12681/benaki.14 


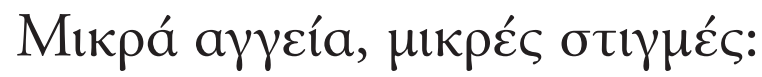

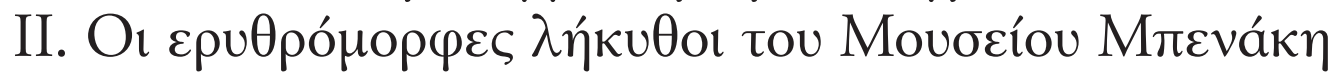

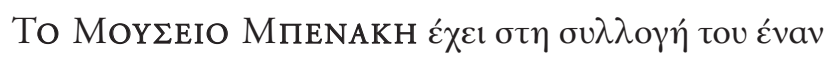

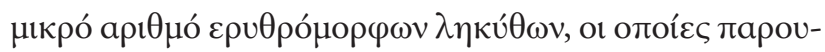

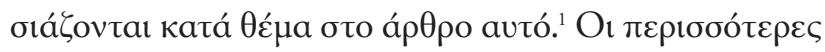

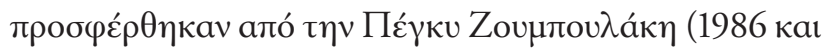

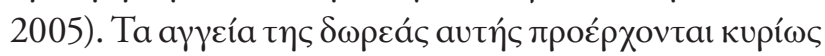

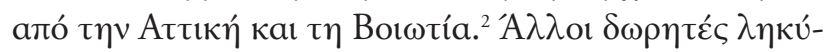

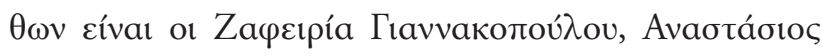

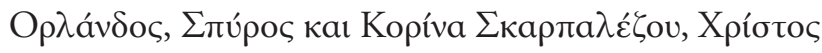

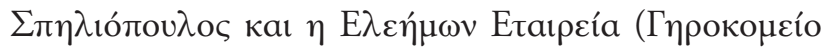

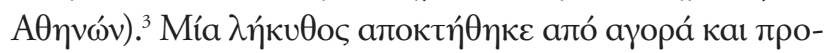

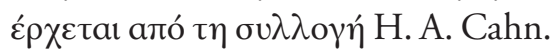

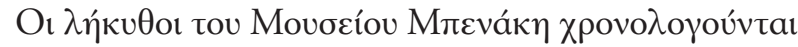

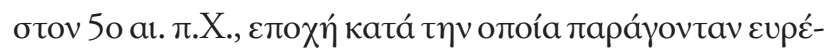

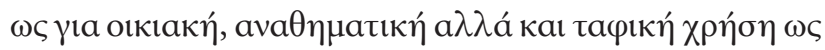

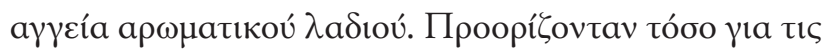

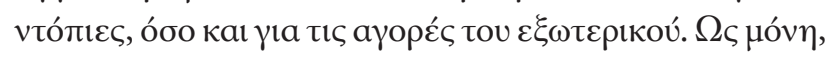

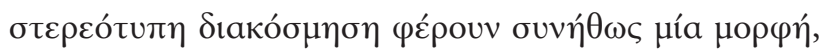

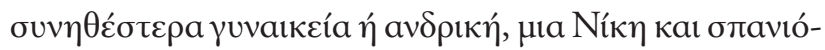

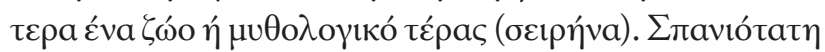

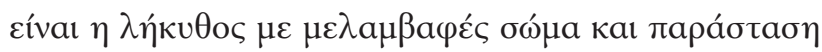

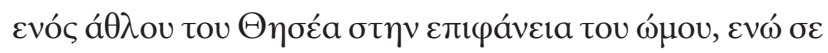

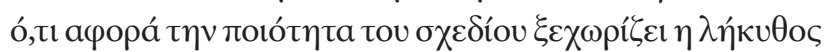

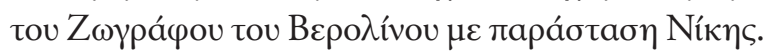

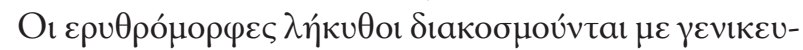

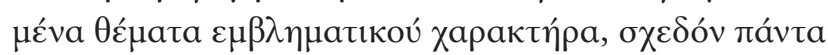

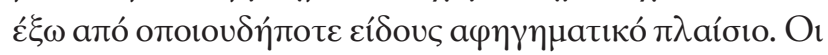

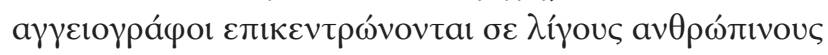

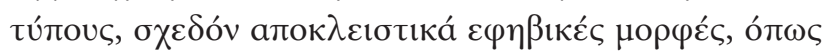

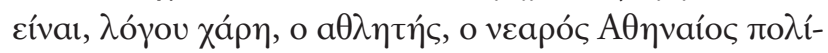

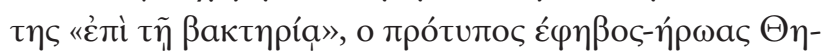

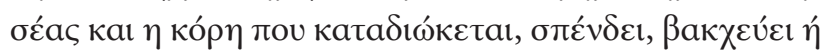

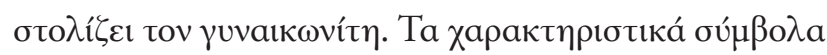

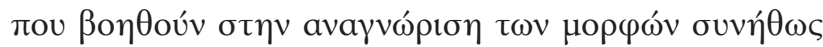

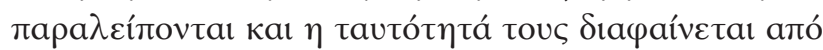

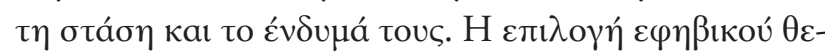

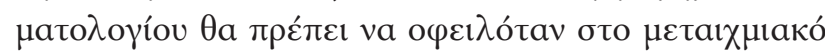

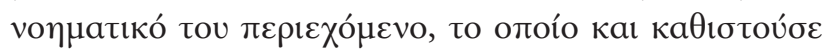

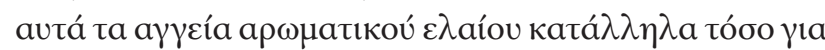

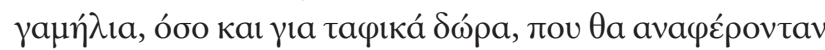

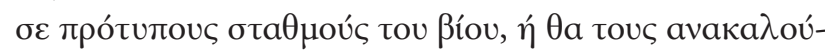

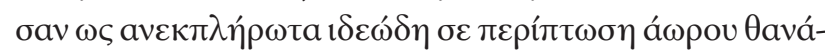

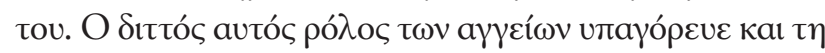

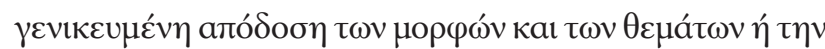

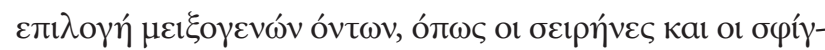

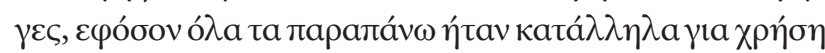

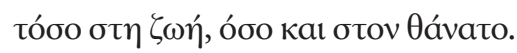

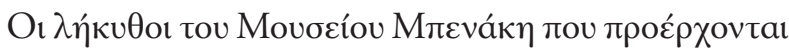

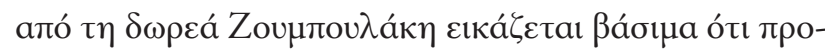

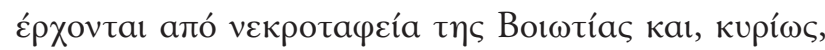

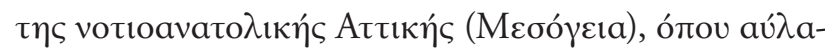

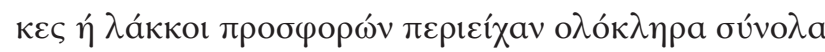

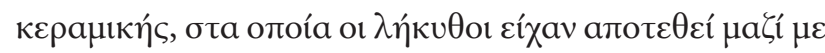

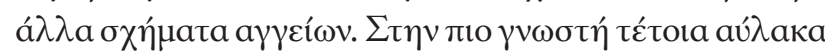

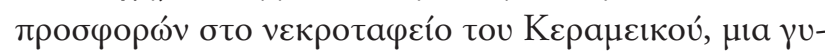

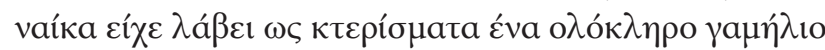

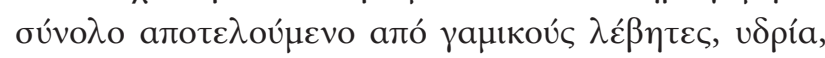

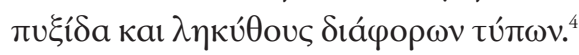

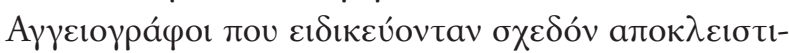

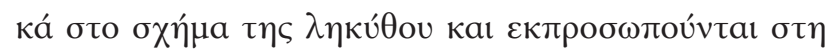

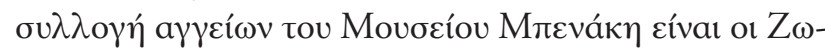

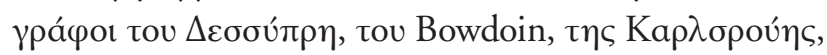

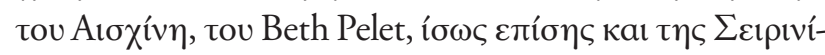



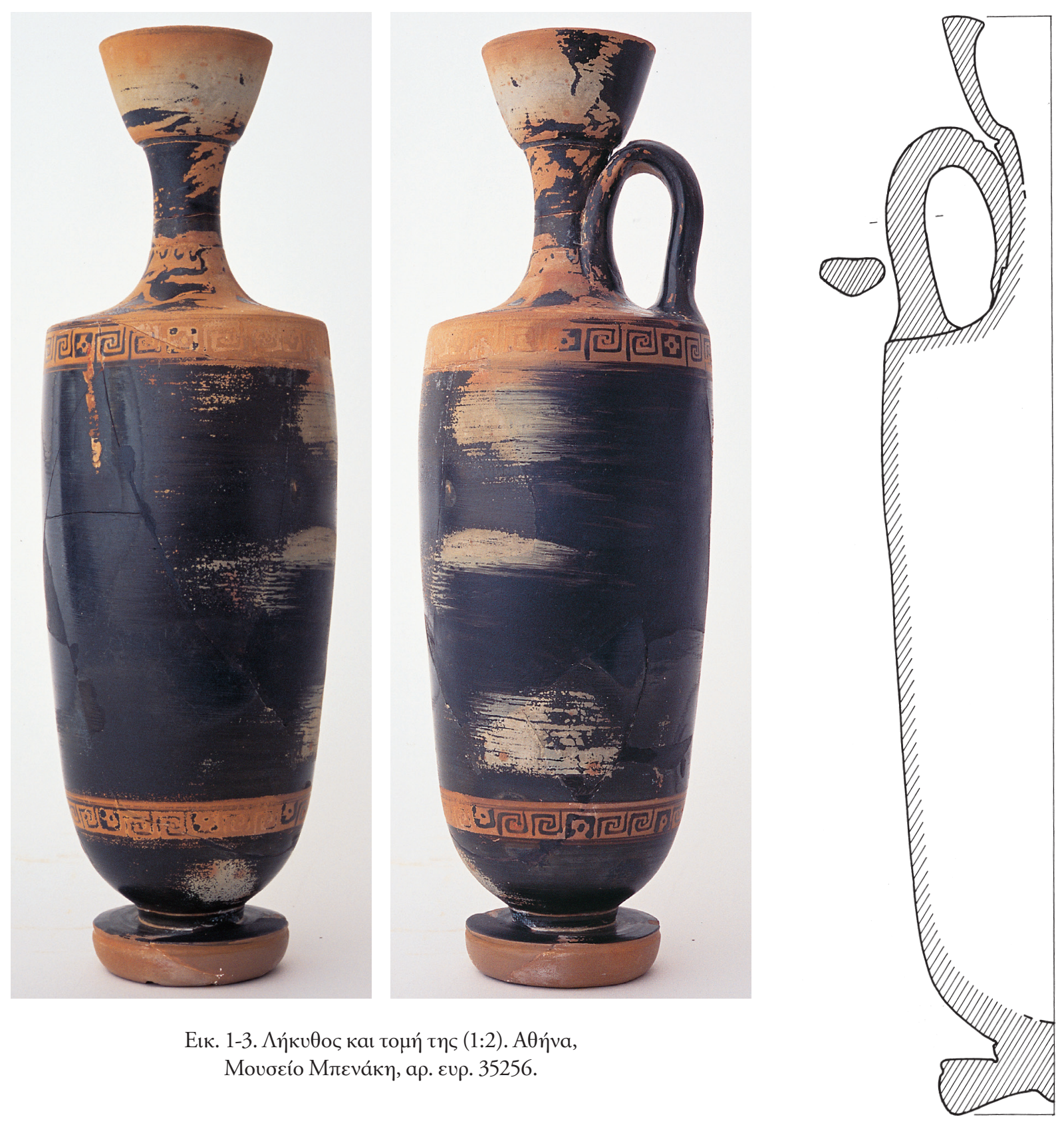

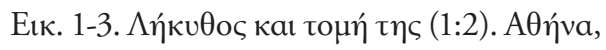

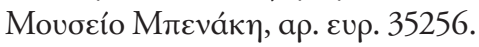

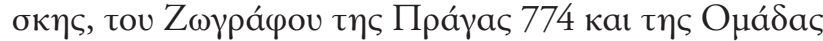

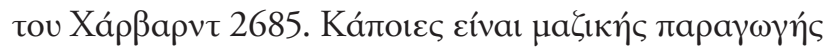
кal $\delta \varepsilon v$ a

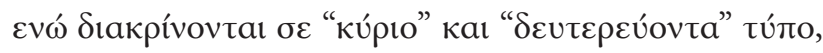

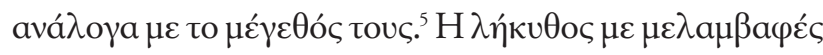

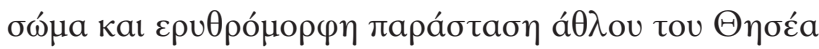

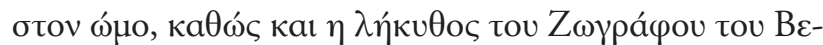

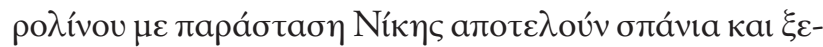

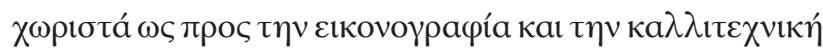

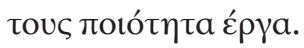

\section{КАТА $\Lambda$ ОГО $\Sigma$}

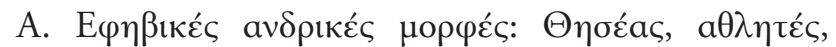

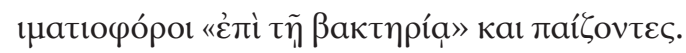

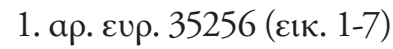

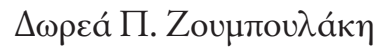

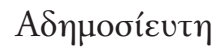

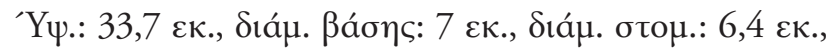

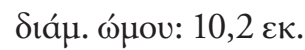



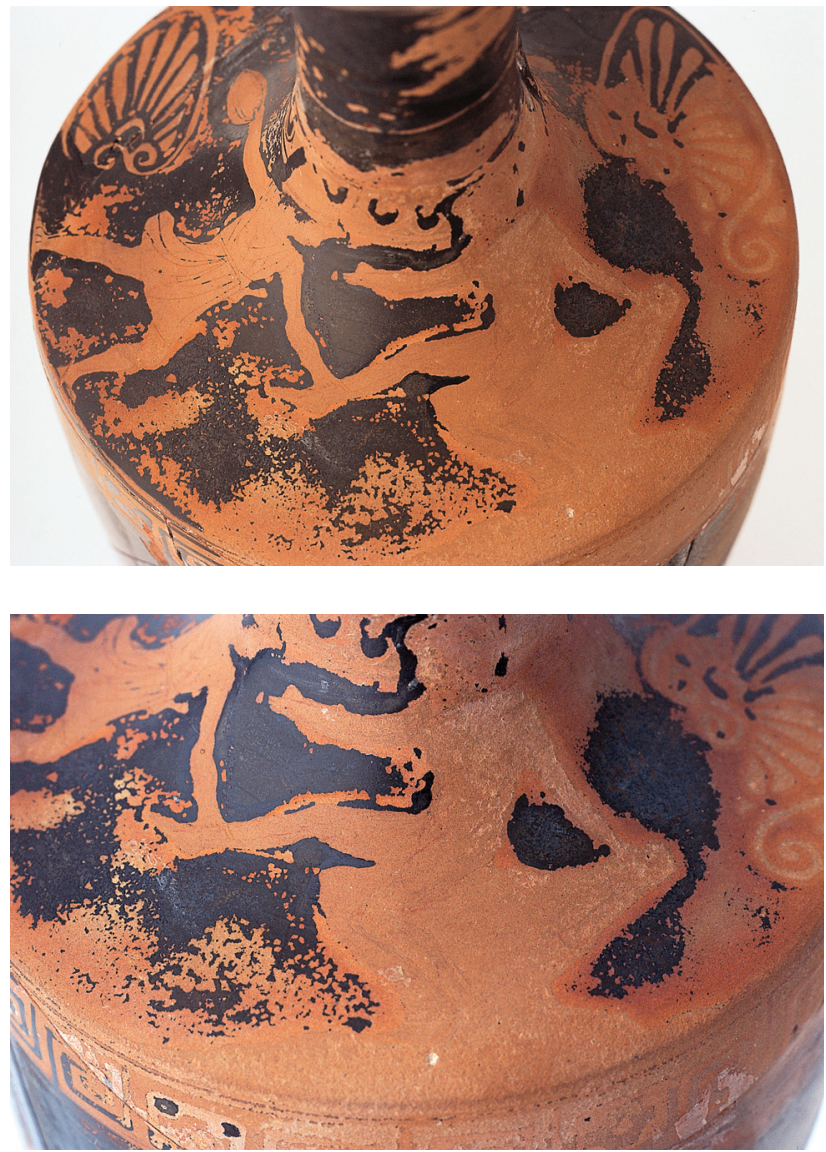
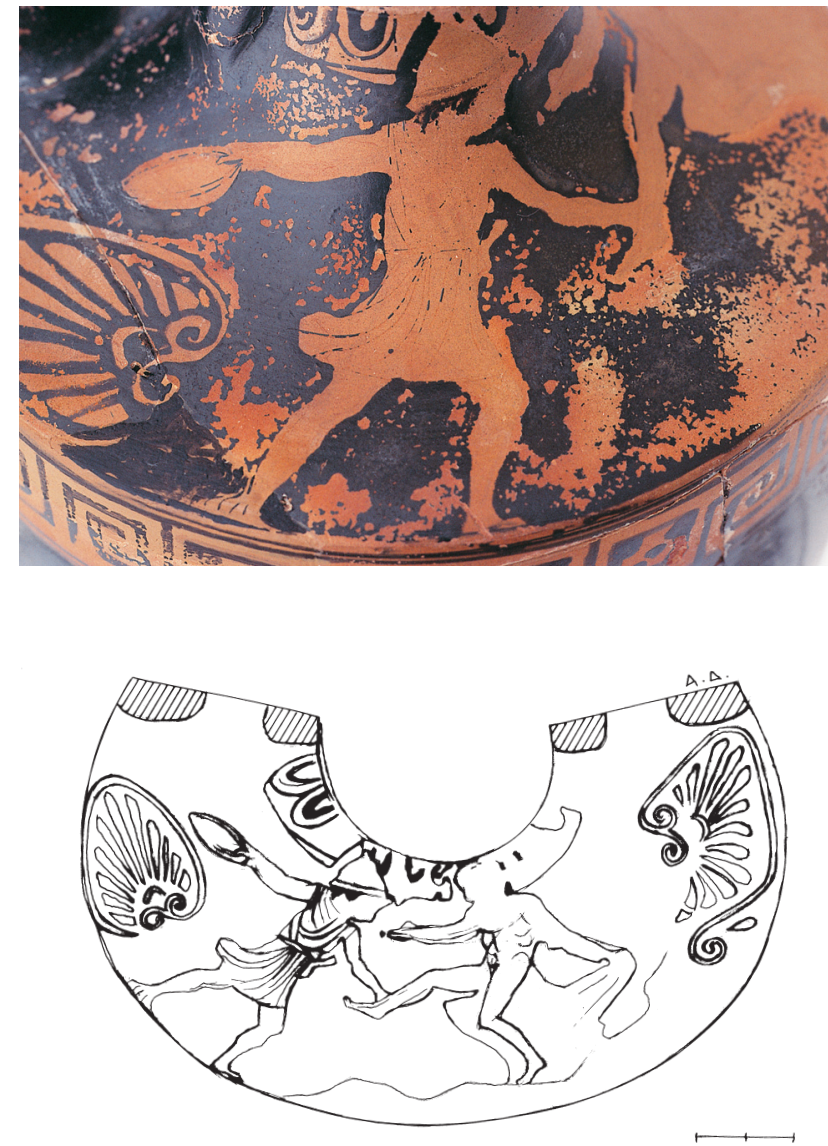

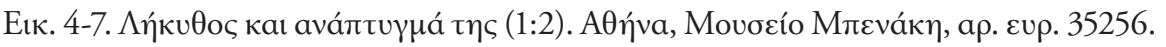

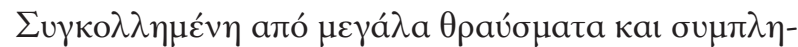

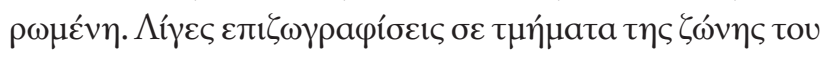

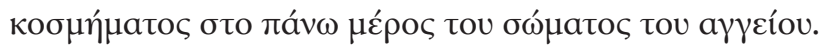

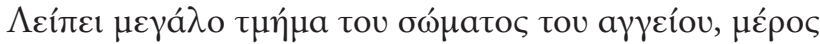

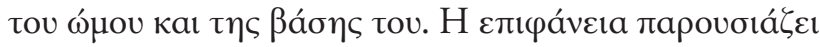

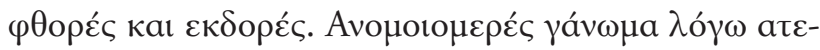

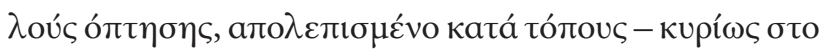

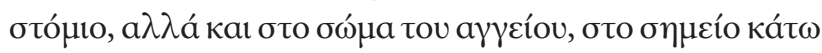

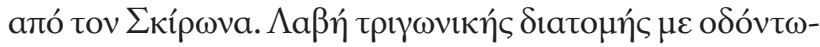

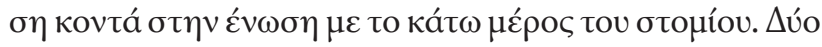

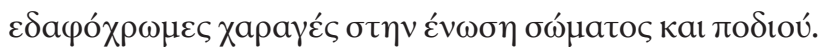

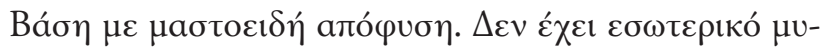


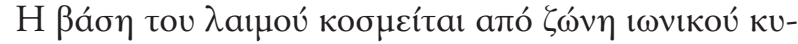

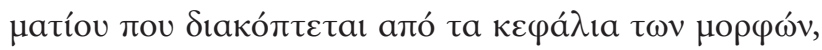

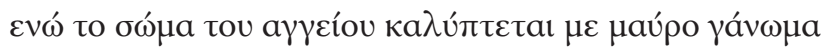

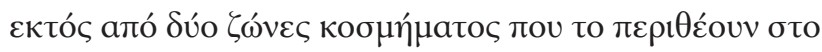

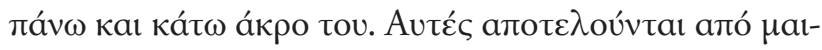

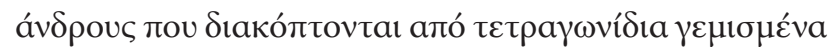

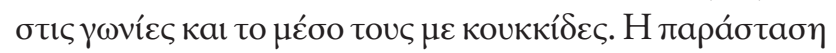

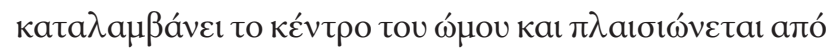

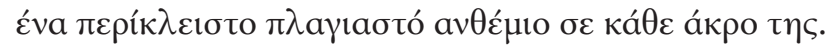

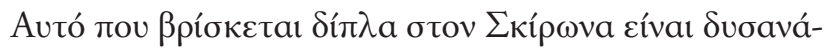

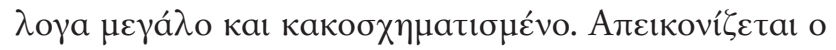

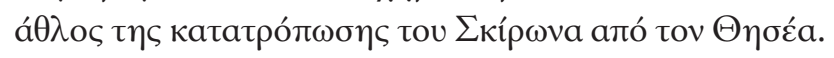

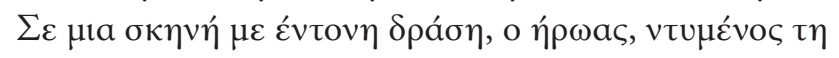

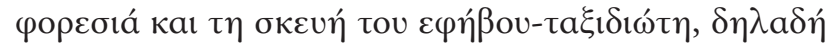

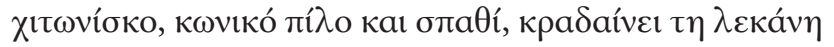

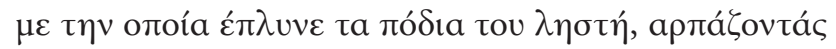

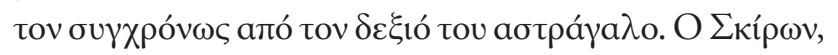

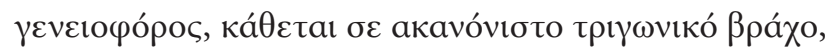

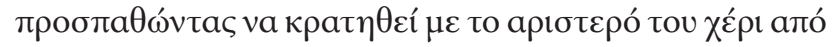

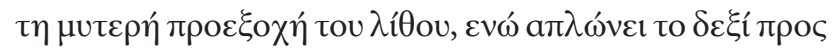

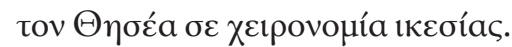

$440-420 \pi . X$.

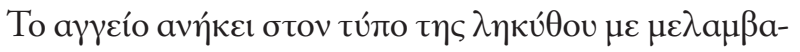




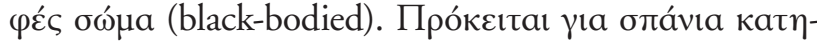

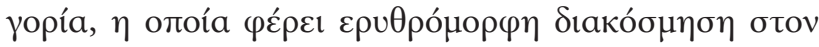

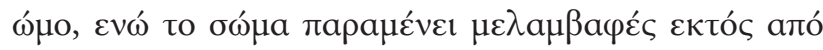

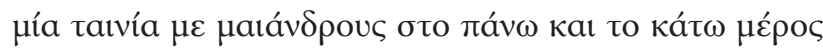

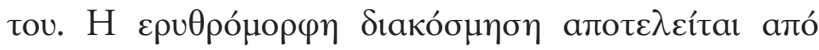

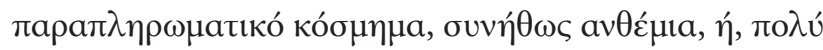

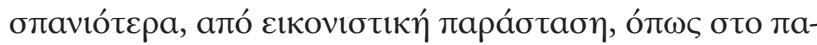

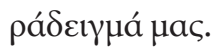

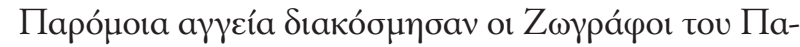

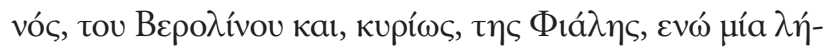

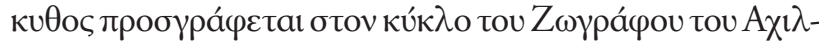

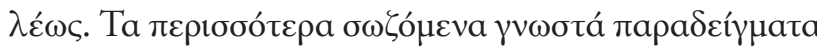

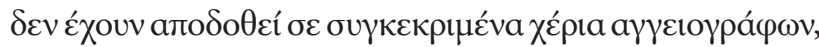

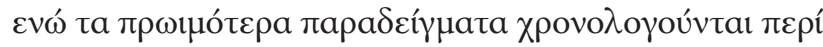

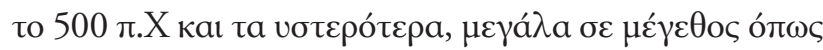

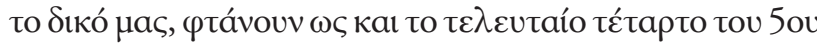

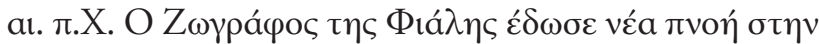

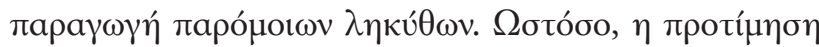

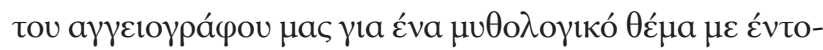

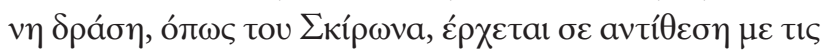

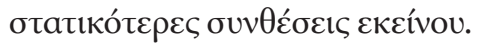

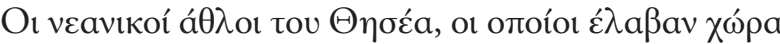

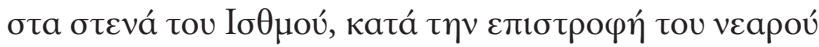

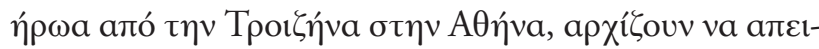

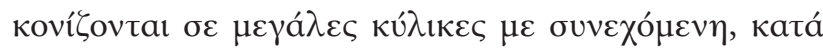
$\varepsilon \pi \varepsilon เ \sigma o ́ \delta ı$ เa, a

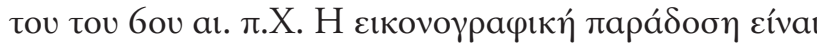

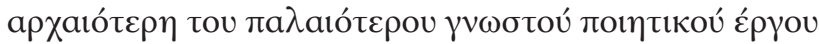

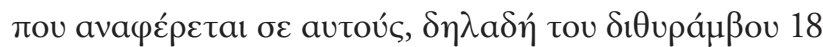

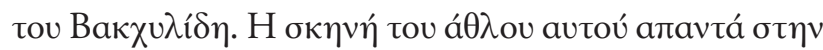

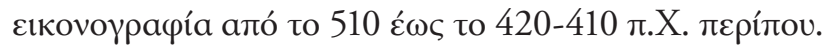

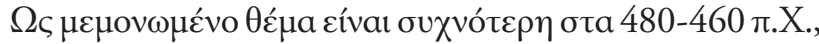

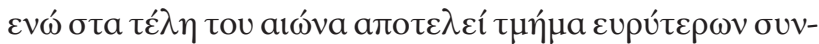

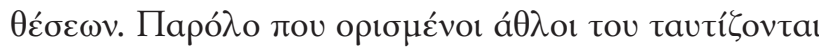

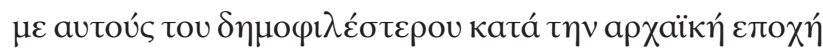

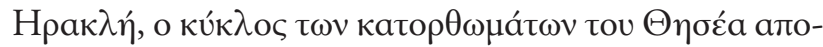

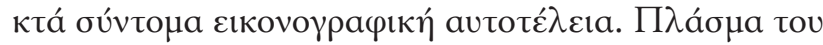

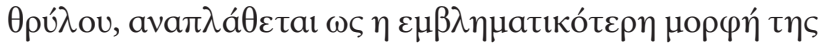

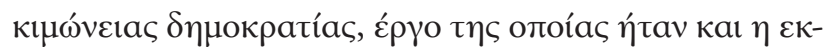

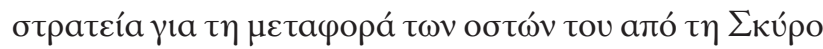

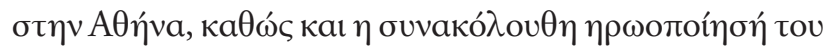

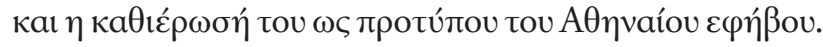

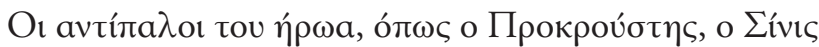

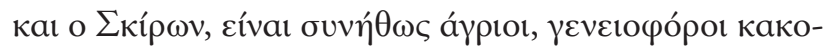

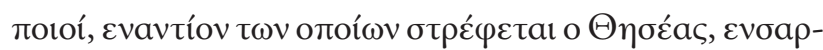

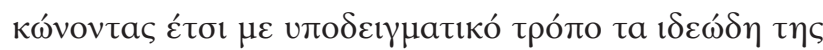

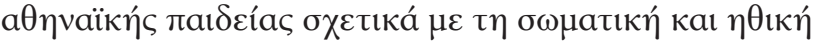

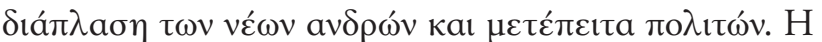

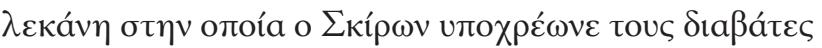

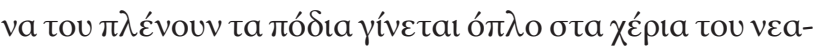

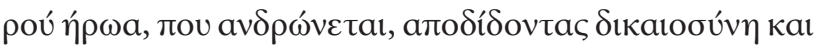

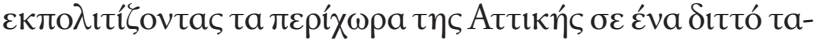
$\xi i ́ \delta ı$ a

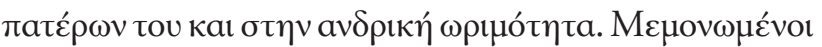
á $\theta \lambda$ ot a

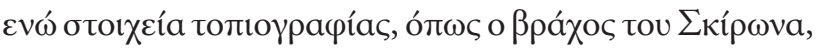

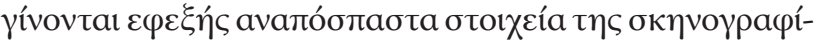

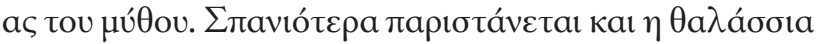

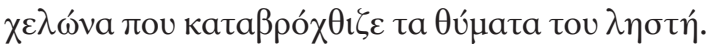

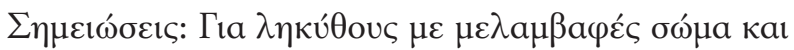

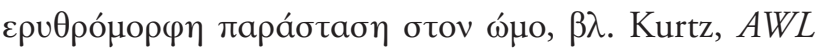
122-27· J.H. Oakley, The Phiale Painter (Mainz 1990) 53

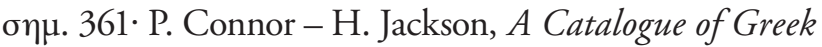
Vases in the Collection of the University of Melbourne at the Ian Potter Museum of Art (Melbourne 2000) 146-48. $\eta$ G. Giudice, Il tornio, la nave, le terre lontane (Roma

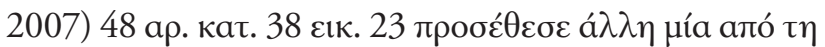

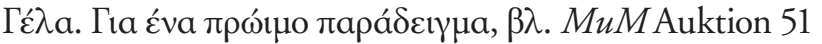

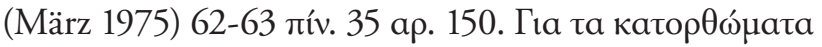

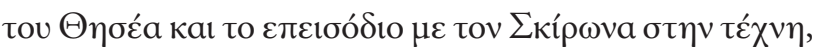
$\beta \lambda$. LIMC VII, $\lambda$. Theseus, 931-32 ap. 97-122 (J. Neils),

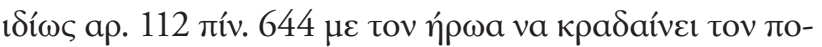

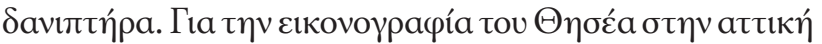

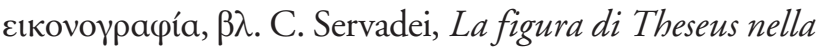

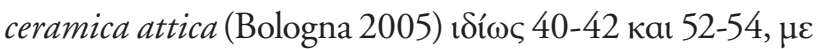

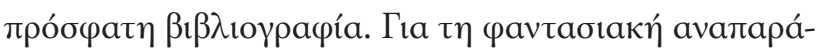

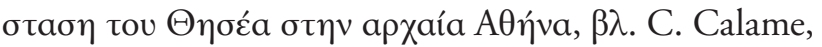
Thésée et l'imaginaire athénien (Lausanne 1990).

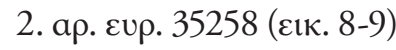

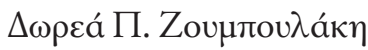

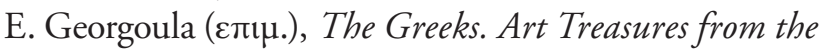

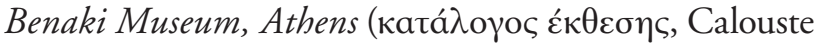
Gulbenkian Museum, Lisbon 2007) 86-87 ap. 39 (V. Sabetai).

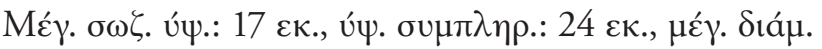

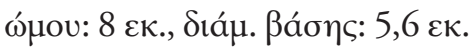

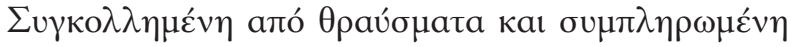
бто ото́

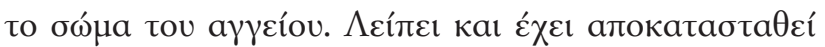

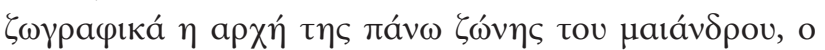

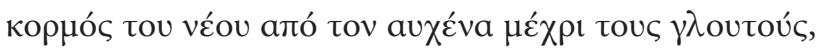



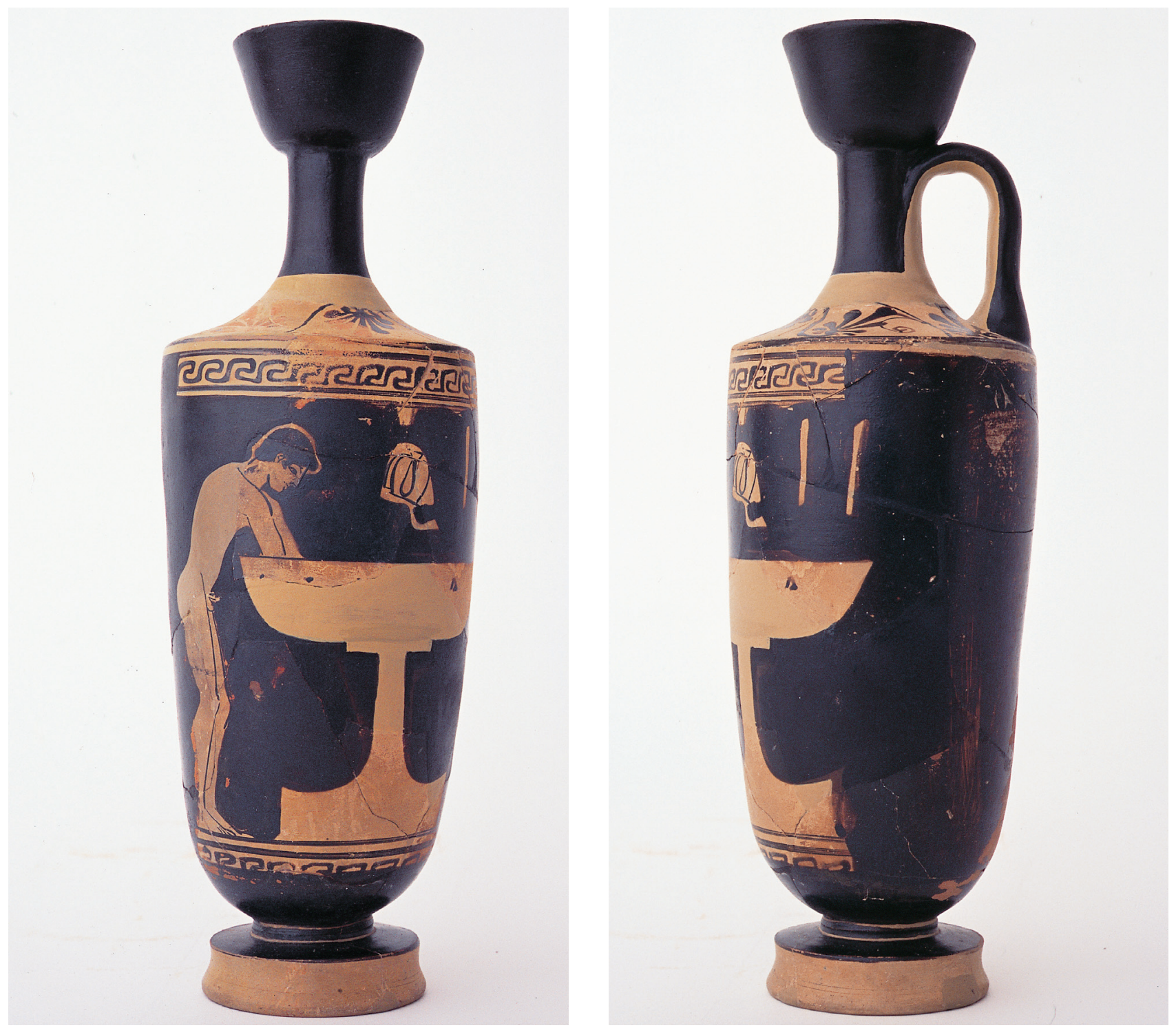

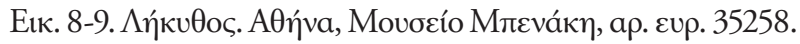

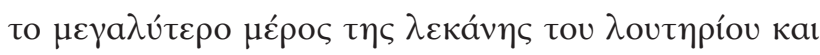

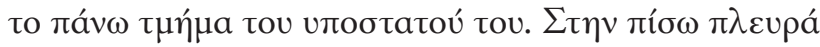

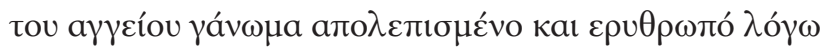

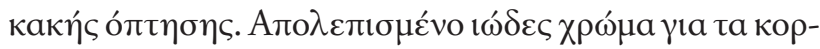

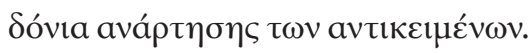

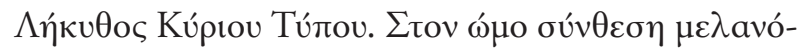

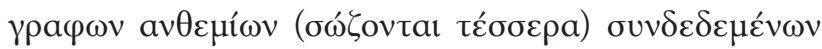

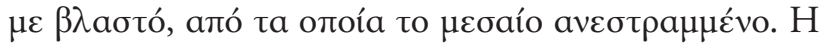

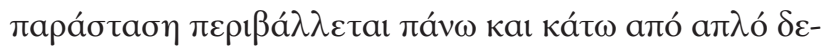

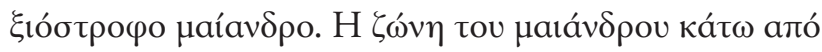

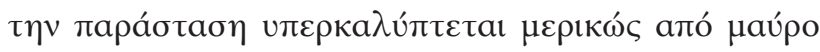

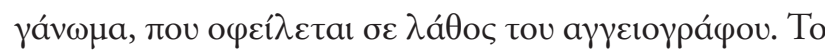

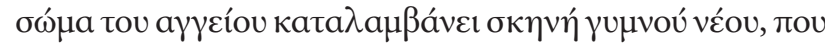

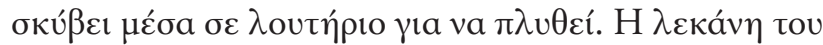

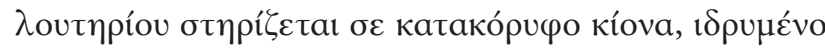

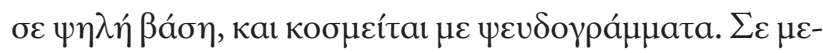

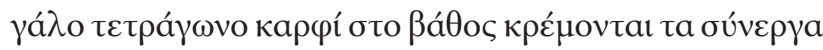

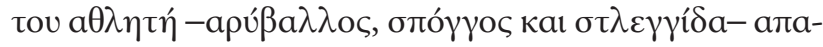

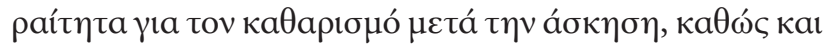

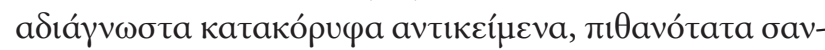
$\delta a ́ \lambda ı$ ı́ $\sigma \tau \lambda \varepsilon \gamma \gamma \dot{i} \delta \varepsilon \varsigma$.

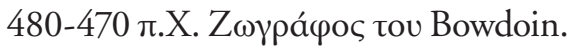



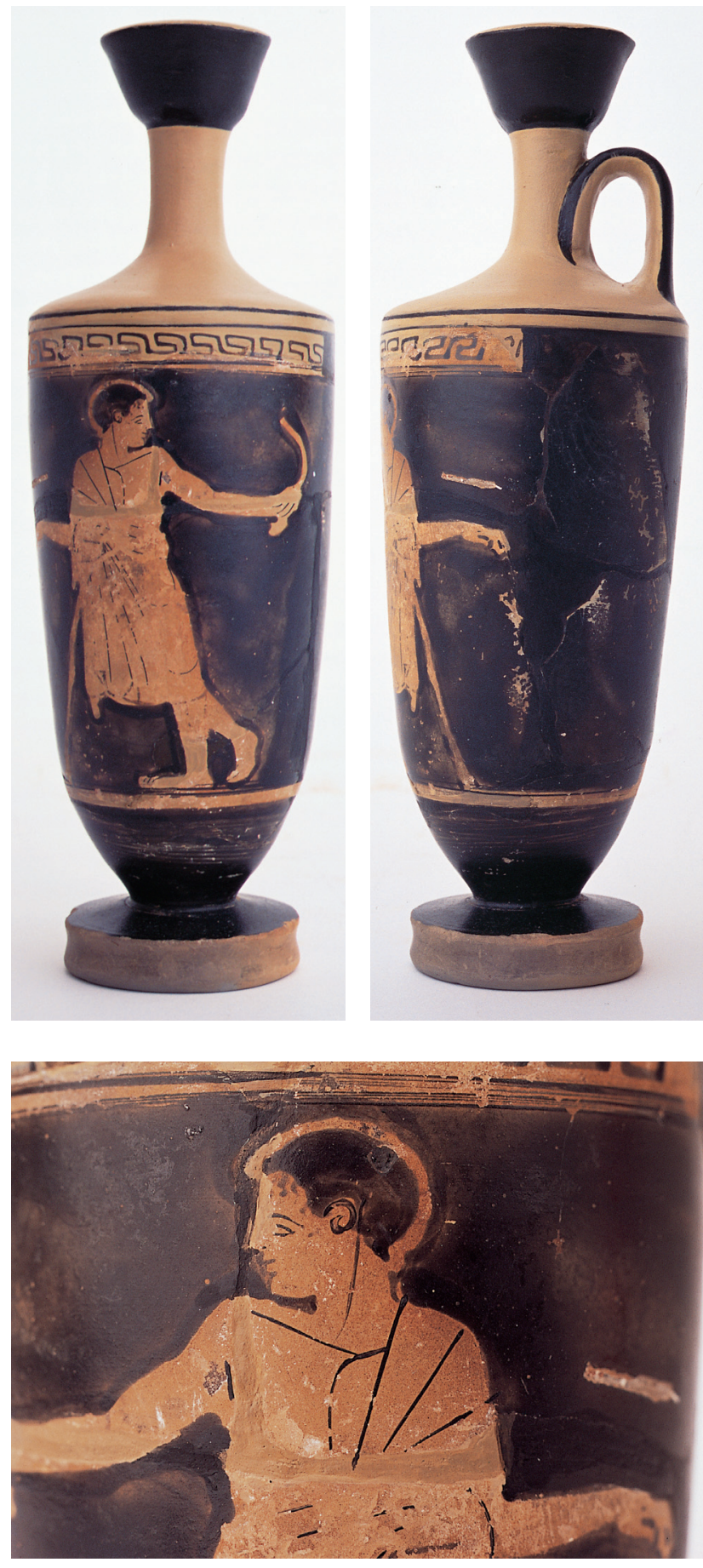

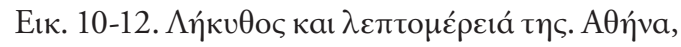

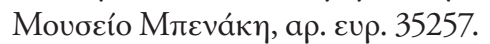

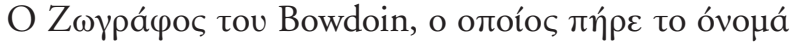

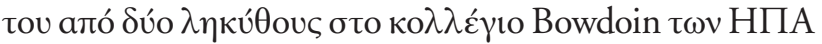

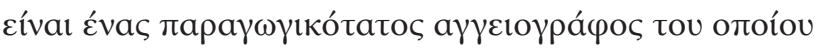

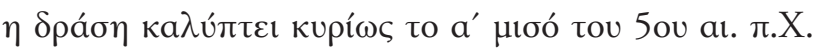

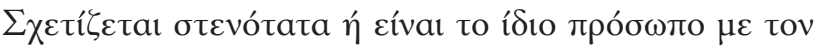
Z

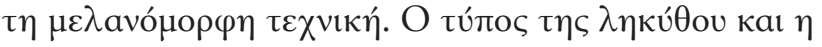

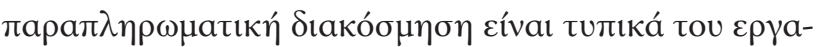

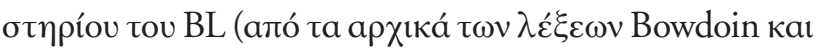

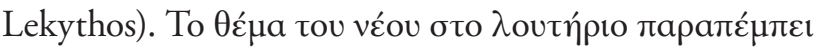

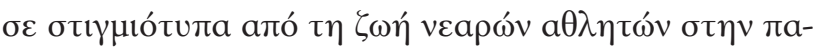

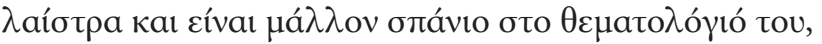

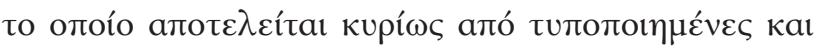

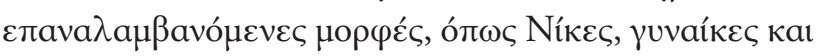

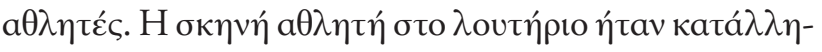

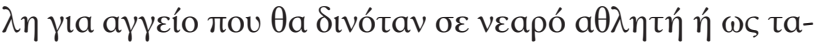

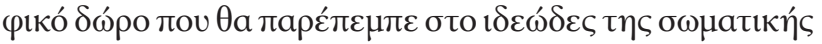

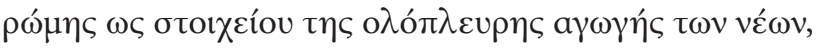

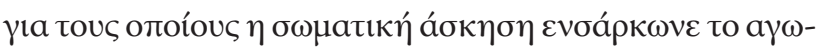

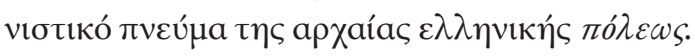

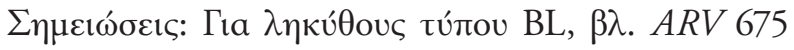

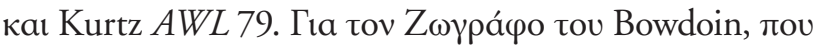

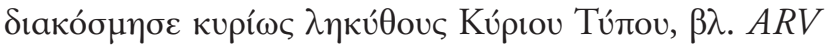
677-94, 1665-1666. Para 405-07, 514. Add 279-280. Haspels, ABL 157-60 C. Weiss, CVA Karlsruhe 3, 81,

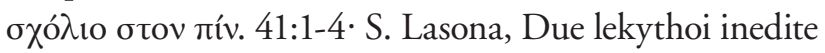
da Leontini e il problema del pittore di Bowdoin, Cronache di archeologia e di storia dell'arte 8 (1969) 53-63 $\cdot$ K. Schauenburg, Athenabüsten des Bowdoin-malers, AA 89 (1974) 149-57 Kurtz, $A W L$ 15-16 H.P. Isler - M. Sguaitamatti

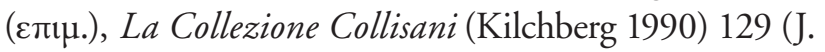
Rickenbach) D.C. Kurtz - J. Boardman, An Athenian Red-figure Neck-amphora by the Athena-Bowdoin Painter,

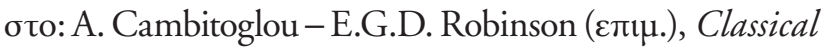
Art in the Nicholson Museum, Sydney (Mainz 1995) 85-

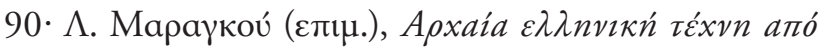

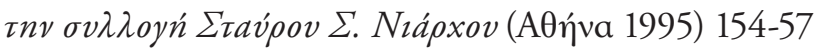

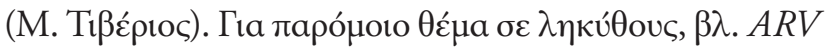
684, 154 H. H. Walters, Red-figured Vases Acquired by the British Museum, JHS 41 (1921) 127 عı. 7· Para 406, 154 ter: Sotheby's, November 27, 1967, 60 ap. 147· ARV1666,

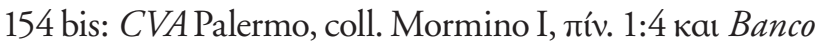

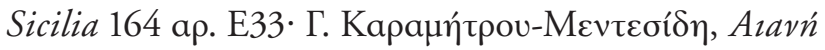

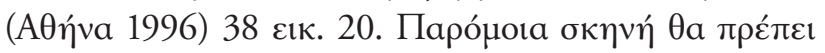

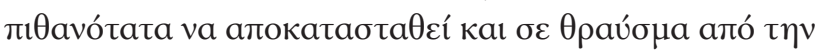

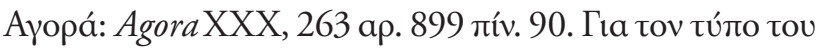


$\lambda$ outทpíou, $\beta \lambda$. Ginouvès, Balaneutikè (Paris 1962) 128 عเк. 85-88. E. N. Gardiner, Greek Athletics, Sports and Festivals (London 1910) 481 عıк. 181.

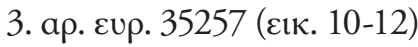

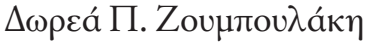

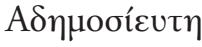

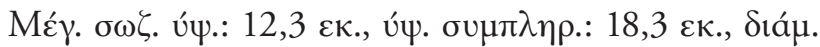

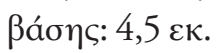

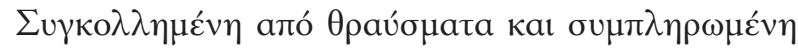

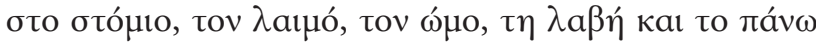

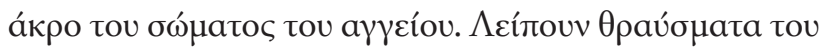

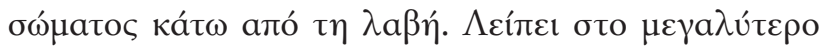

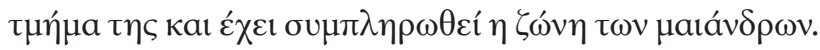

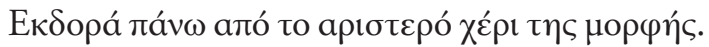

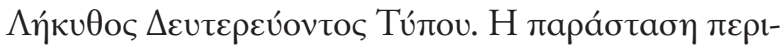

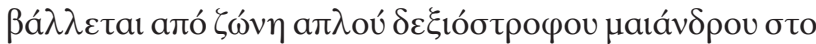

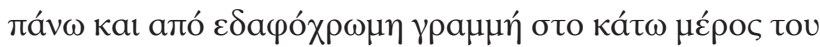

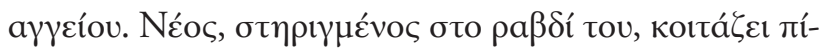

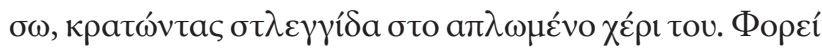

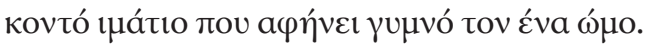

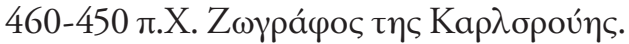

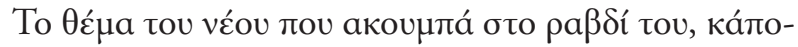

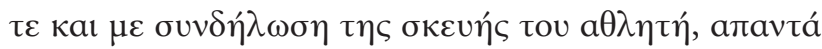

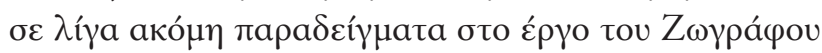

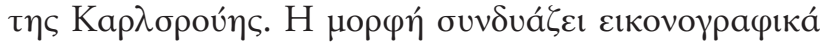

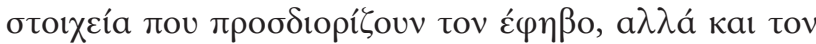

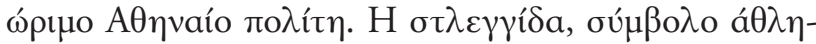

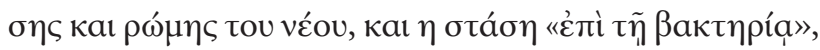

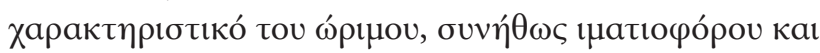

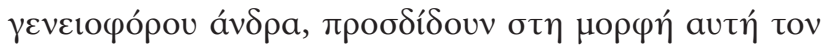

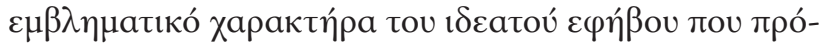

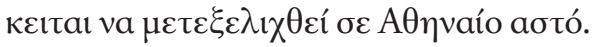

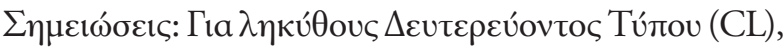
$\beta \lambda$. Kurtz, $A W L$ 84· Agora XXX, 46. Гta tov Z $\omega \gamma \rho a ́ \varphi o$

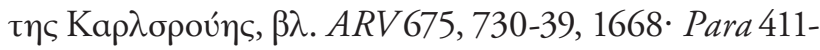

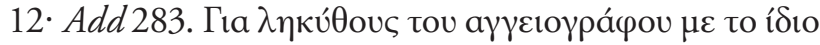

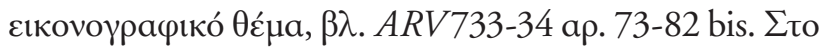

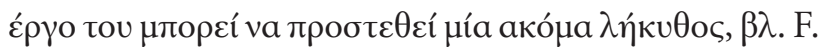
G. Lo Porto, Civiltà indigena e penetrazione greca nella Lucania orientale (Roma 1973) MonAnt48, serie misc. 1,

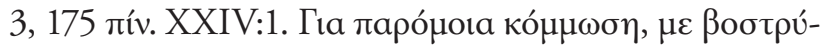

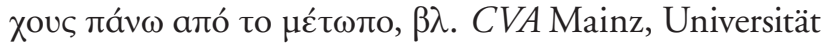

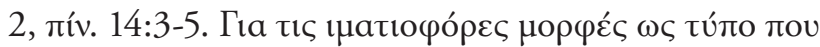

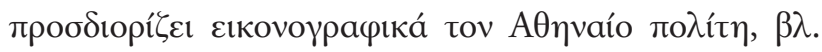
H.G. Hollein, Bürgerbild und Bildwelt der attischen De- mokratie auf den rotfigurigen Vasen des 6-4 Jahrh. v. Chr.

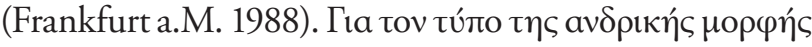
$\mu \varepsilon \beta$ ßактүрía, $\beta \lambda$. S. Couvret, L'homme au bâton. Statique et statut dans la céramique attique, Mètis 9-10 (1994-1995) 257-81· P. Brulé, Bâtons et bâton du mâle, adulte, citoyen,

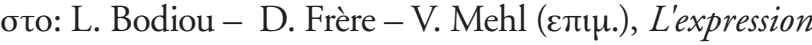
des corps (Rennes 2006) 75-84.

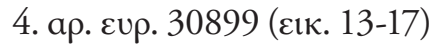

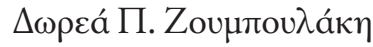

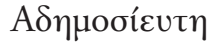

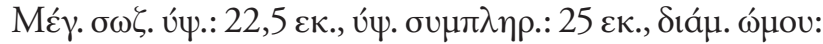

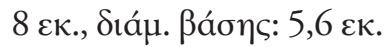

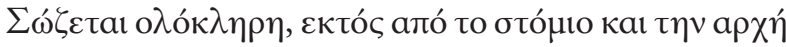

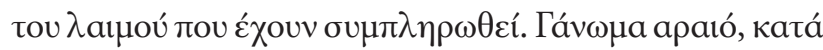

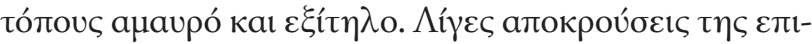

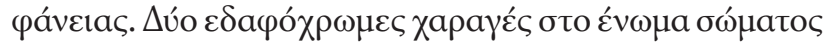

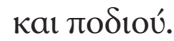

$\Lambda \eta ́ \kappa u \theta$ oc Kúpiou Tútou. Stov

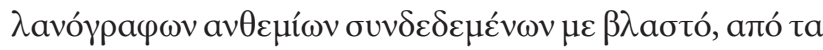

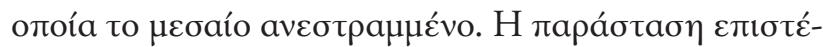

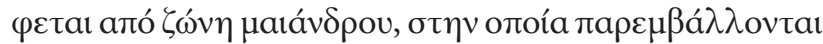

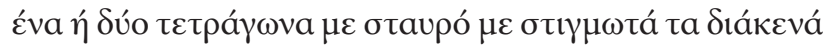

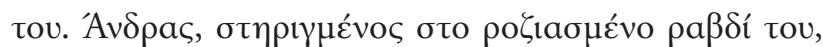

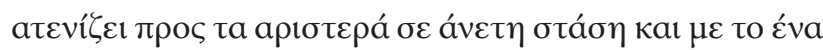

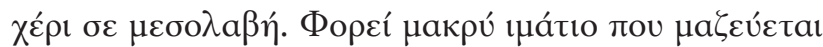

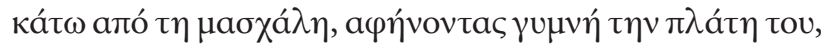

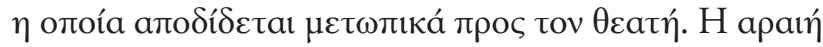

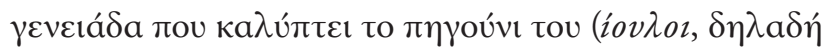

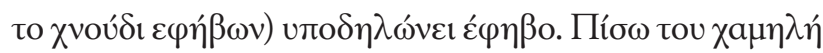

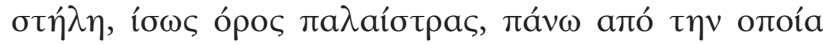

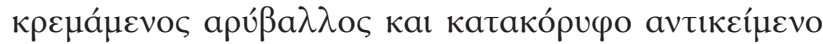

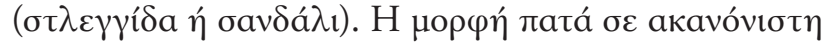

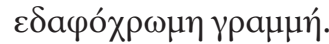

Пврі́ то $430 \pi . X$. Z Painter).

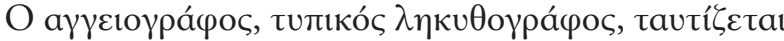

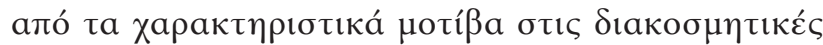

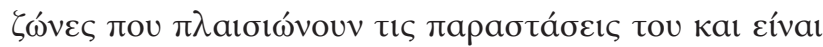

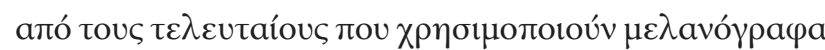

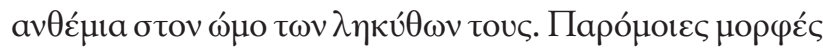

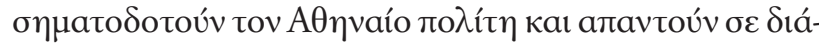

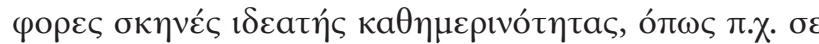

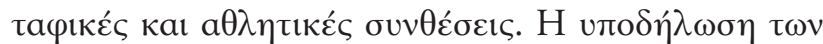

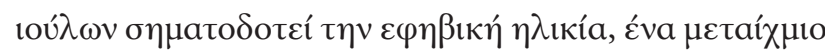

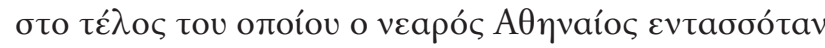



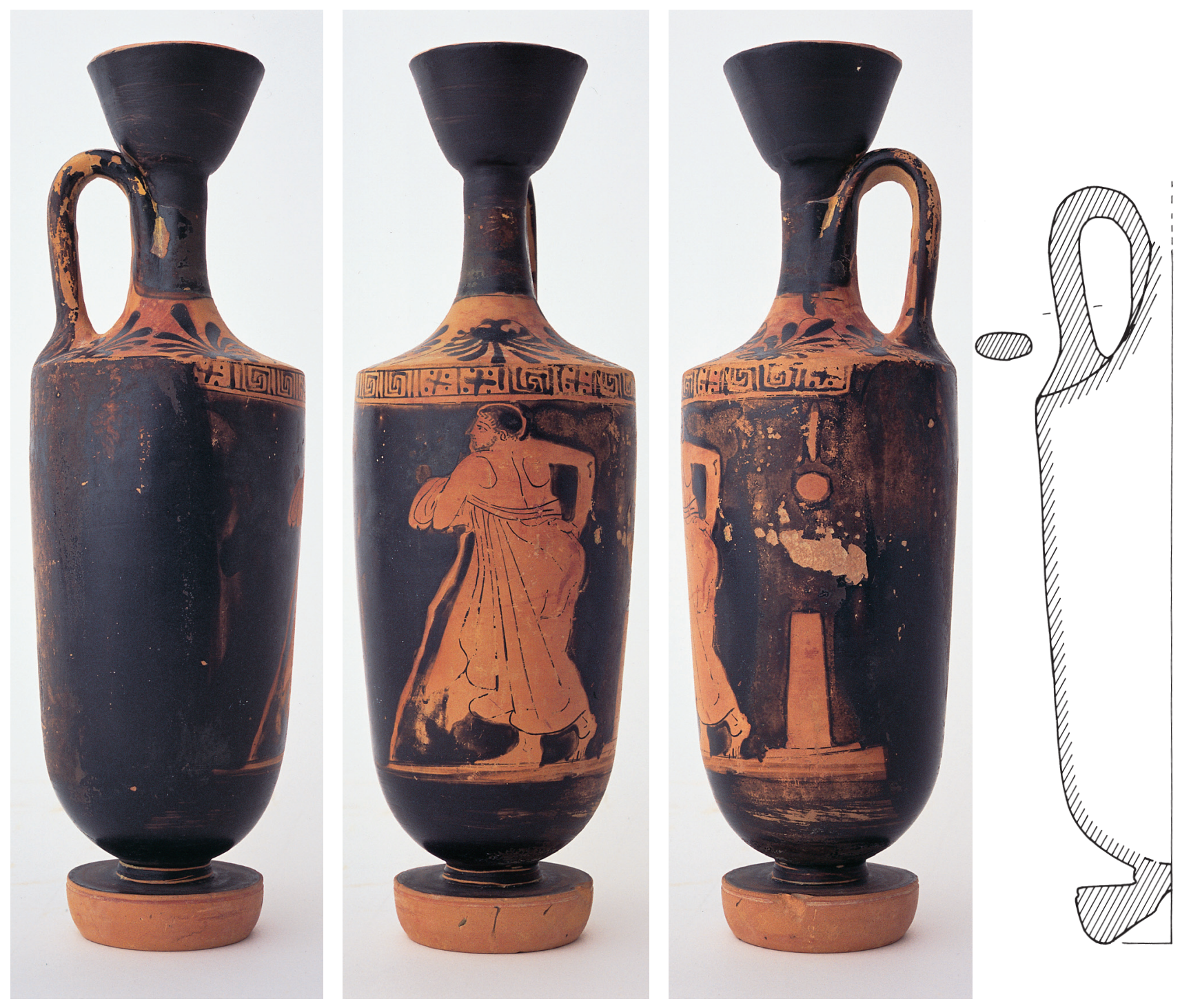

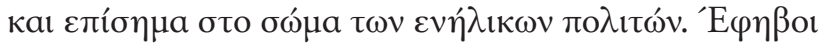

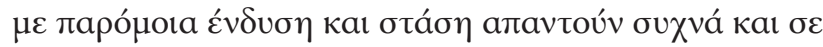

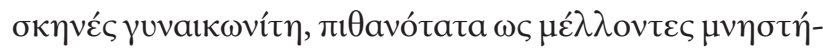

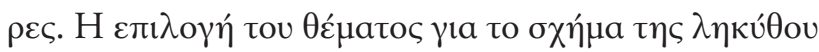

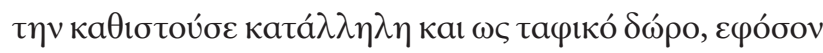

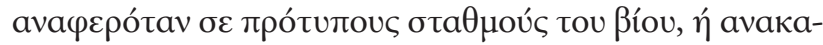

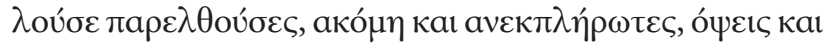

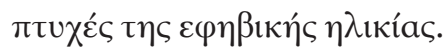

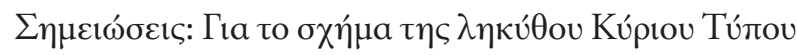

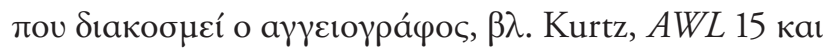

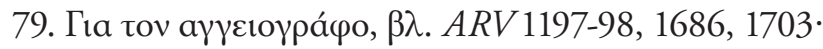

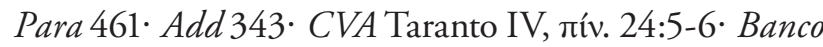

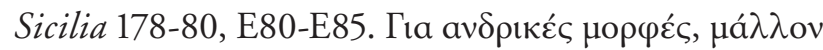

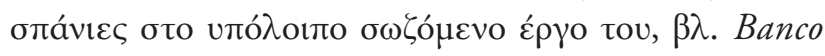

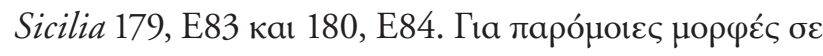

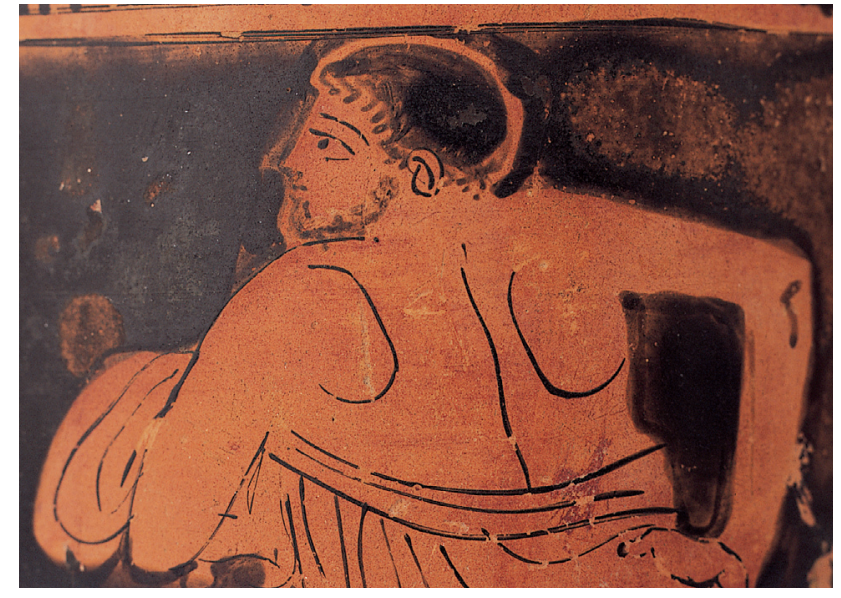

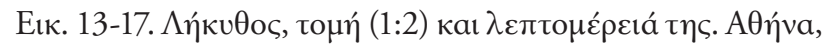

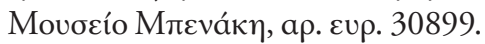



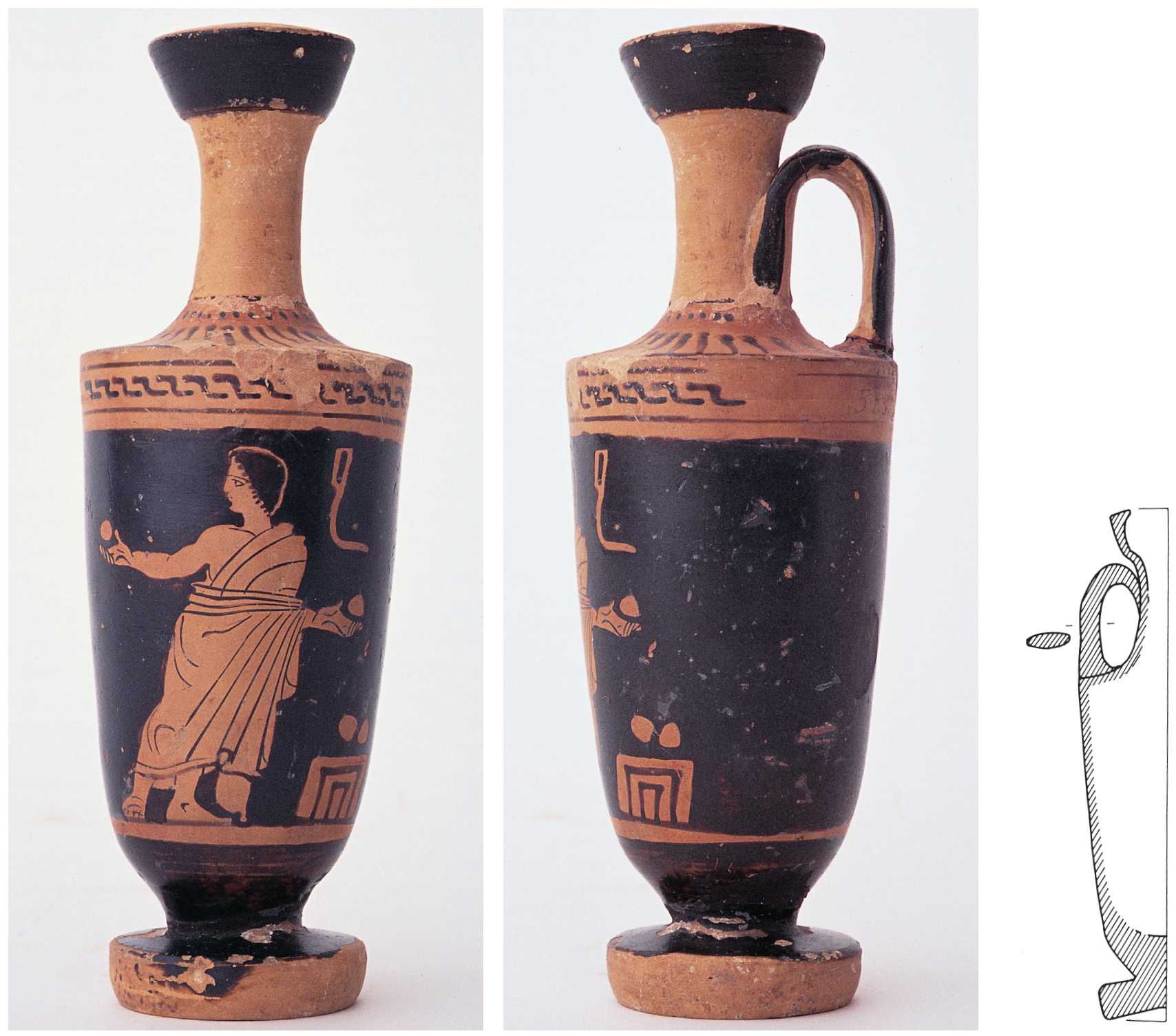

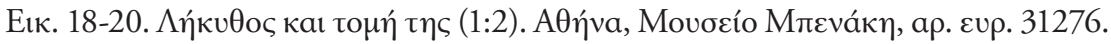

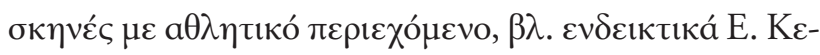

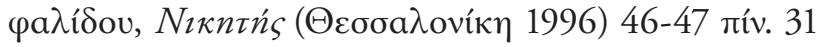

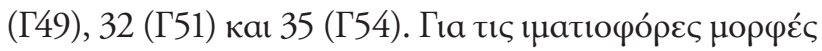
 $\pi \mathrm{o} \lambda$ í $\eta, \beta \lambda$. H.G. Hollein, Bürgerbild und Bildwelt der attischen Demokratie auf den rotfigurigen Vasen des 6-4

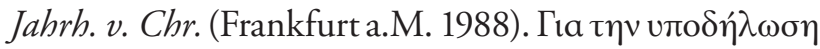

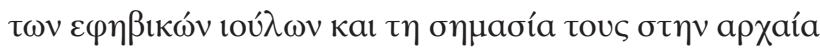

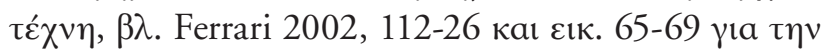

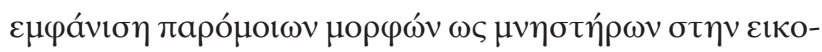

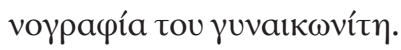

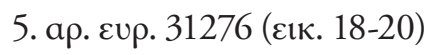

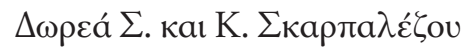

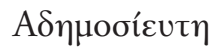

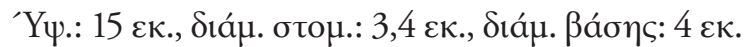

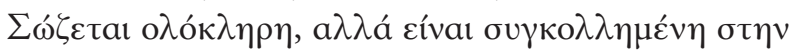

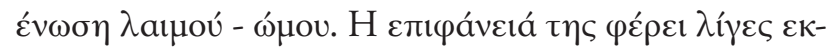

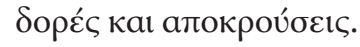

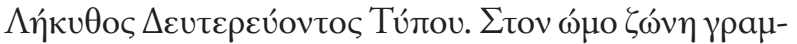

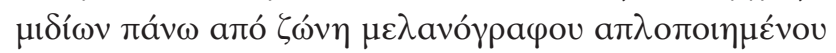

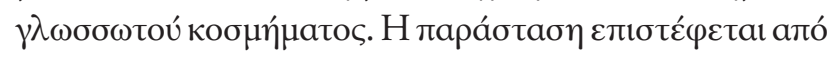

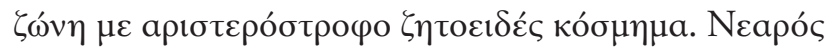




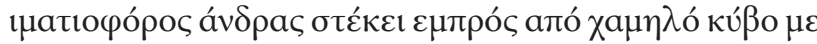

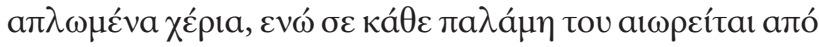

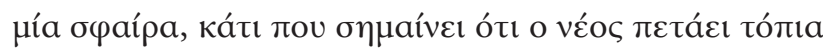

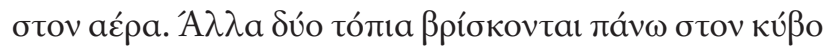

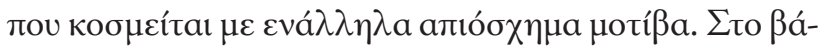

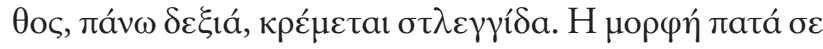

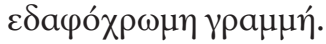

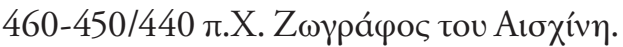

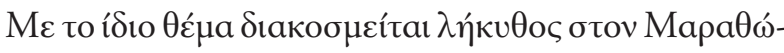

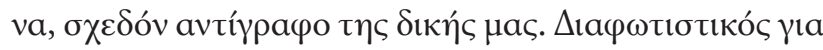

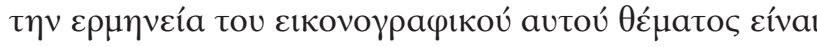

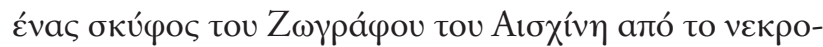

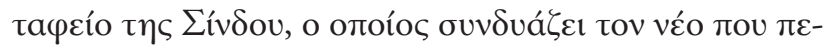

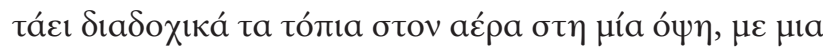

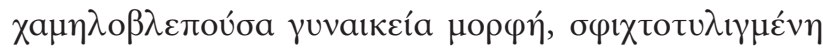

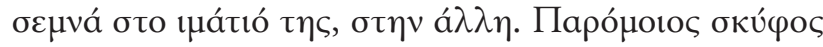

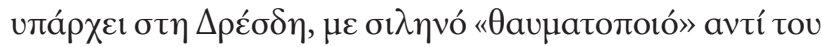

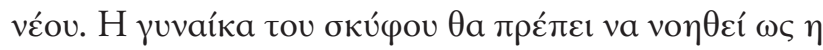

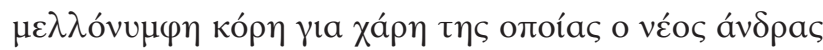

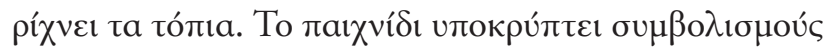

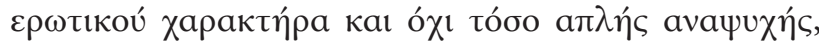

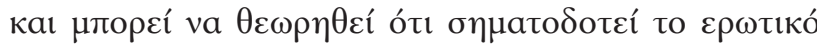

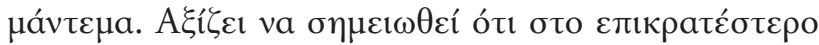

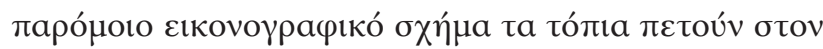

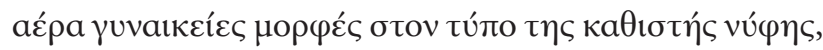

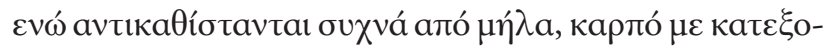

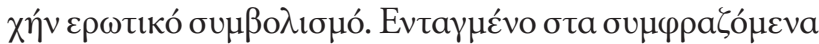

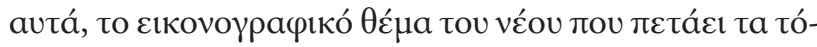

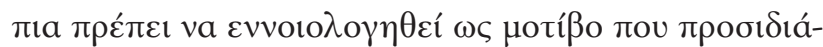

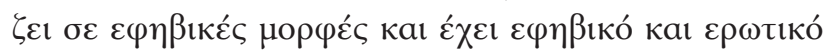

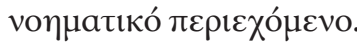

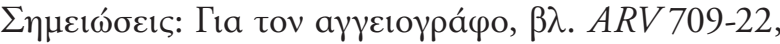

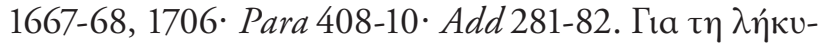

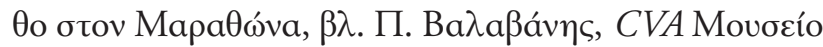

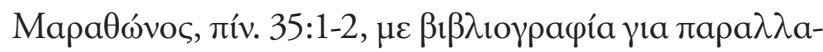

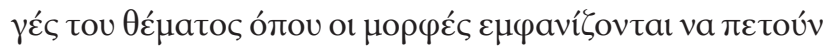

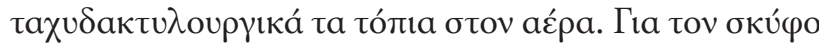

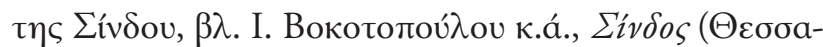

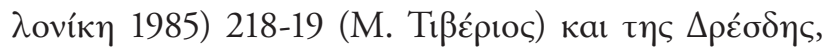
$\beta \lambda$. K. Knoll, Alltag und Mythos (Dresden 1998) 96-97 ap. 38. Гı т to $\theta \dot{\mu} \mu a, \beta \lambda$. W.E. Sweet, Sport and Recrea-

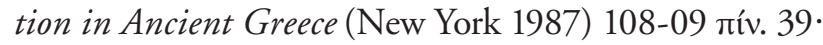
F.A.G. Beck, Album of Greek Education (Sydney 1975)

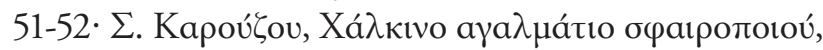

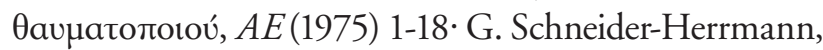
Der Ball bei den Westgriechen, BABesch 46 (1971) 123-
33. R. Patrucco, Lo sport nella Grecia antica (Firenze 1972) 333-50 H. Immerwahr, An Inscribed Terracotta

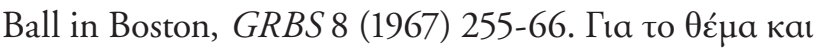

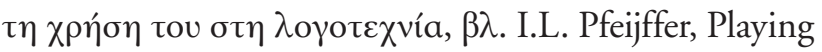
Ball with Homer. An Interpretation of Anacreon 358 PMG, Mnemosyne 53 (2000) 164-84. Calame, Choruses 145. Chr. Sourvinou-Inwood, "Reading" Greek Culture

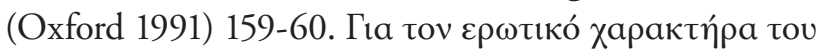
$\pi a \imath v v \delta ı$ เó $\mu \varepsilon$ tómıa, $\beta \lambda$. S. Karouzou, Vases from Odos Pandrosou, JHS 65 (1945) 42· E. Böhr, CVA Tübingen 4,

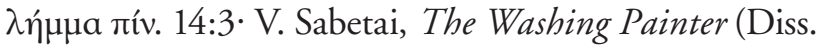
University of Cincinnati 1993) 82-84.

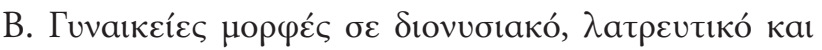

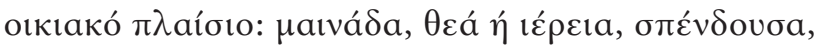

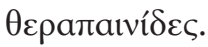

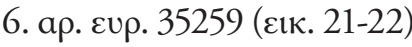

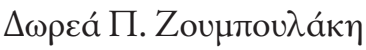

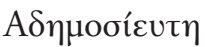

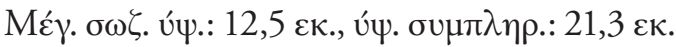

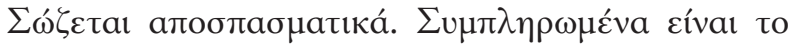

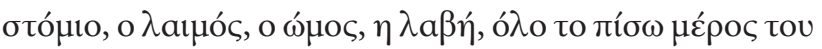

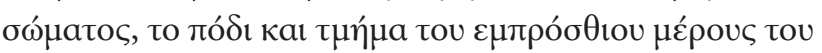

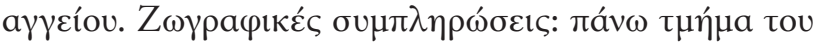

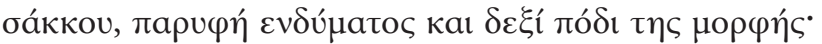

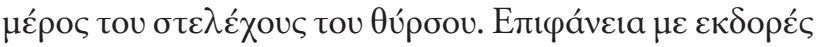
каı атокрои́бєเ५.

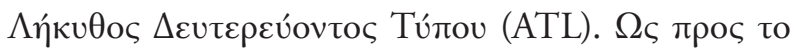

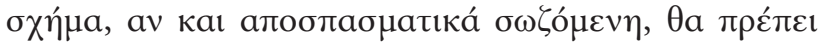

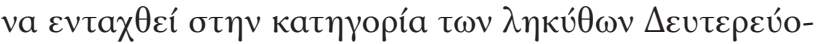

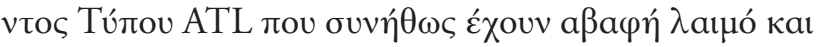

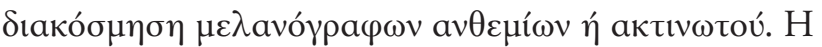

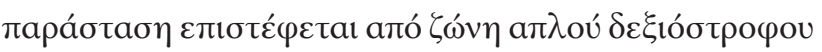

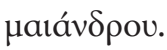

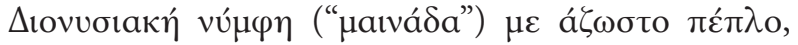

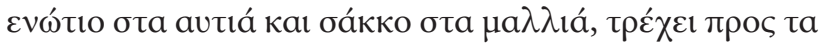

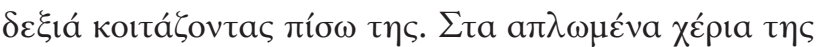

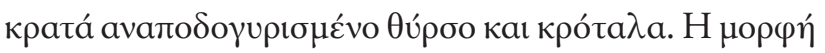

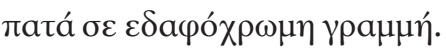

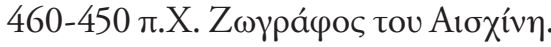

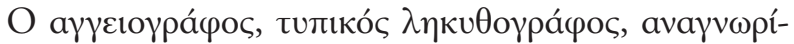

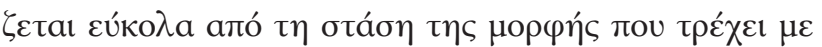

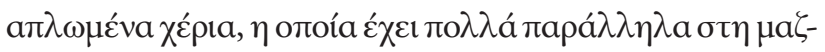

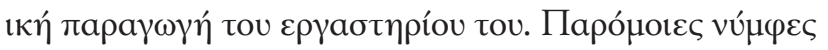



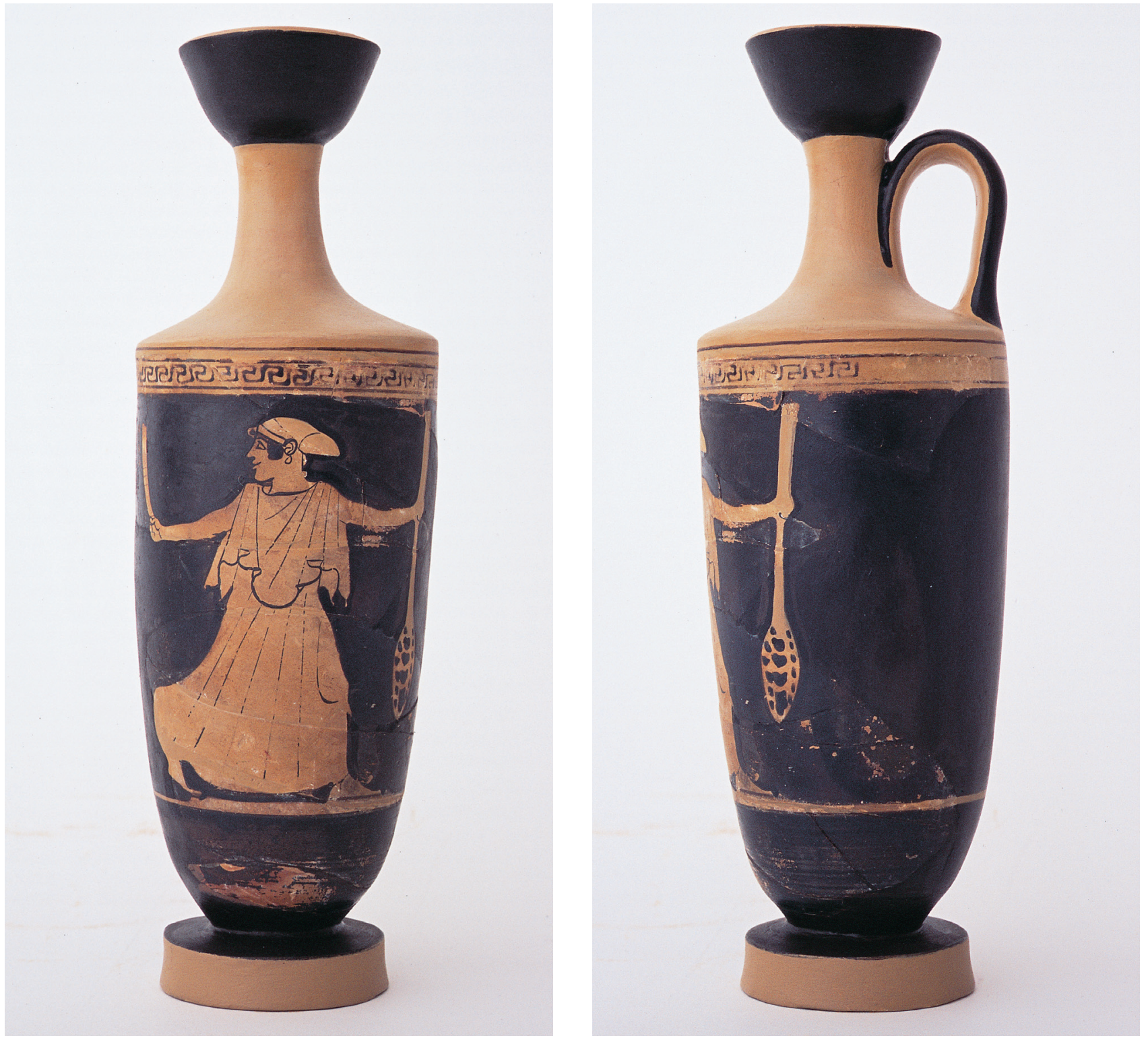

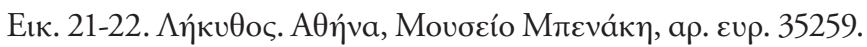

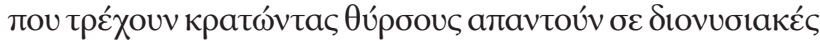

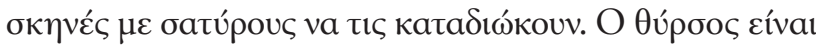

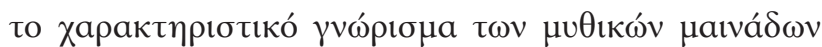

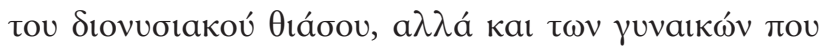

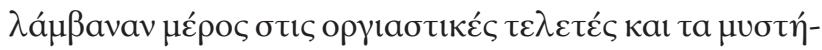

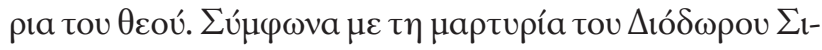

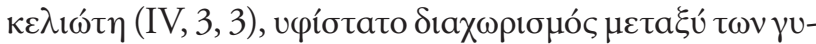

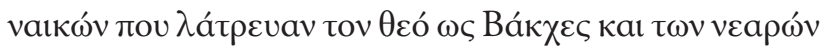

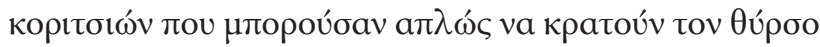

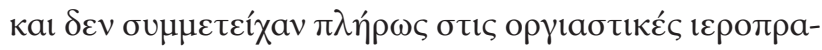

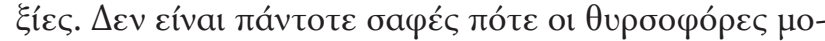

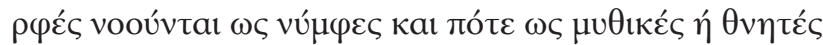

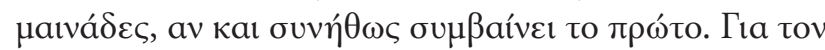

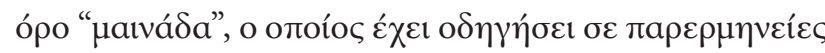

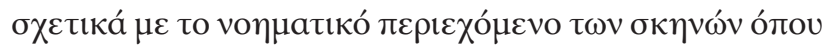

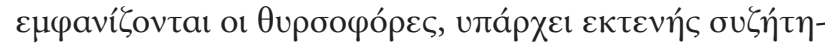

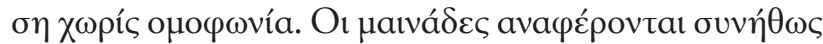

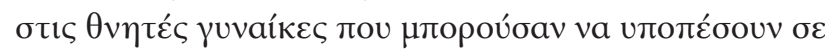

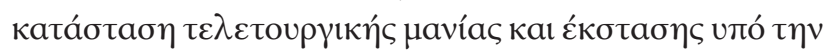

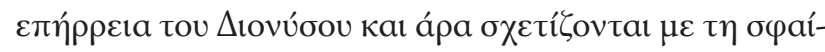




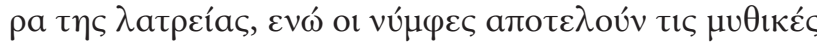

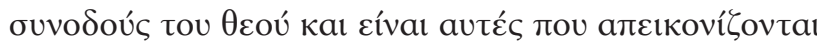

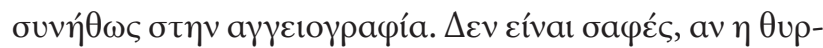

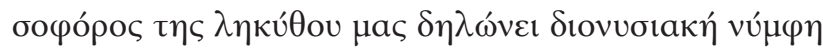

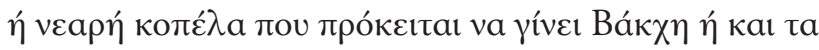

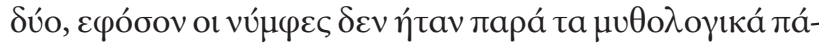

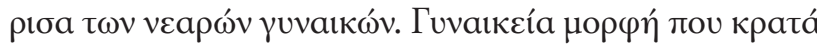

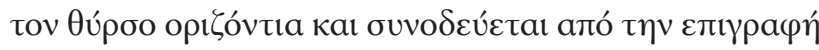

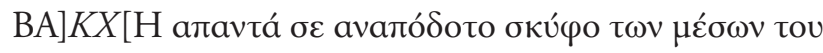

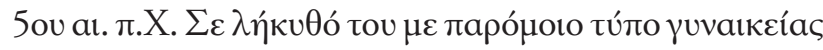

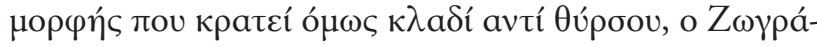

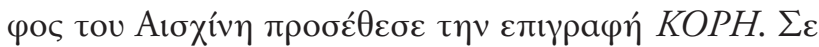
ó,tı a

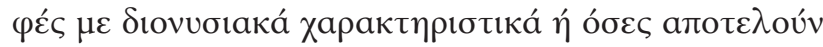

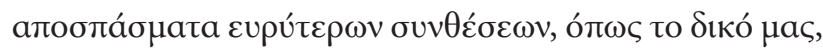

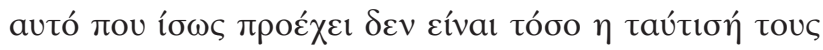

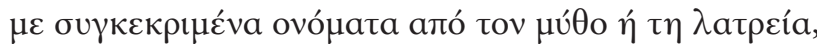
ó

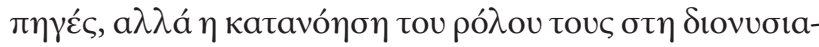

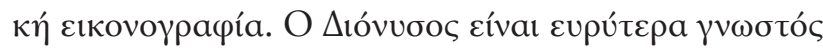

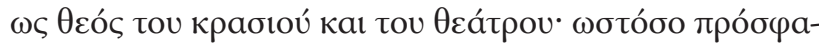

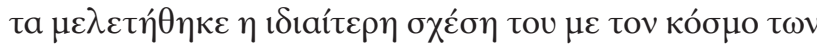

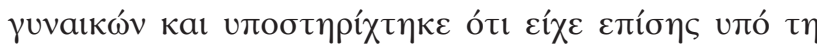

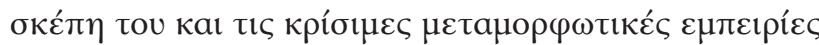

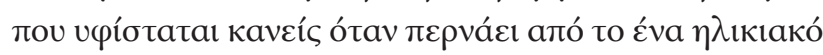

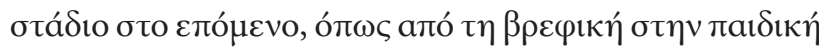

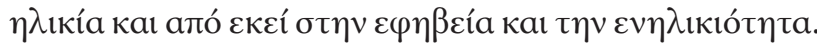

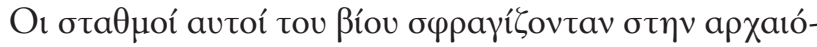

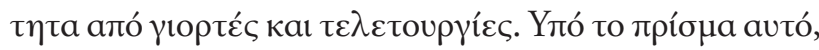

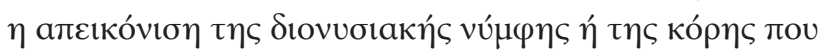

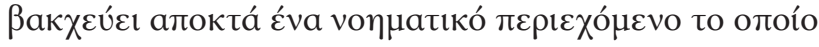

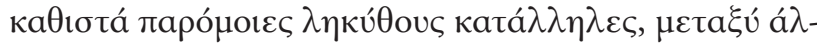

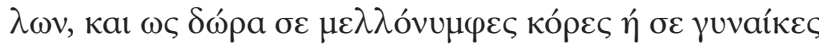

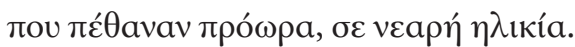

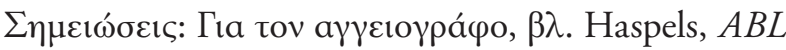
178. ARV 709-22, 1667-68, 1706· Para 408-10· Add

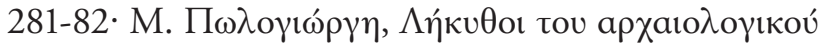

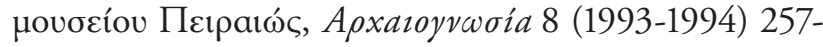

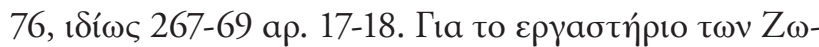

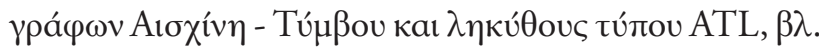
ARV675 Kurtz, $A W L$ 82-83· S. Pülz, Eine Lekythos des

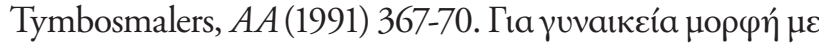

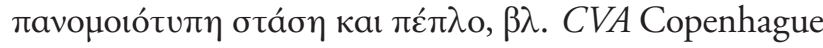

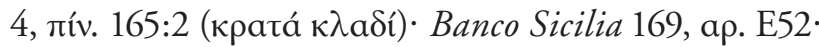

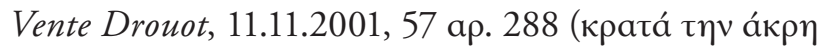

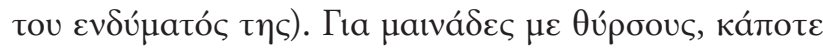

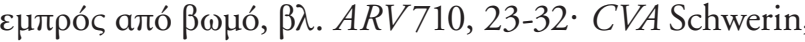

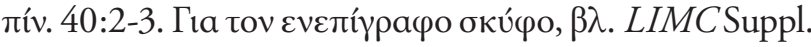

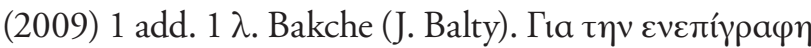

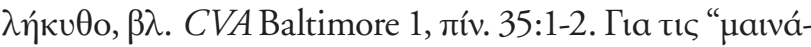
$\delta \varepsilon \varsigma$ ”, $\beta \lambda . \gamma \varepsilon v i \kappa a ́$ S. Moraw, Die Mänade in der attischen Vasenmalerei des 6. und 5. Jahrhunderts v. Chr. (Mainz

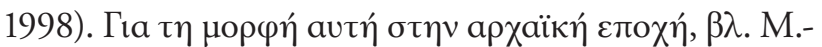

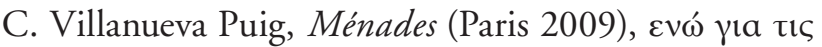

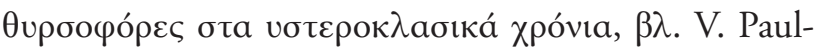
Zinserling, Der Jena Maler und sein Kreis (Mainz 1994)

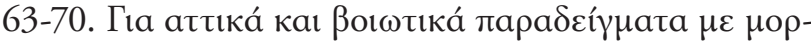

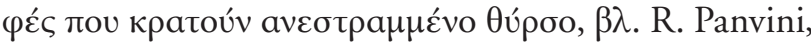

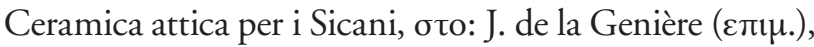
Les clients de la céramique grecque. Cahiers du CVA

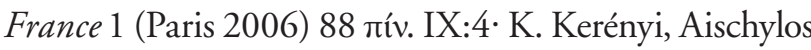
und das Werk eines Vasenmalers in Ancona, RM68 (1961)

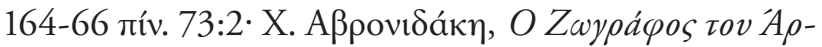

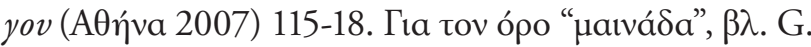
Schmidhuber, Dionysische Frauen in der griechischen Vasenmalerei: Nymphen oder Mänaden?, ÖJh 76 (2007) 353-70 · P. Diez del Corral Corredoira, $Y$ Dioniso desposó

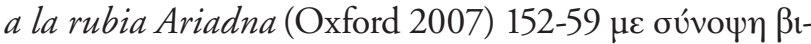

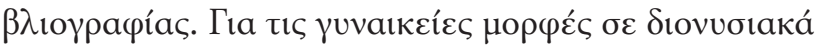

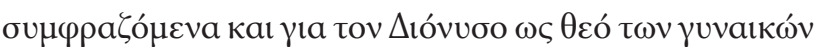

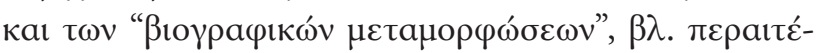
$\rho \omega$ C. Isler-Kerényi, Dionysos in Archaic Greece (Leiden

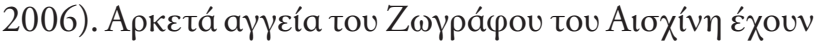

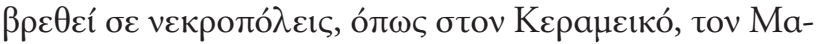

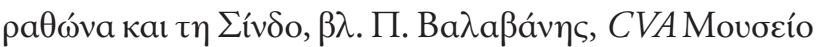

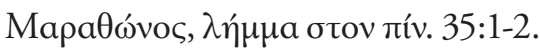

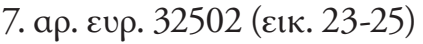

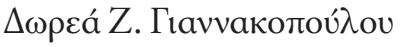

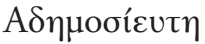

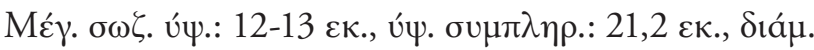
$\omega$ ஸिov: $8 \varepsilon \kappa$.

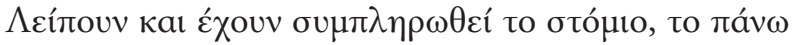

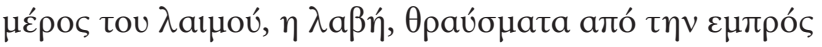

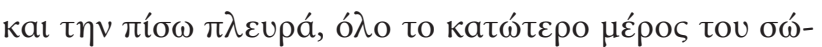

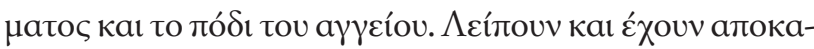

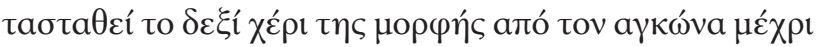

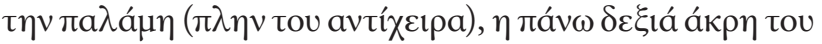

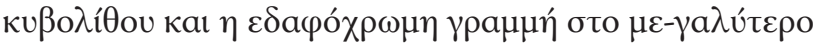

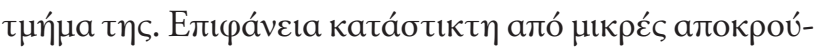

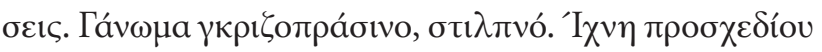

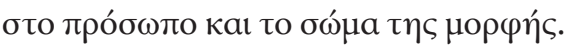




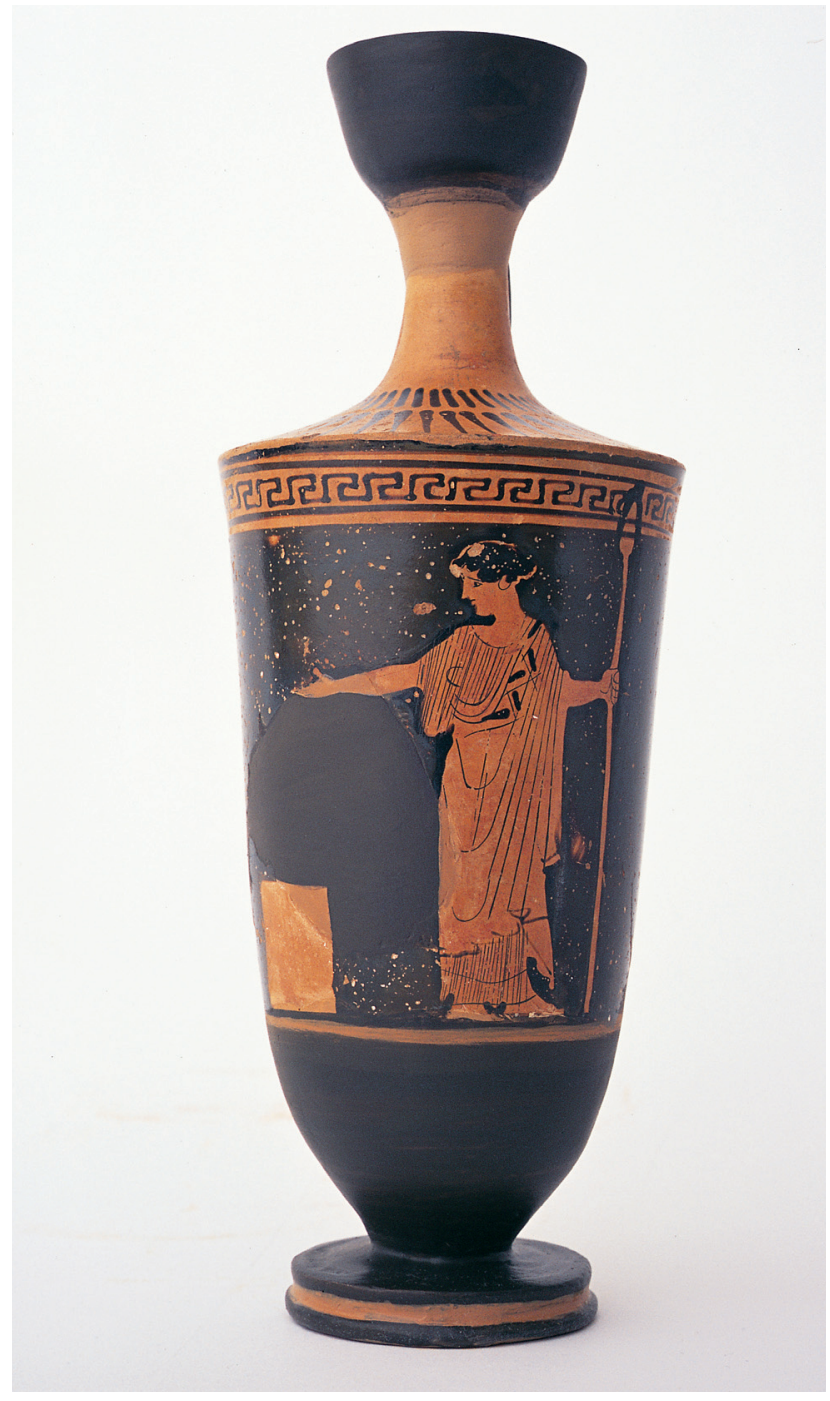

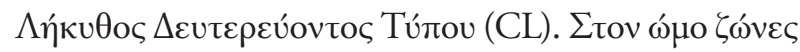

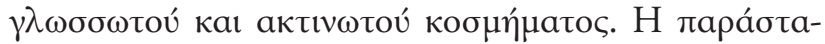

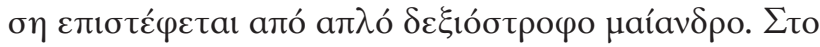

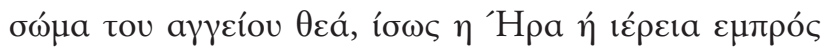

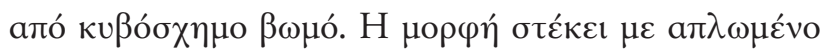

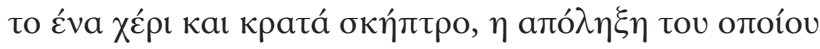

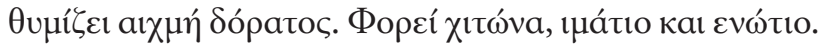

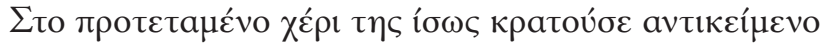
a

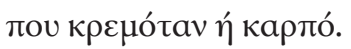

\section{$460-450 \pi . X$.}

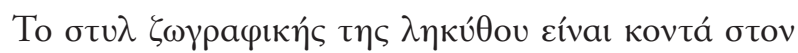

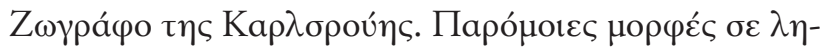

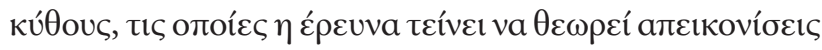

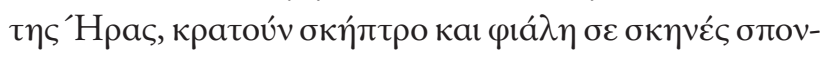

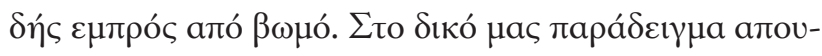
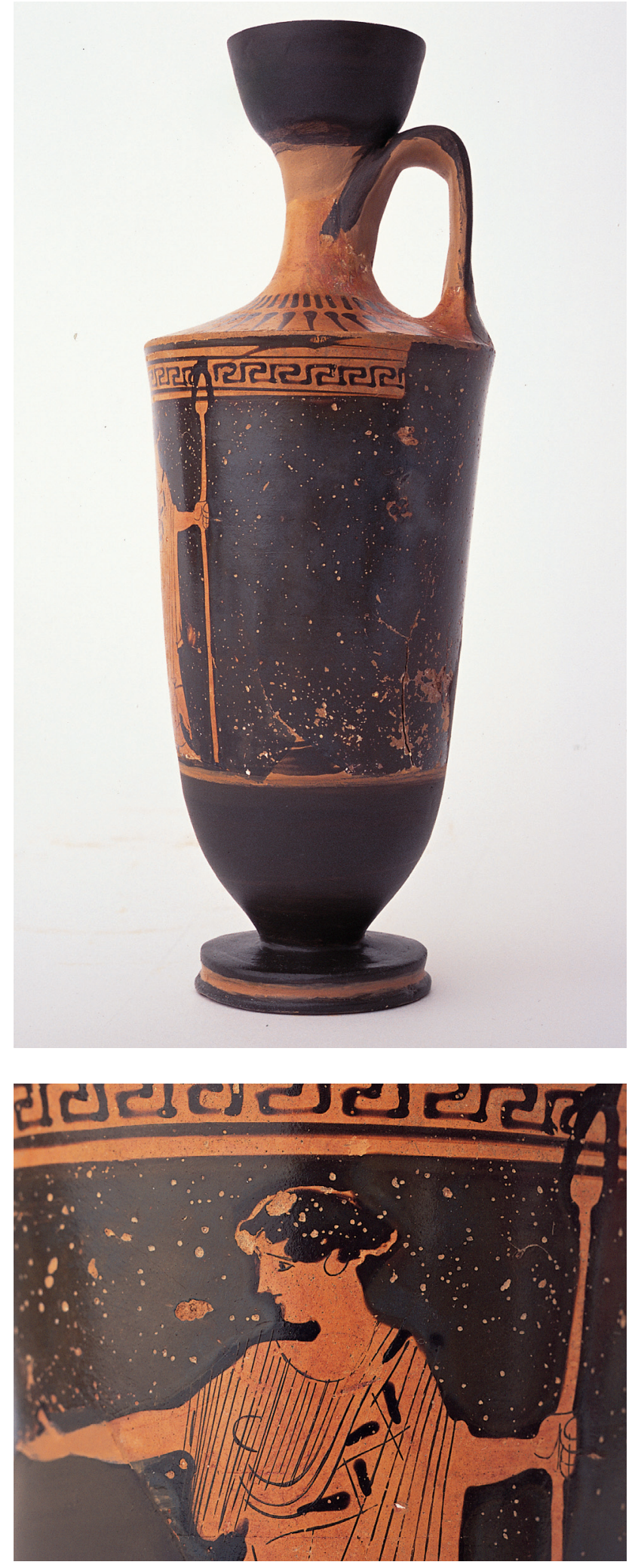

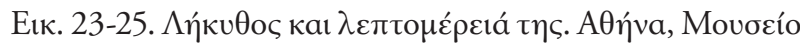

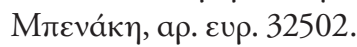



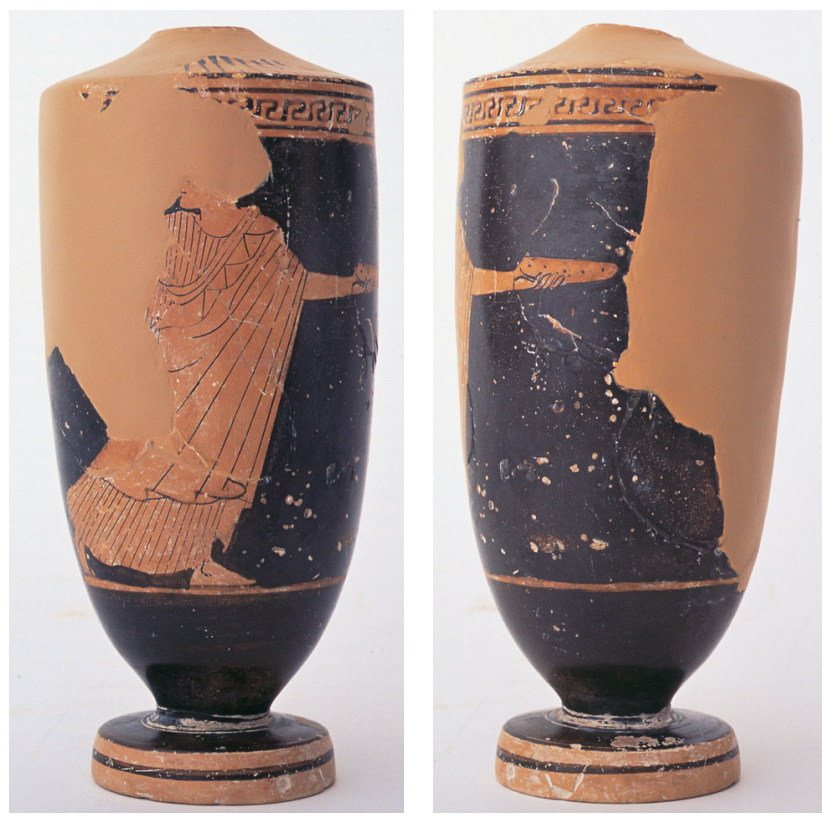

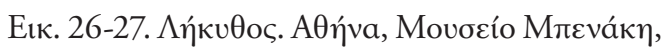
ap. عup. 31620.

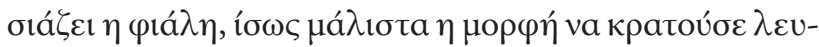

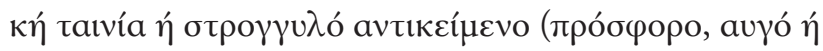

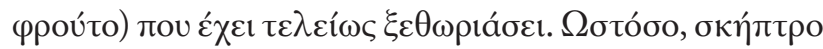

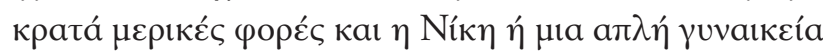

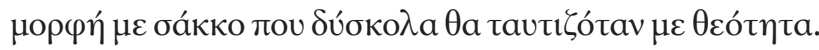

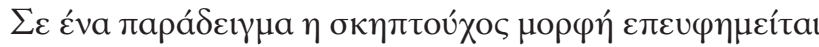

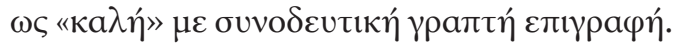

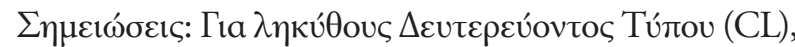

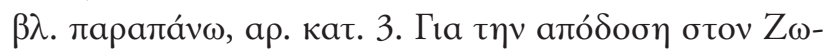

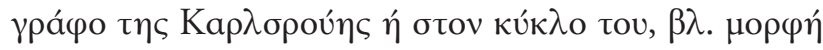

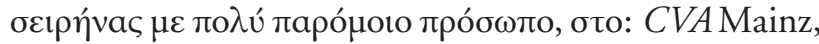

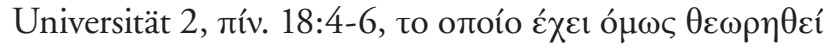

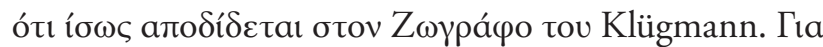

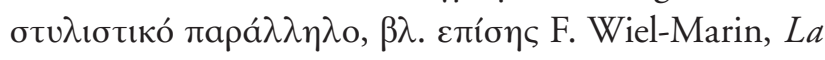
ceramica attica a figure rosse di Adria. La famiglia Bocchi e l'archeologia (Padova 2005) 270-71 ap. 1129. Гta oтév-

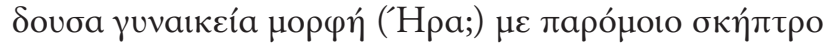

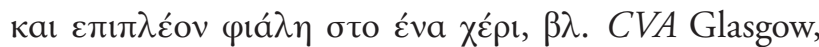
nív. 30:1· S. Barresi - S. Valastro, Vasi attici figurati, vasi sicelioti (Catania 2000) 114 ap. 93. Гहvıкá yıa to

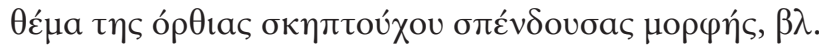

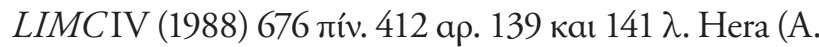

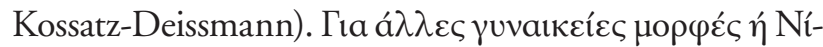

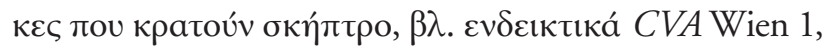

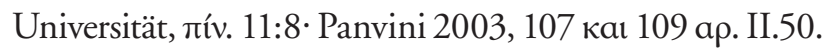

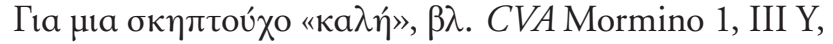

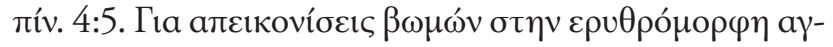

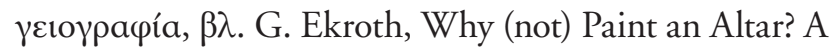
Study of Where, When and Why Altars Appear on Attic Red-figure Vases, oтo: V. Nørskov - L. Hannestad - C. Isler-Kerényi - S. Lewis, The World of Greek Vases (Roma 2009) 89-114.

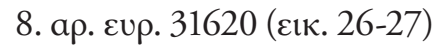

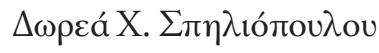

A

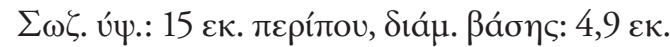

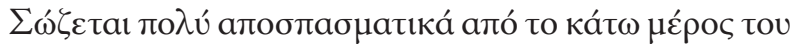

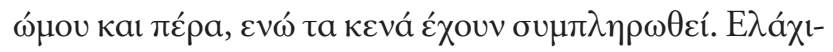

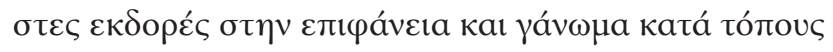

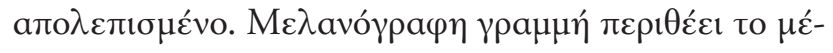

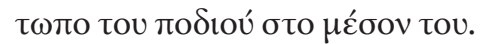

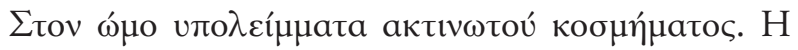

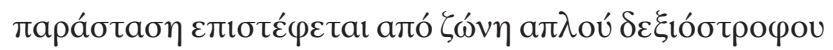

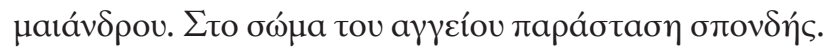

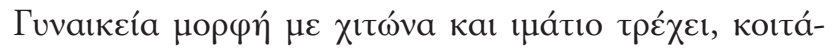

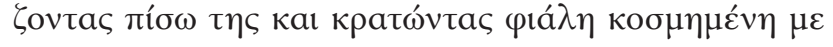

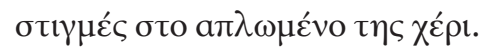

$460-450 \pi . X$.

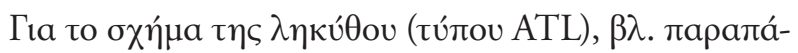

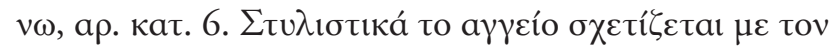
Z

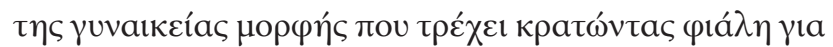

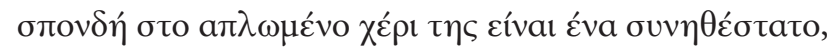

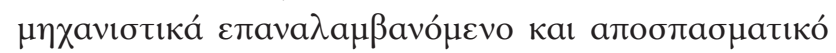

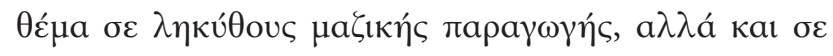

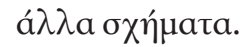

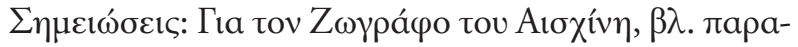

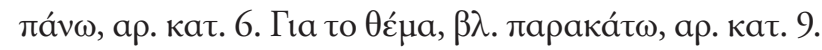

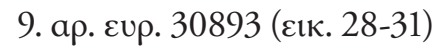

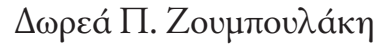

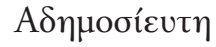

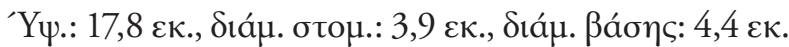

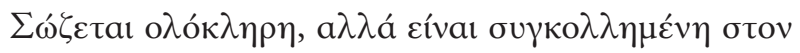

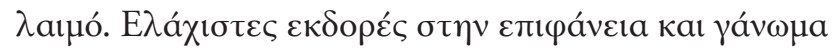

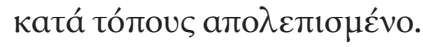

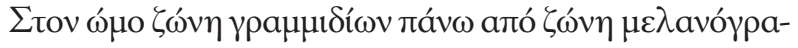

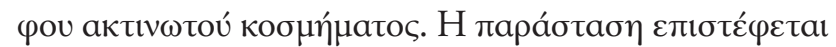

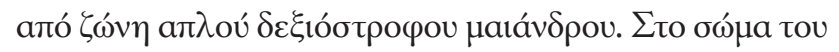

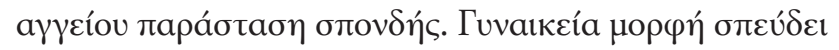



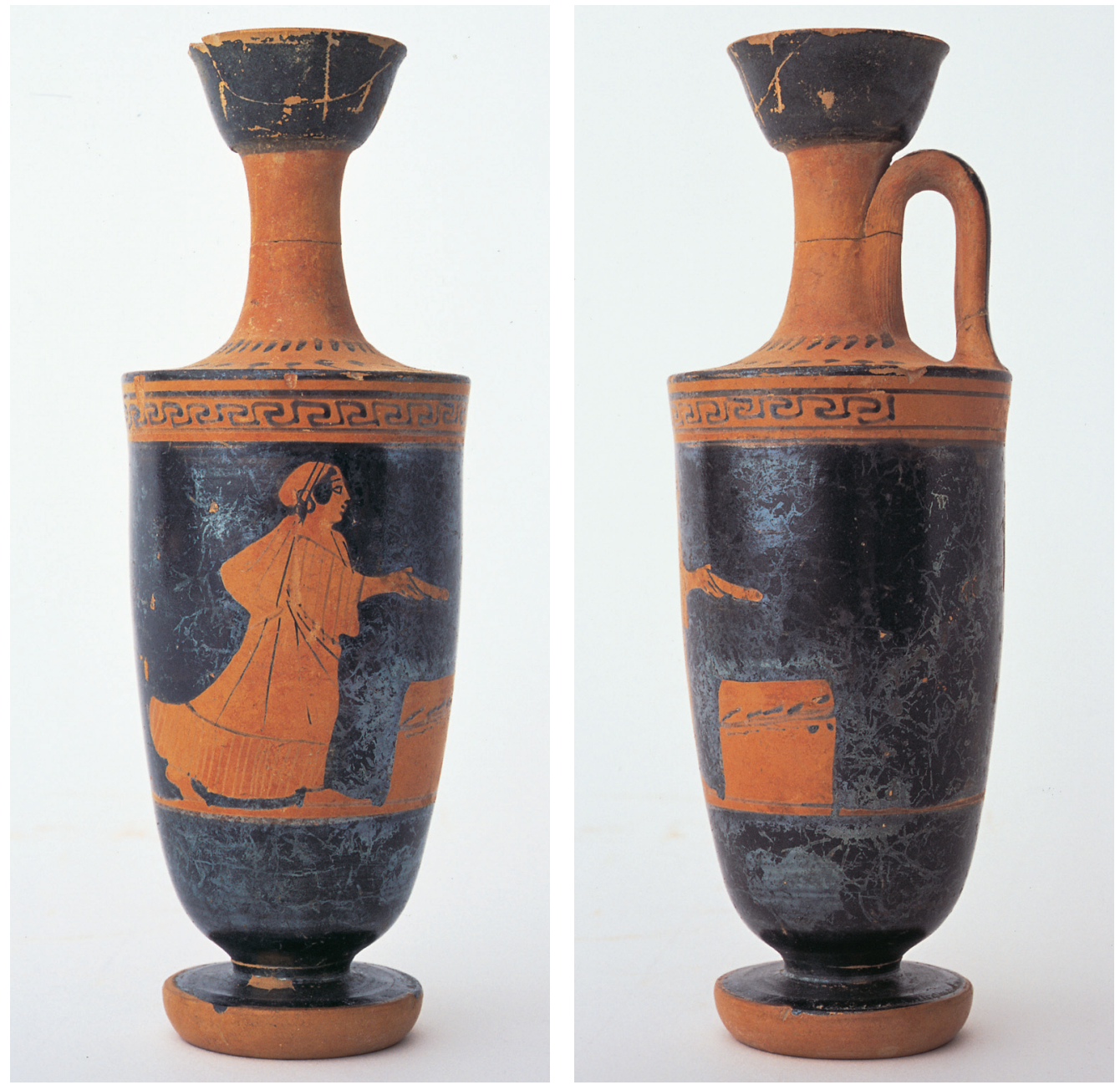

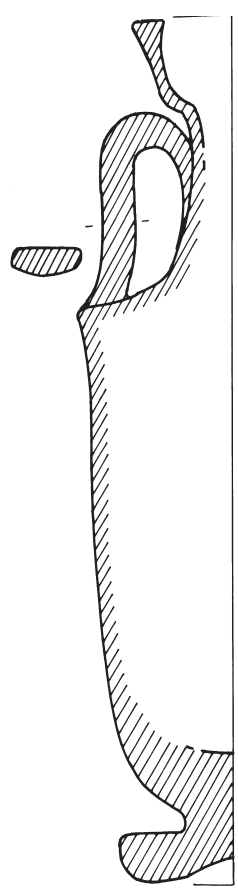

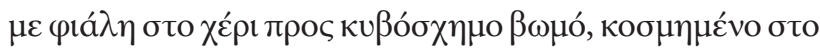

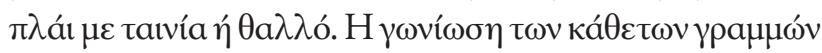

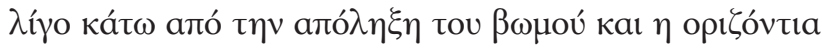

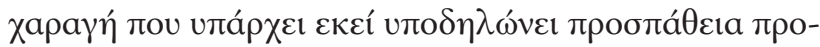

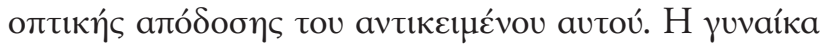

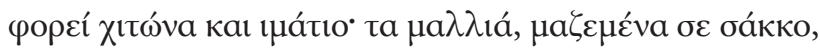

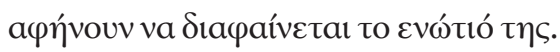

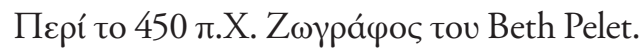

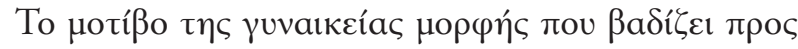

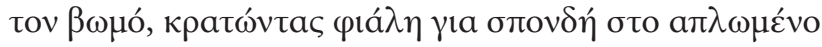

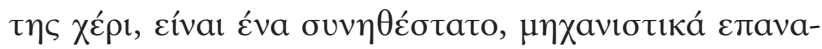

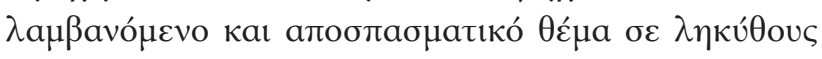

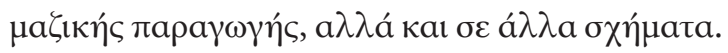

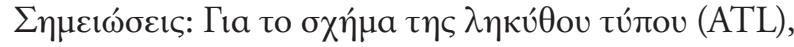

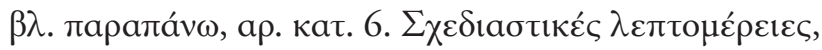

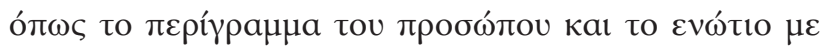

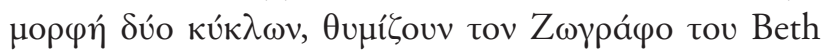

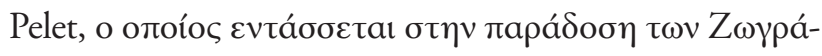

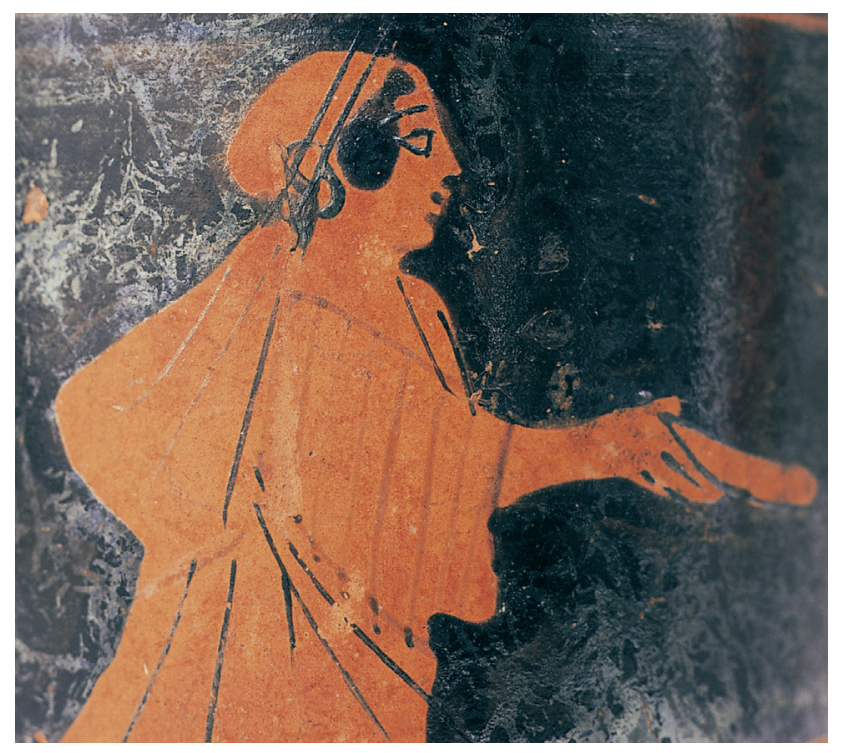

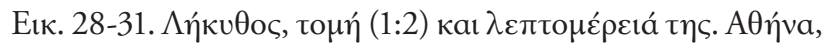

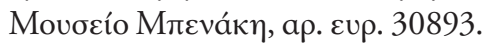




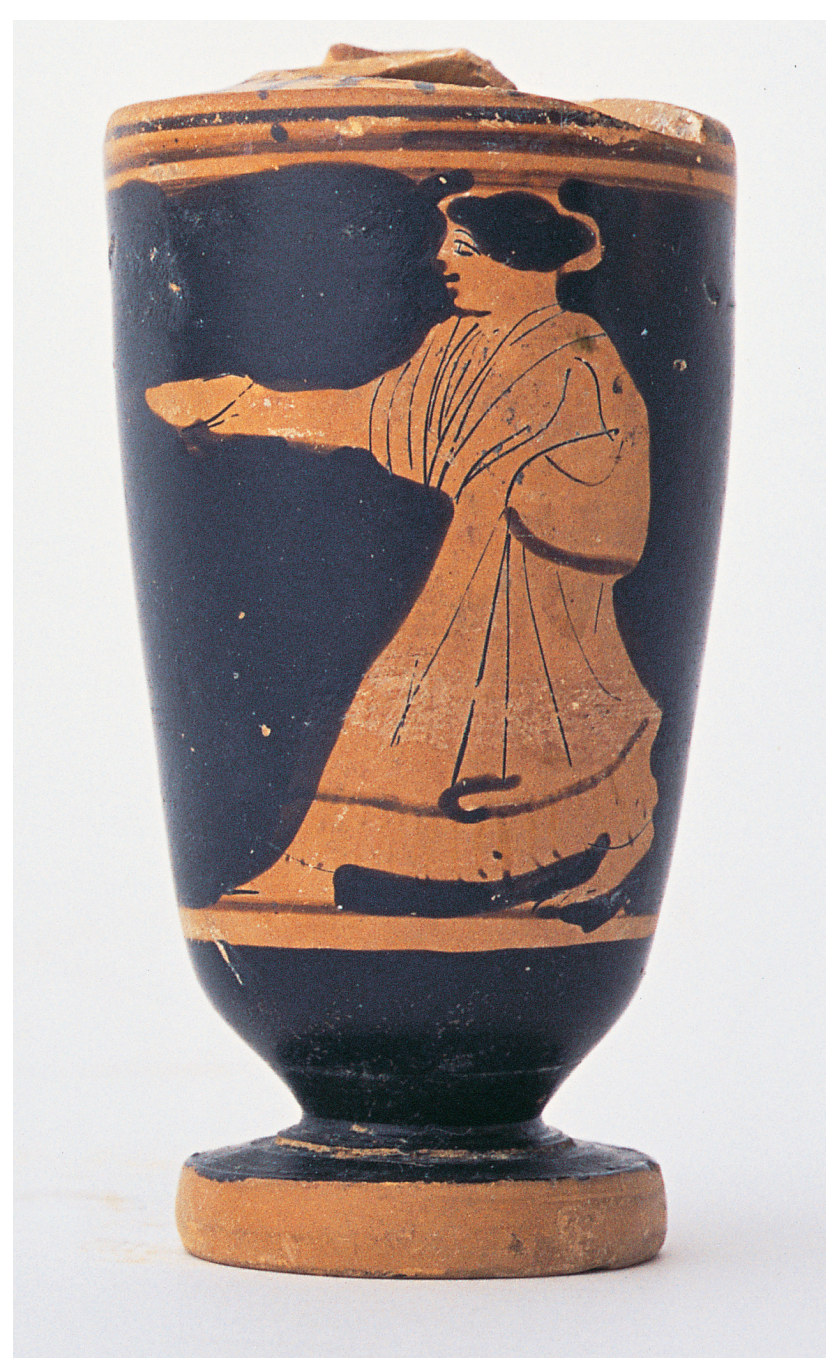

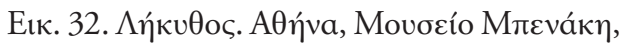

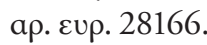

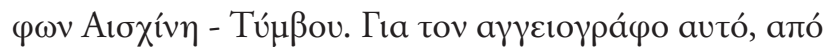

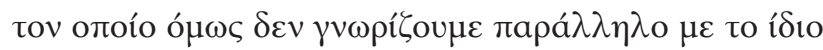

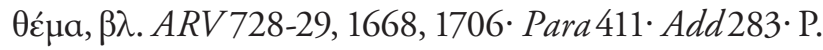
Amandry к.á., Collection de l'École Française d'Athènes, BCH 96 (1972) 56-58 عाк. 41 (J.-J. Maffre) C CVA Kiel 1,

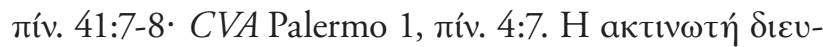

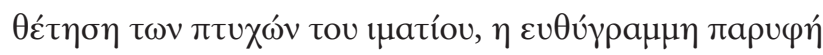

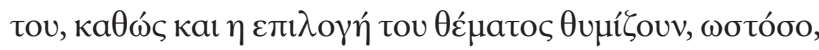
каı тоv Z

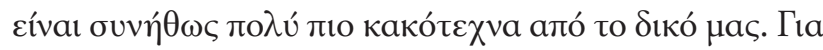

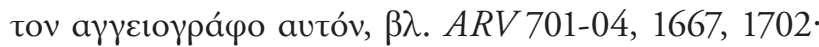

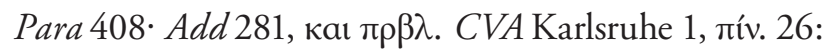

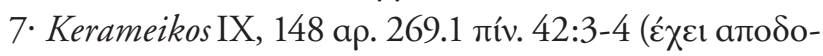

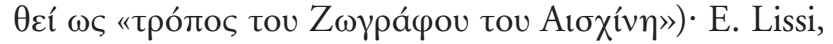
La collezione Scaglione a Locri, AMSM Grecia, n.s. IV

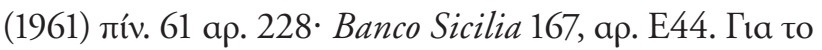

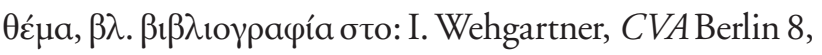

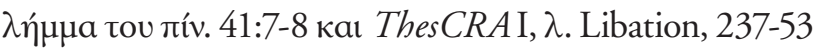

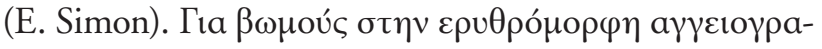

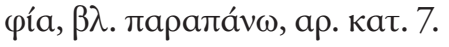

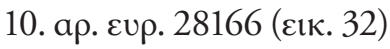

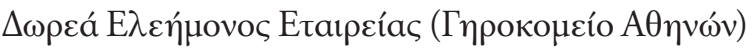

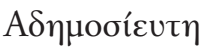

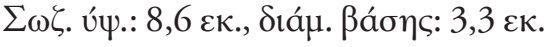

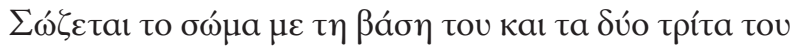

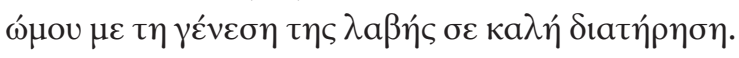

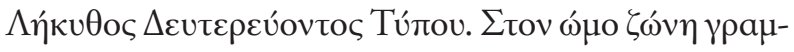

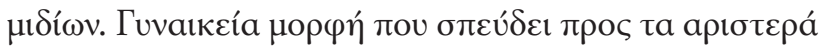

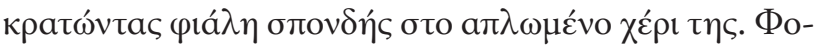

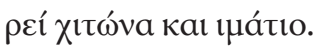

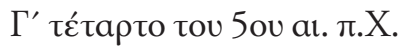

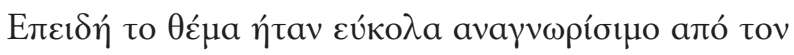

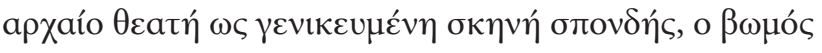

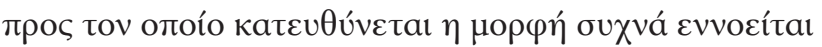

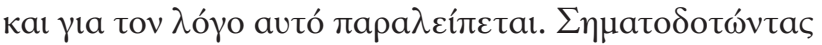

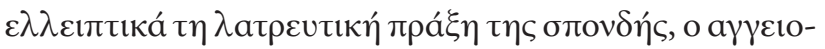
үрá

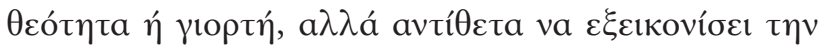

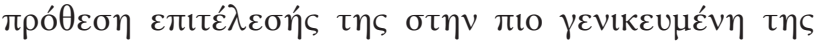
$\mu о \rho \varphi \eta ́ . ~ \Delta \varepsilon v \varepsilon v \delta$ เа

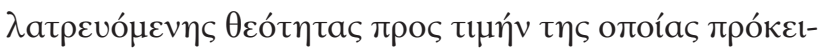

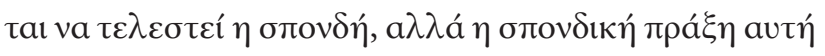

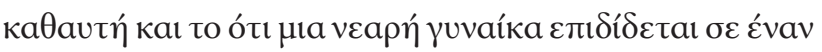

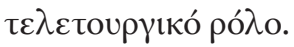

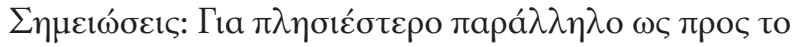

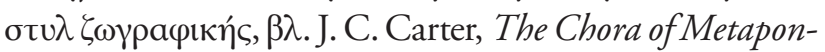
to: The Necropoleis 2 (Austin, TX 1998) 612-13 ap. T350-

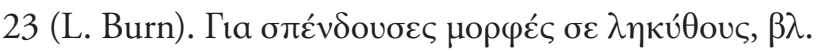

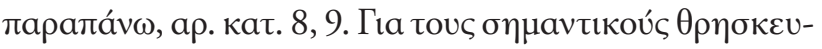

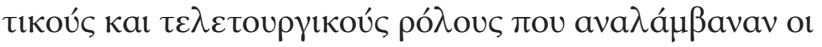

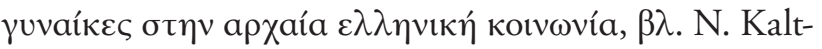

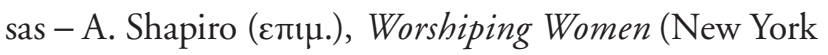

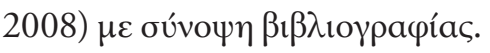

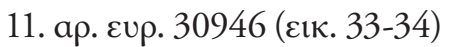

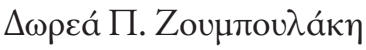

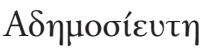

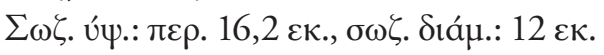



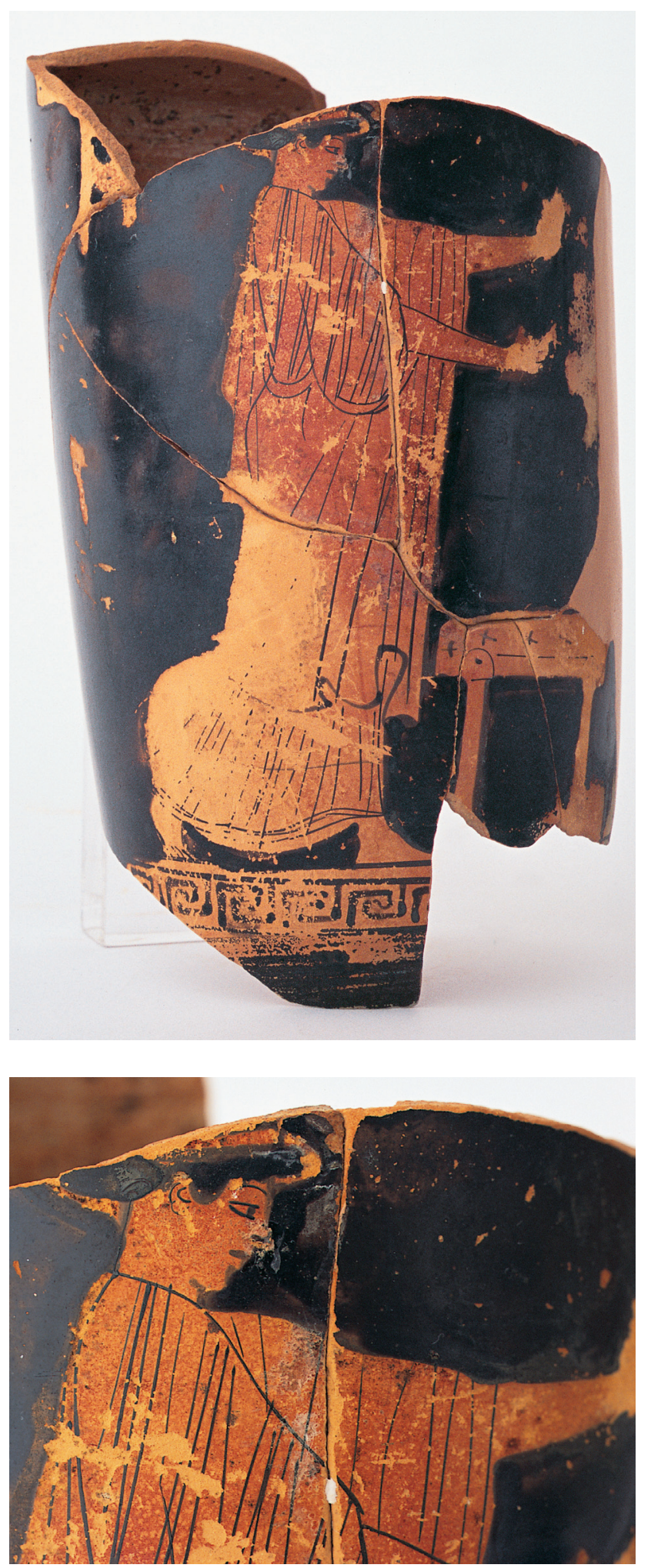

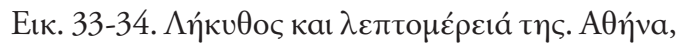

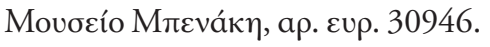

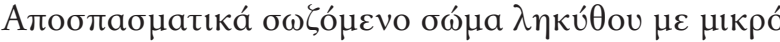

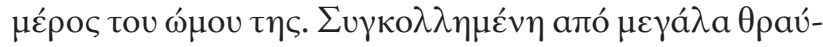

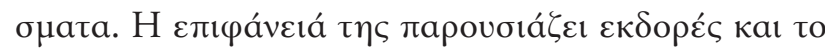

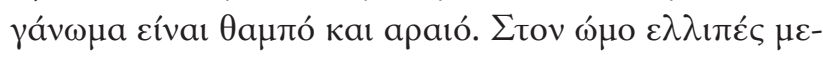

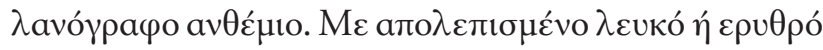

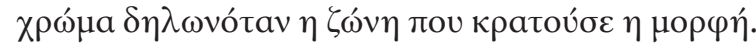

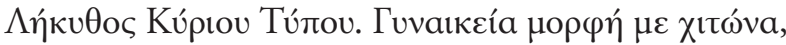

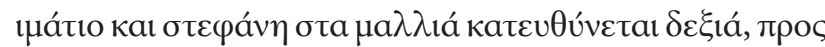

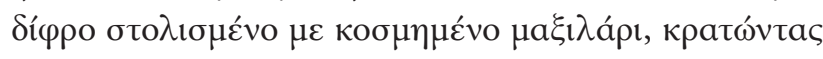

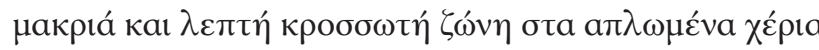

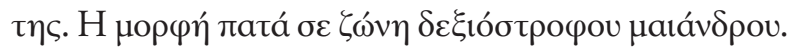

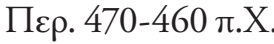

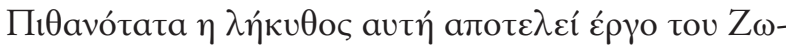

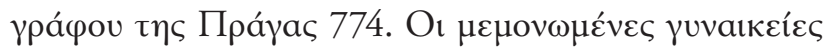

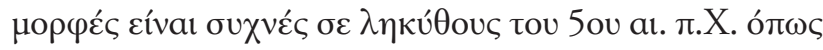

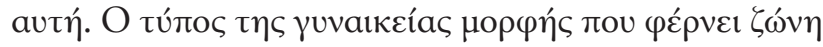

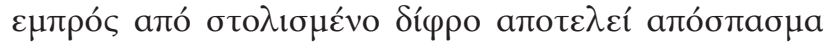

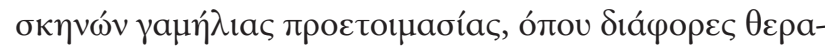

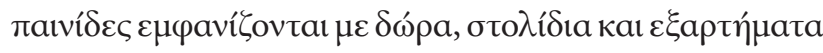

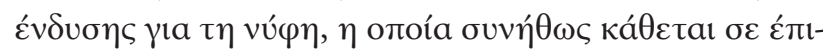

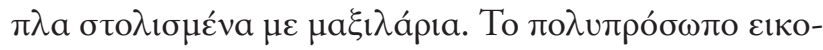

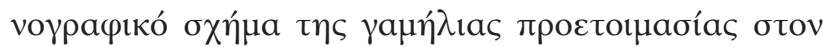

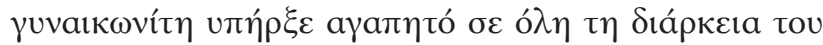

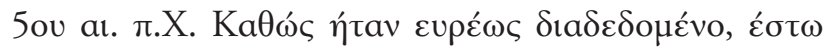

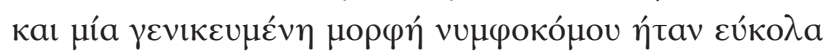

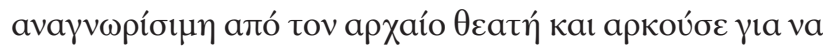

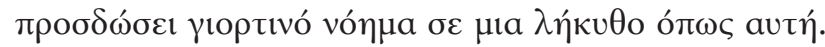

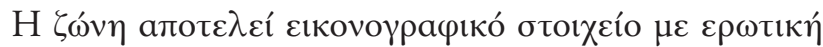

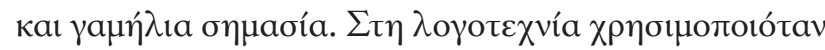

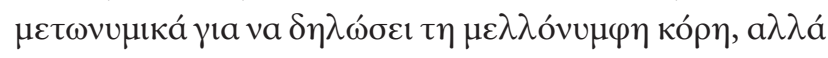

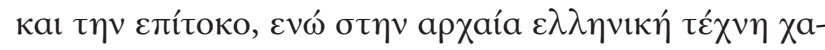

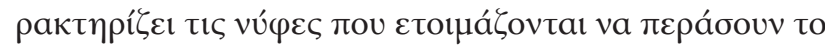

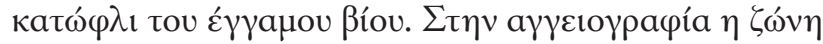

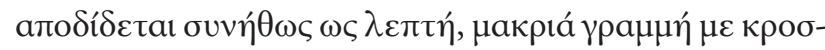

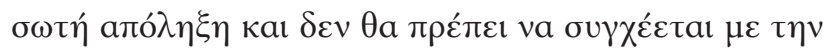

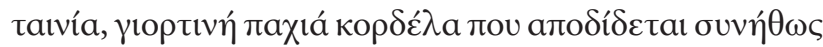

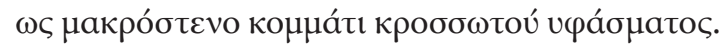

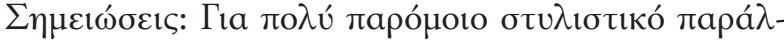

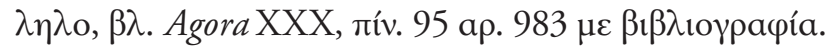

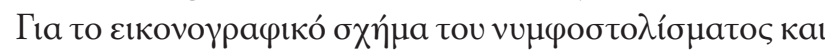

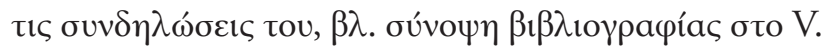

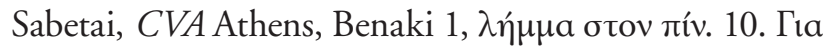

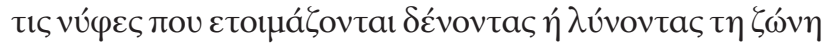
touc, $\beta \lambda$. V. Sabetai, Aspects of Genre and Nuptial Imagery in Fifth Century Athens: Issues of Interpretation and Methodology, oto: J.H. Oakley - W.D.E. Coulson - O. 

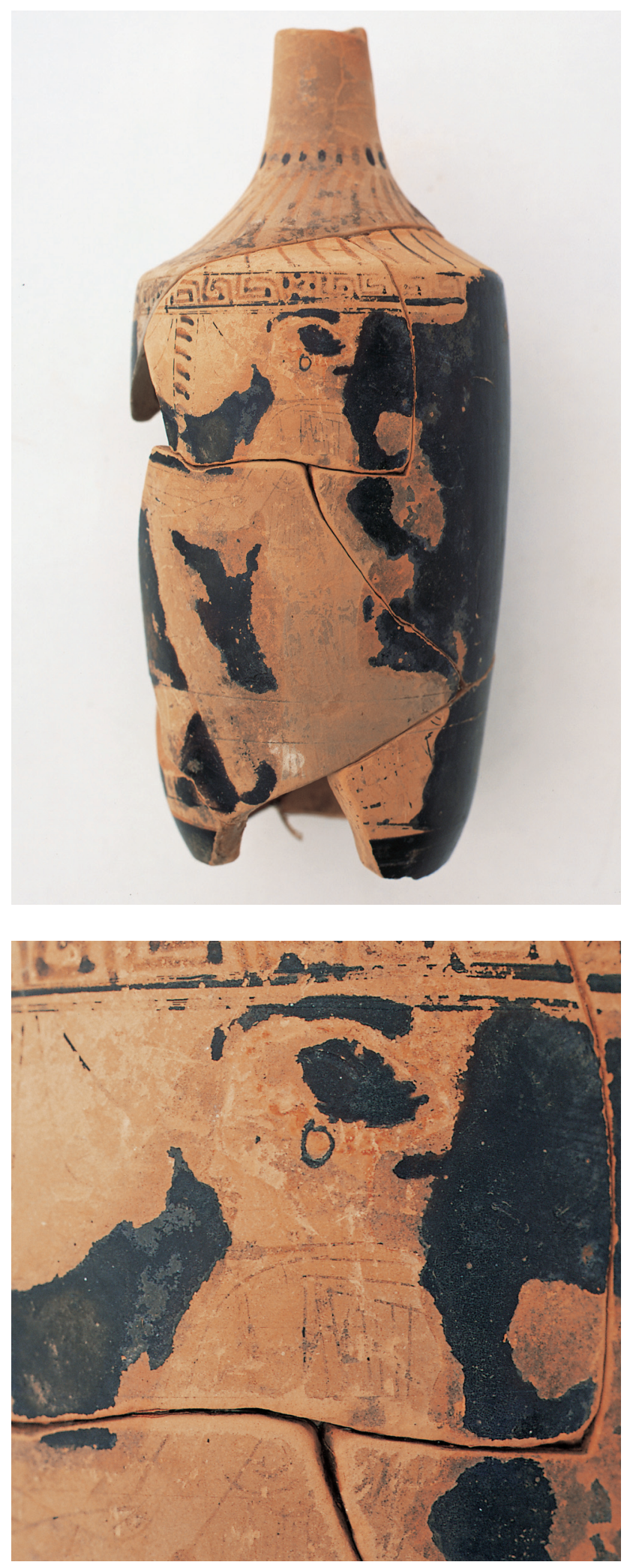

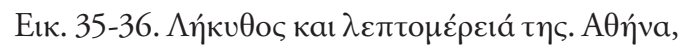

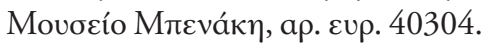

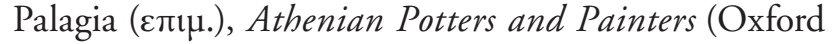

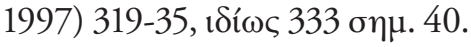

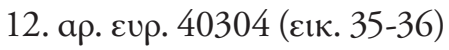

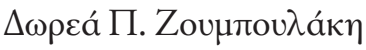

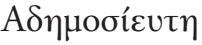

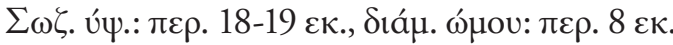

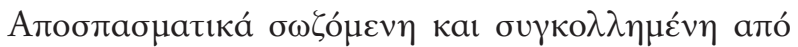

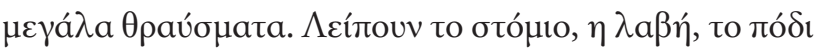

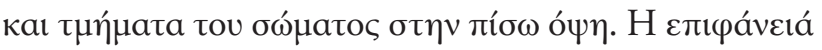

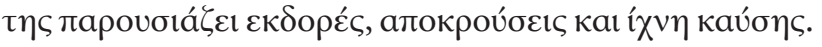

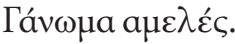

$\Lambda \eta ́ \kappa$

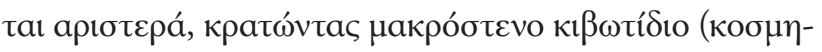

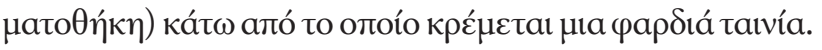

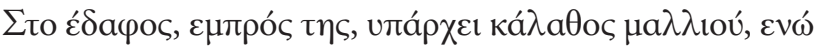

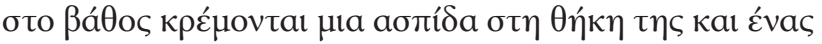

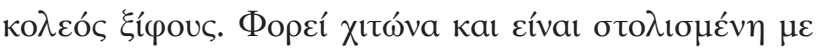

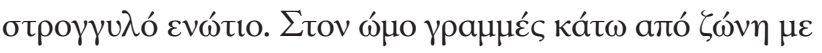

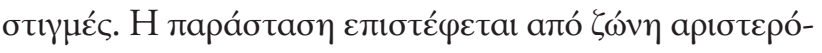

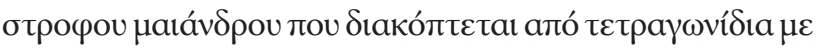

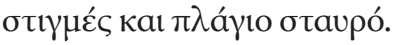

Пвр. $420 \pi . \mathrm{X}$.

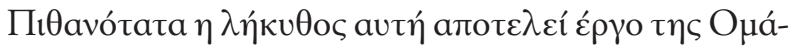

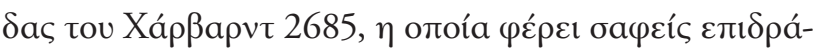

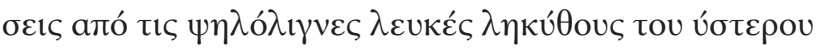

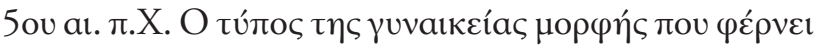

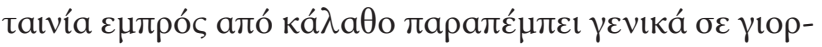

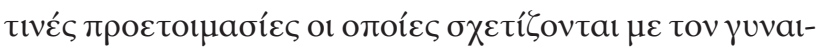

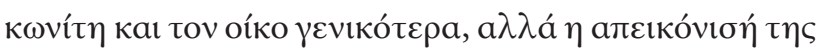

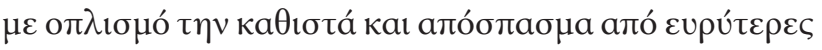

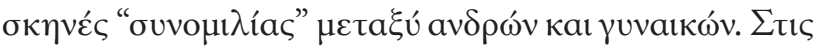

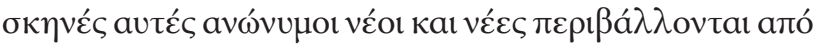

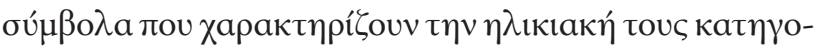

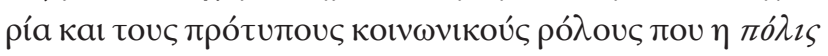

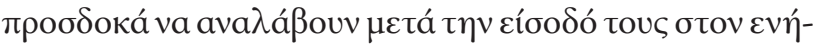

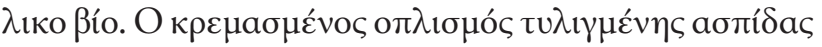

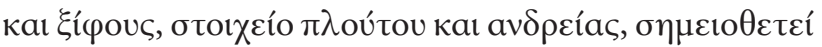

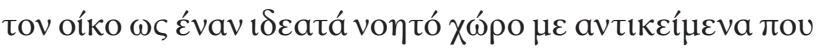

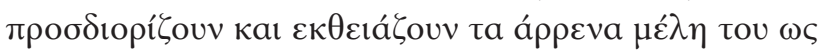
$\varepsilon \cup ́ \pi$ o

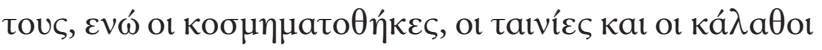

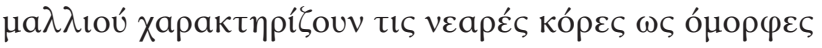

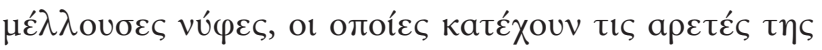

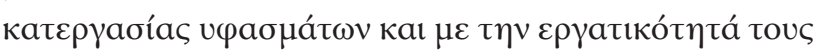

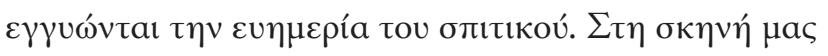



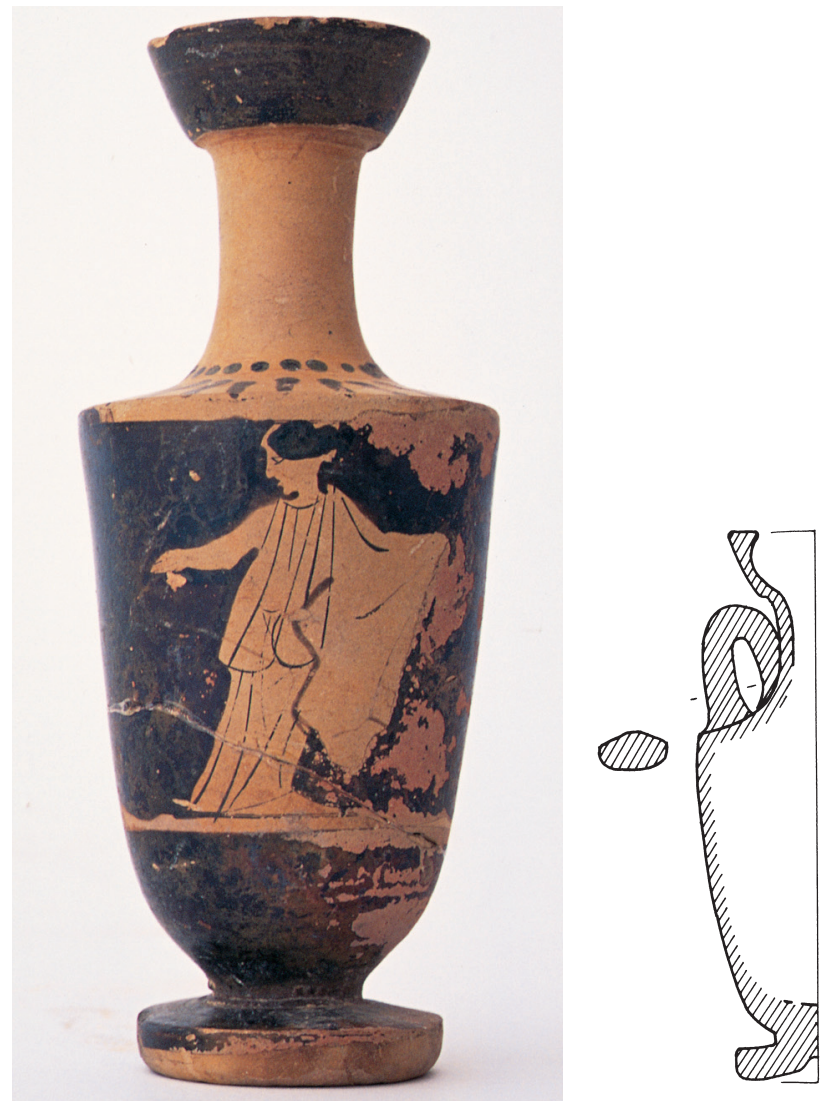

Еıк. 37-38.

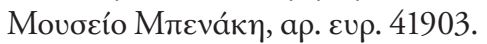

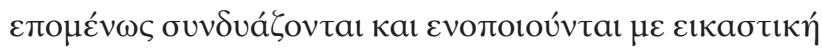

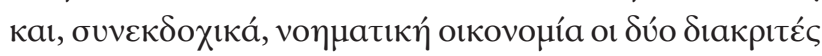

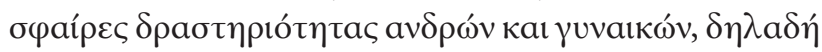

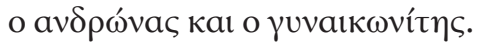

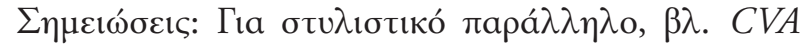

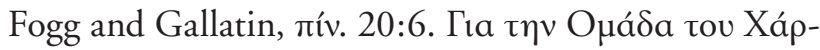

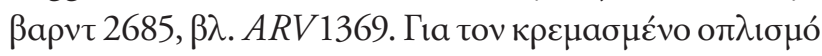

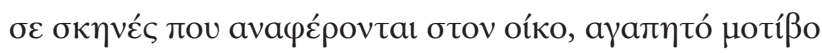

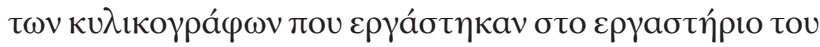

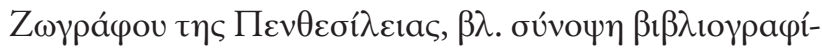

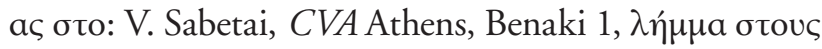

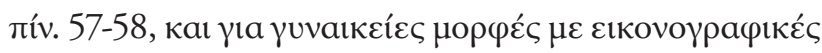

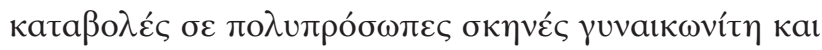

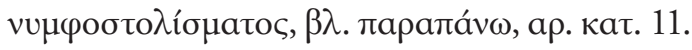

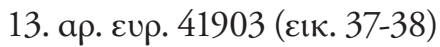

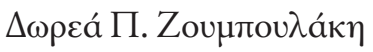

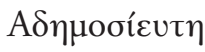

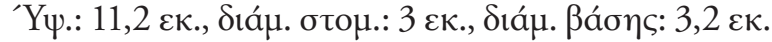

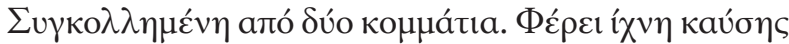

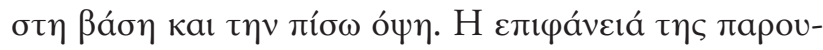

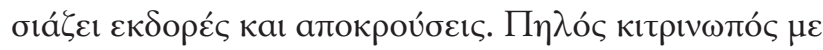

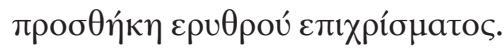

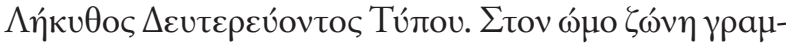

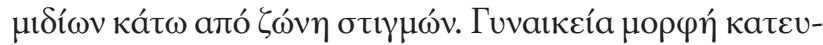

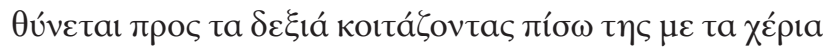

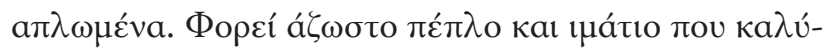

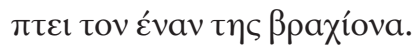

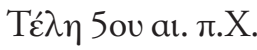

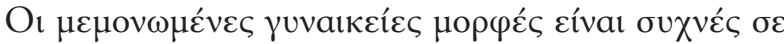

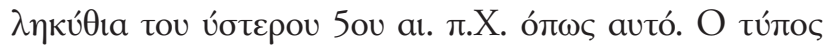

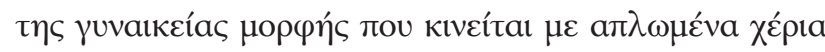

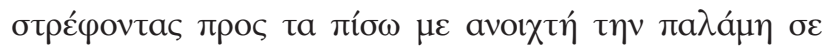

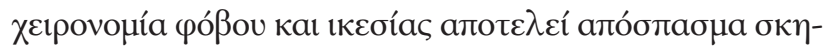

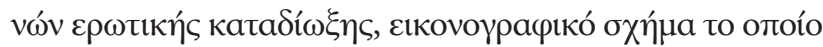

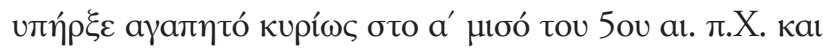

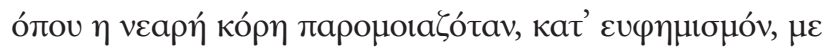

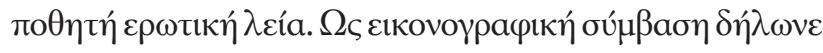

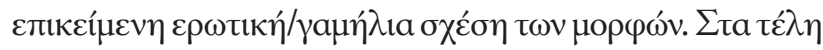

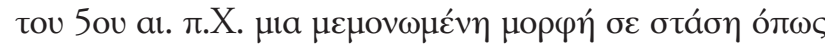

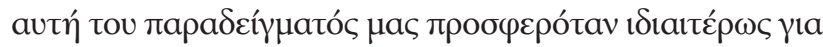

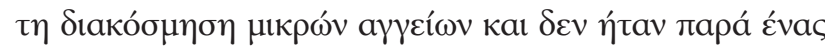

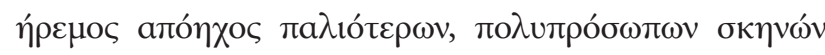

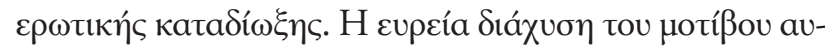

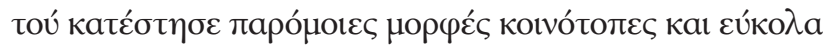

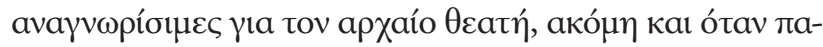

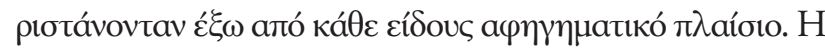

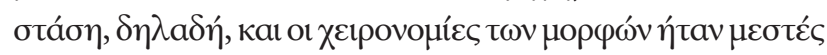

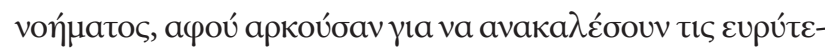

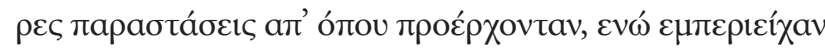

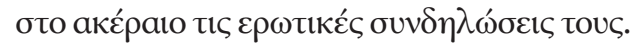

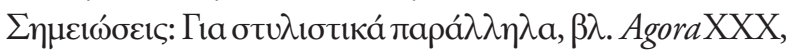
Tív. 89 ap. 887· Panvini 2003, 106 ap. II:47· CVA Copen-

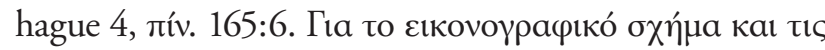

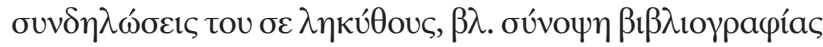
бто O. Dräger, CVAErlangen 2, $\lambda \eta \mu \mu \mu$ бтоv тív. 40:8-9.

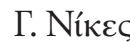

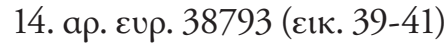

Алоктй $\theta \eta \kappa \varepsilon$ a H. A. Cahn, ap. 768.

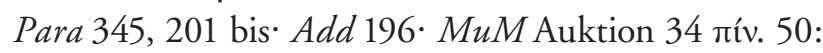



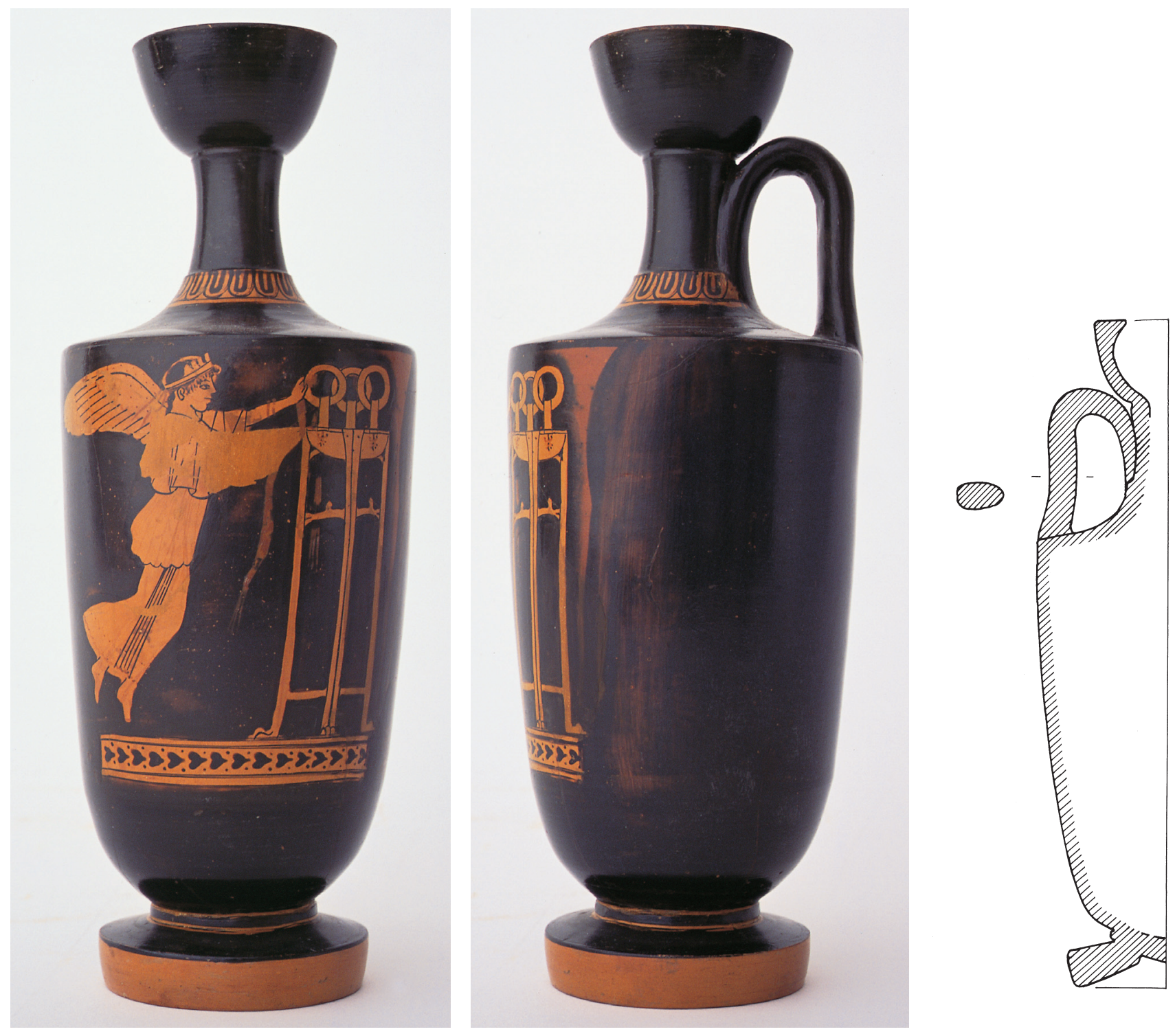

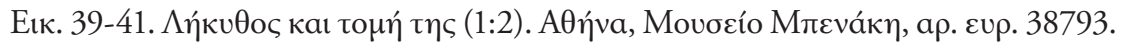

$155 \cdot$ H. Froning, Dithyrambos und Vasenmalerei in Athen

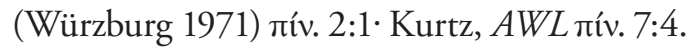

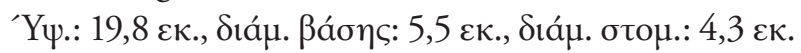

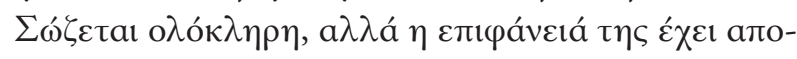

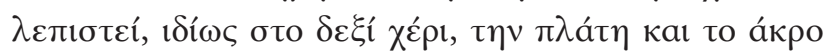

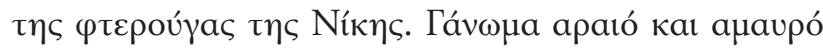

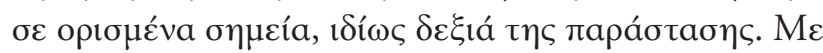

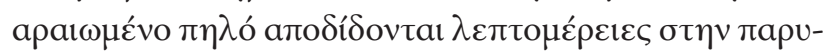

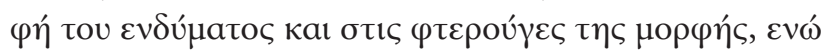

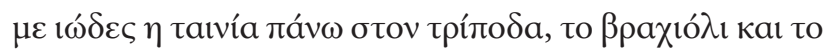

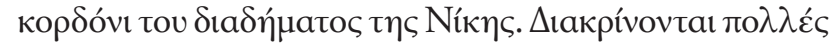

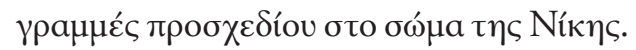

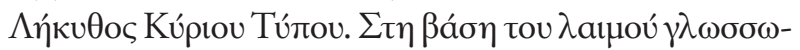

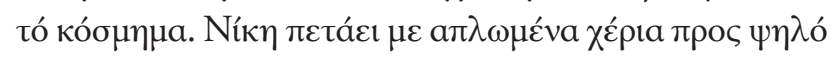

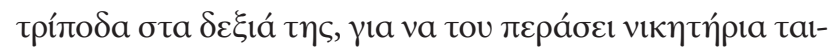

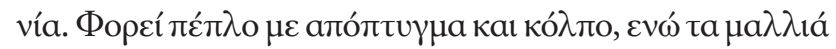

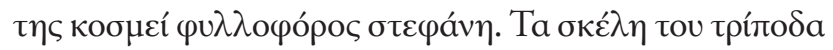

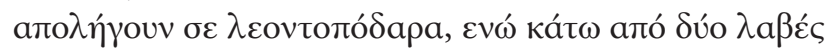

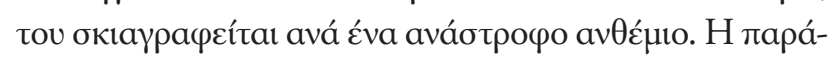

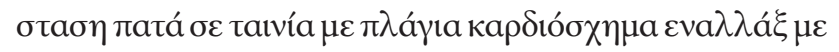




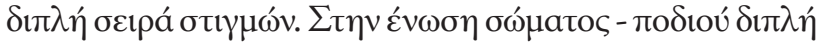

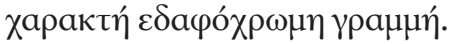

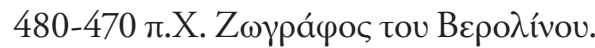

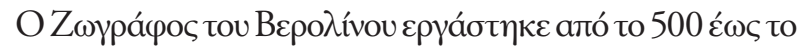

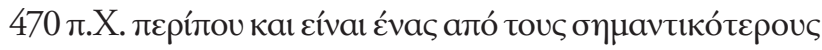

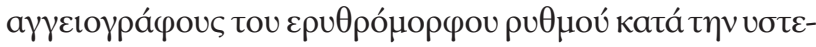

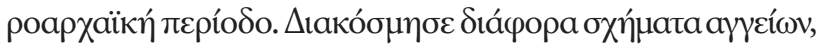

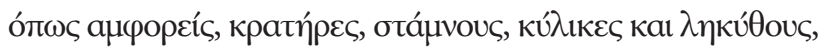

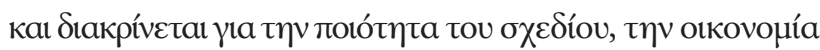

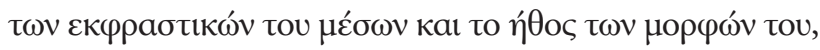

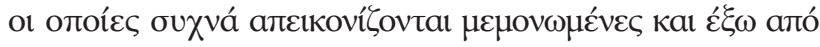

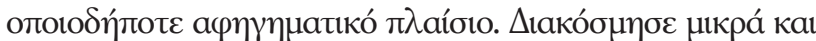

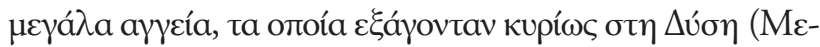

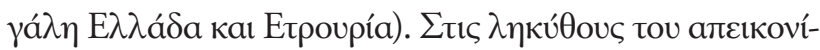

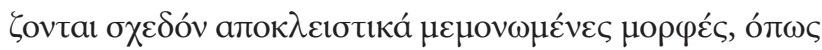

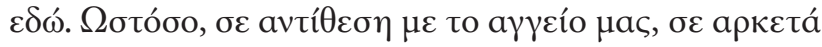

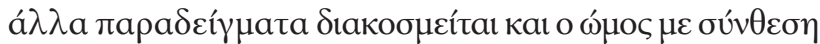

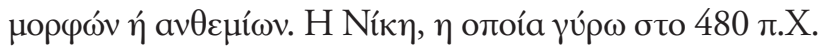

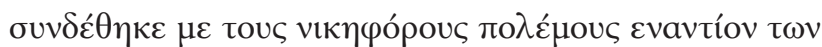

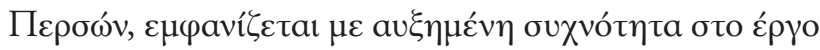

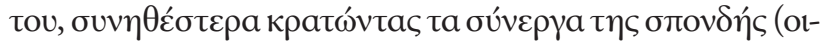
voхó

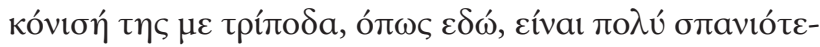

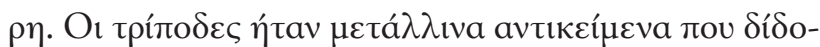

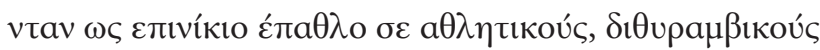

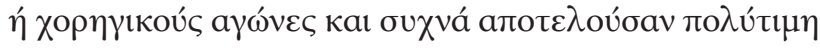

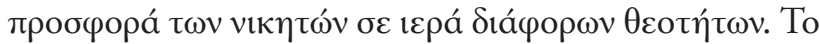

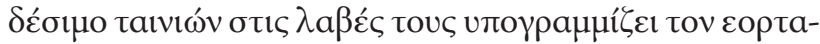

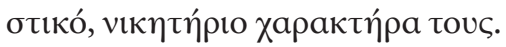

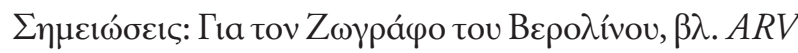
196-216 Para341-46 Add 190-97 D.C. Kurtz, The Ber-

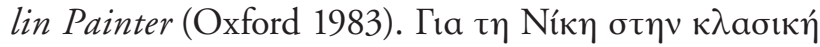

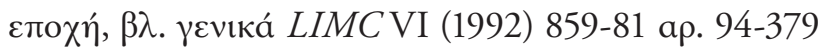

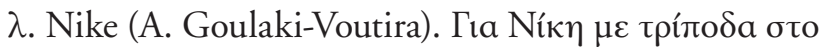

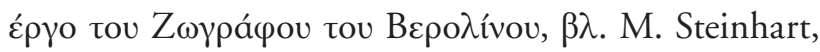
Töpferkunst und Meisterzeichnung (Mainz 1996) 103-06

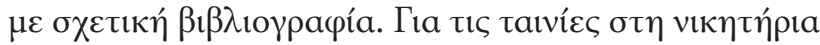

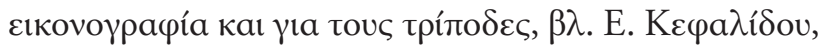

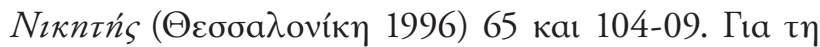

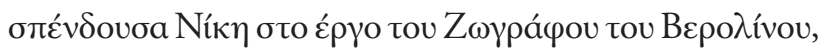

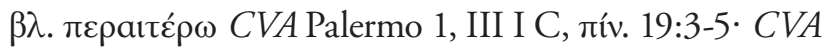

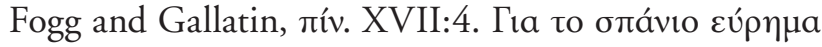

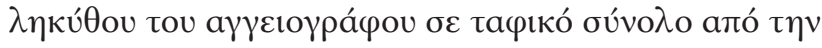

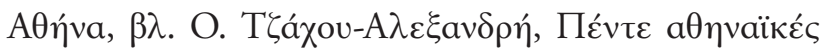

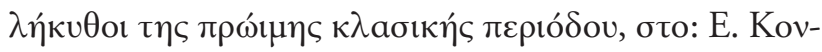

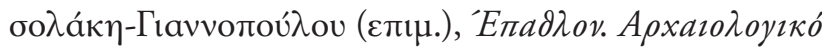

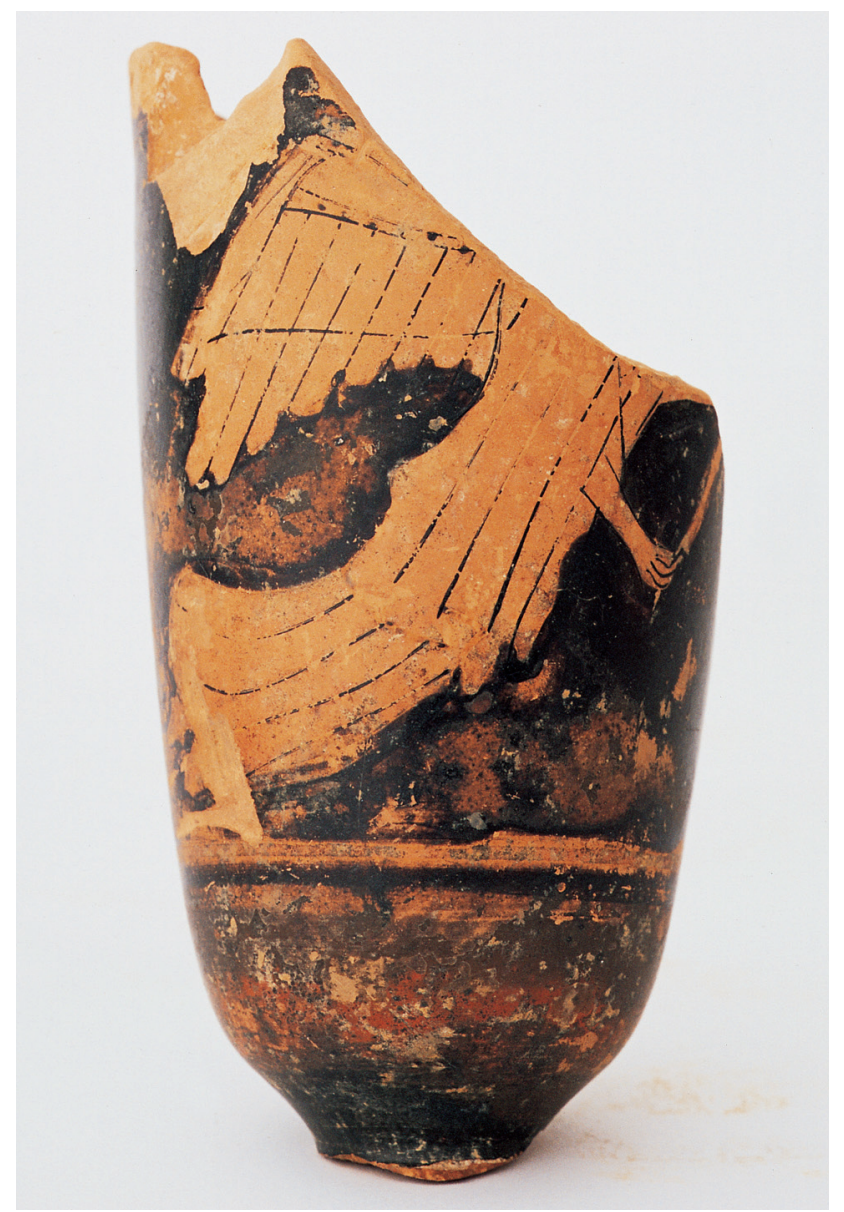

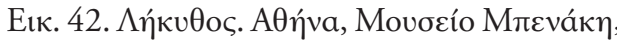

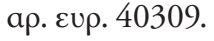

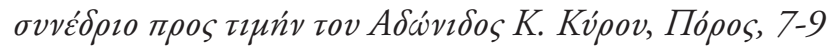

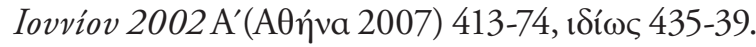

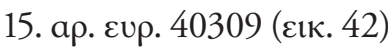

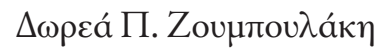

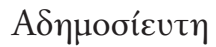

$\sum \omega \zeta . \cup ́ \psi .: 11 \varepsilon \kappa$.

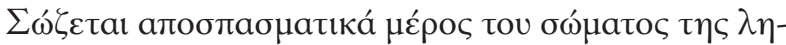

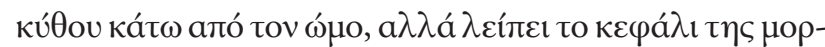

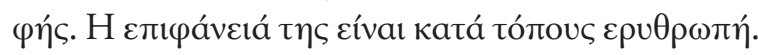

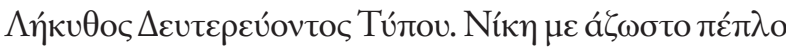

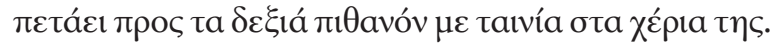

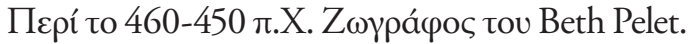

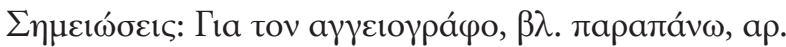

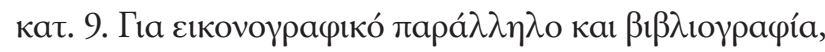
$\beta \lambda$. O. Dräger, CVA Erlangen 2, tív. 40:6,10,11. 


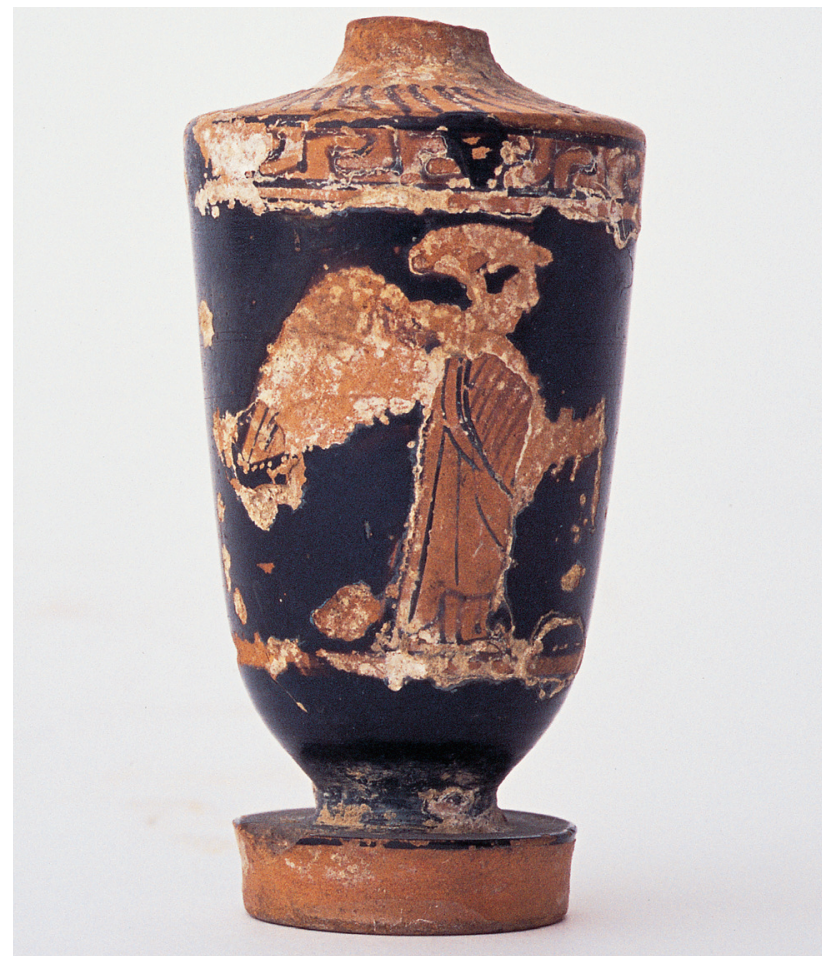

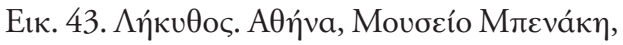

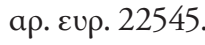

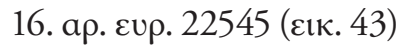

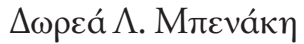

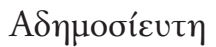

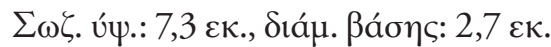

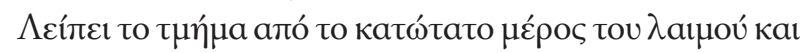

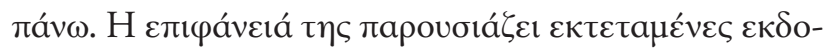

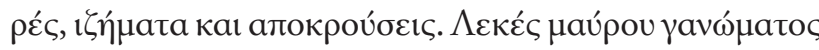

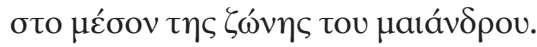

$\Lambda \eta ́ \kappa$

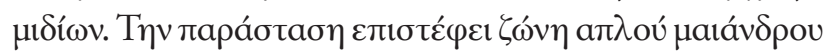

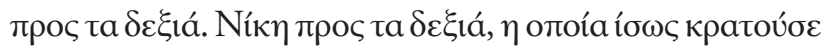

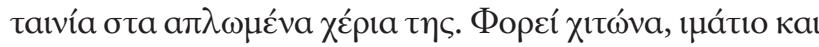
ба́кко.

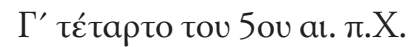

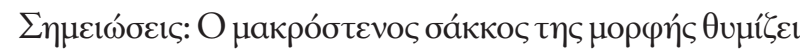

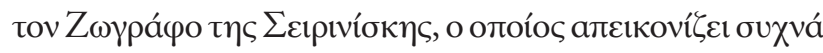

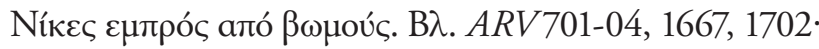

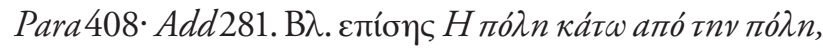

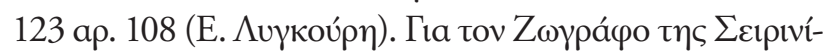

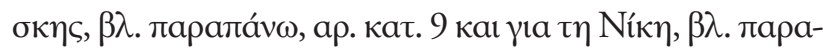
$\pi a ́ v \omega$, ар. кат. 14.

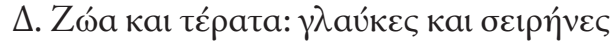

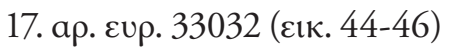

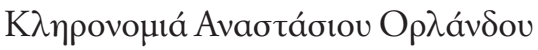

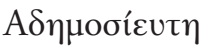

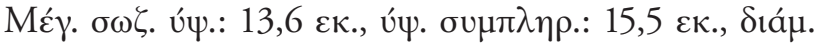

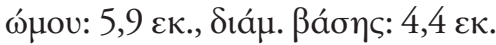

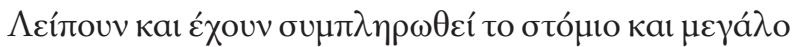

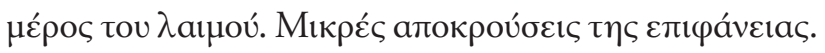

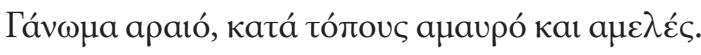

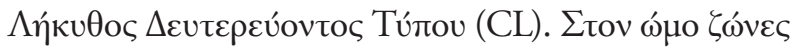

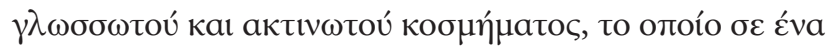

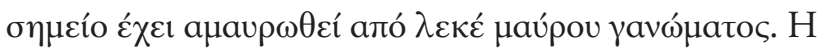

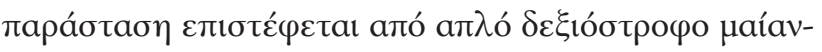

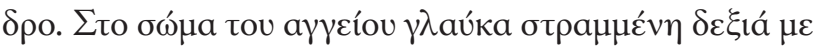

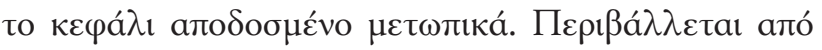

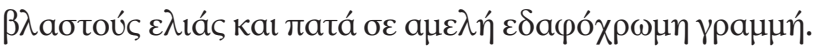

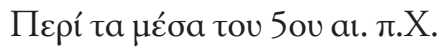

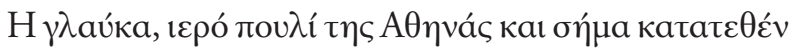

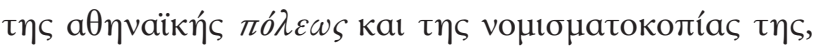

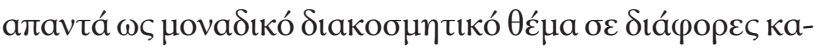

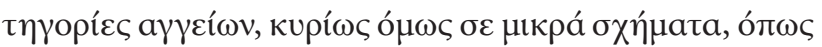

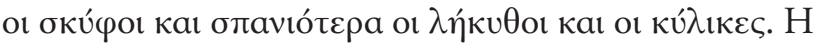

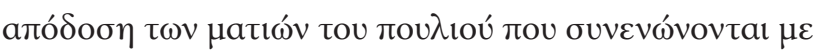

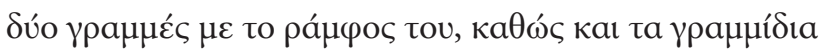

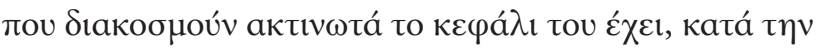

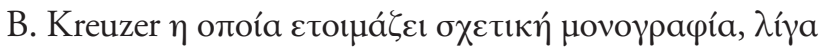

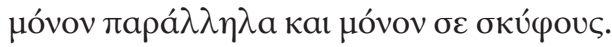

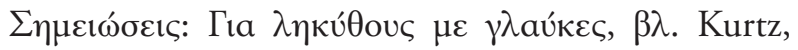

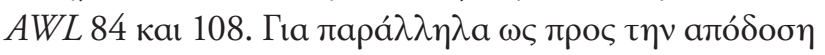

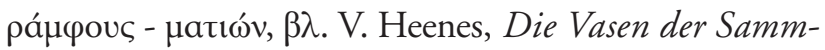
lung des Grafen Franz I. von Erbach zu Erbach (= Peleus

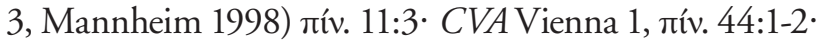

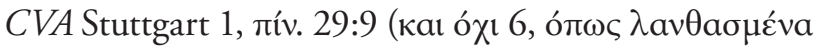

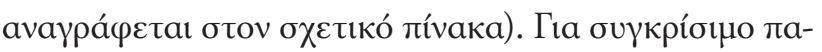

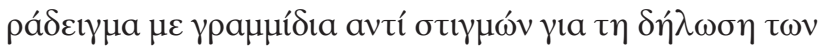
$\pi \tau i \lambda \omega v, \beta \lambda$. J. Jehasse $-L$. Jehasse, La nécropole préromaine

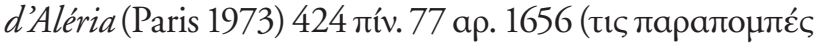

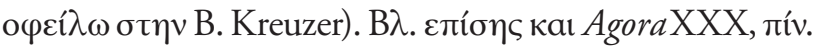

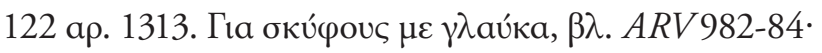

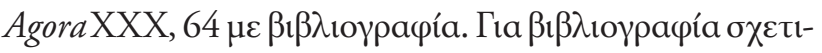

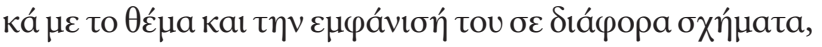

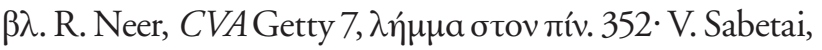

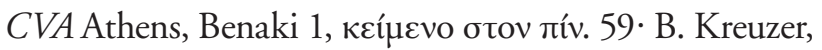
Eulen aus Athen: 520-480 B.C., oto: C. Weiß-E. Simon $(\varepsilon \pi t \mu)$, Folia in memoriam Ruth Lindner collecta (Det- 

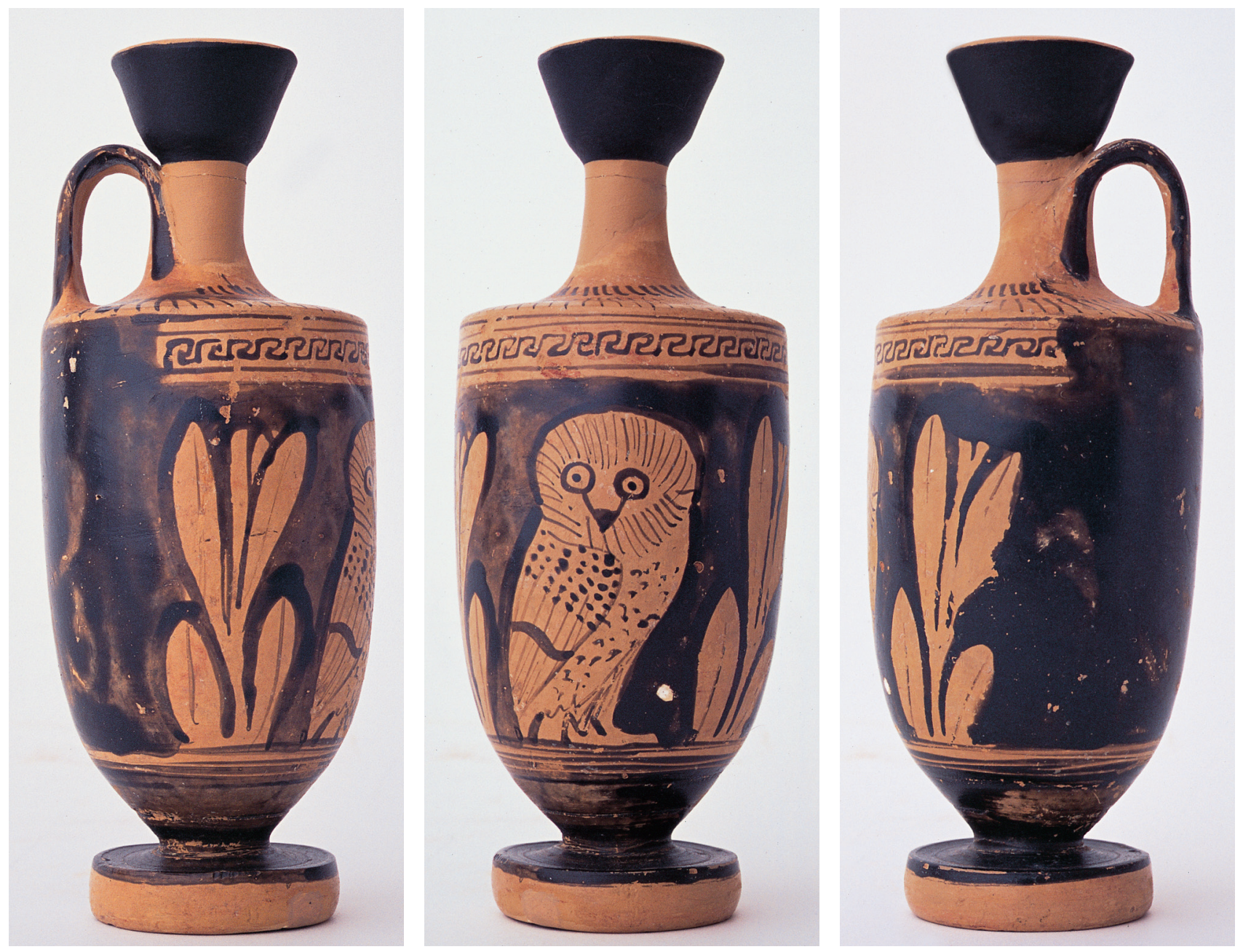

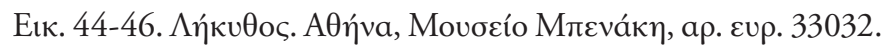

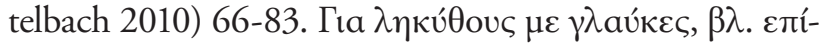

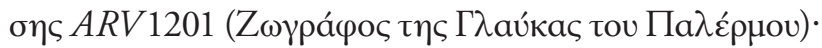

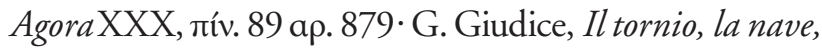

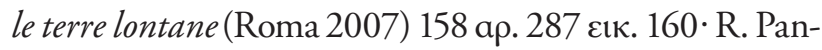
vini, Ceramiche attiche figurate del Museo Archeologico di Caltanissetta (Bari 2005) 95 ap. III:28. CVAAmsterdam 4,

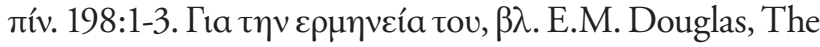
Owl of Athena, JHS 32 (1912) 174-78 - M.H. Groothand, The Owl on Athena's Hand, Babesch 43 (1968) 35-51 C. Melldahl - J. Flemberg, Eine Hydria des Theseus-Malers mit einer Opferdarstellung, oto: From the Gustavianum Collections in Uppsala 2 (= Acta Universitatis Upsaliensis: Boreas 9, Uppsala 1978) 57-79, ıoí $\omega \varsigma$ 73-75 . C. Bron, La gent ailée d'Athéna Poliade, oto: C. Bron-E. Kassapoglou

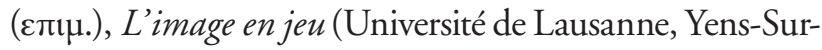

Morges 1992) 47-84· H. Hoffmann, Dulce et decorum est pro patria mori: the imagery of heroic immortality on Athe-

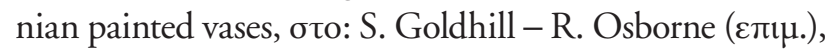
Art and Text in Ancient Greek Culture (Cambridge 1994)

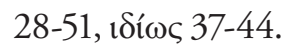

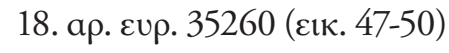

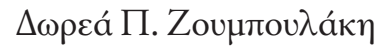

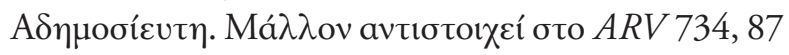

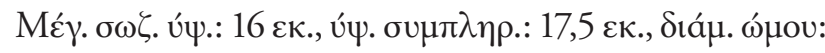

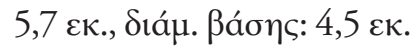

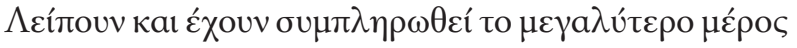

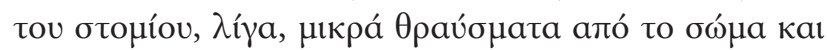

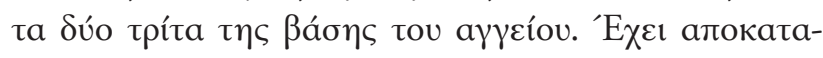

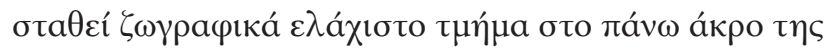



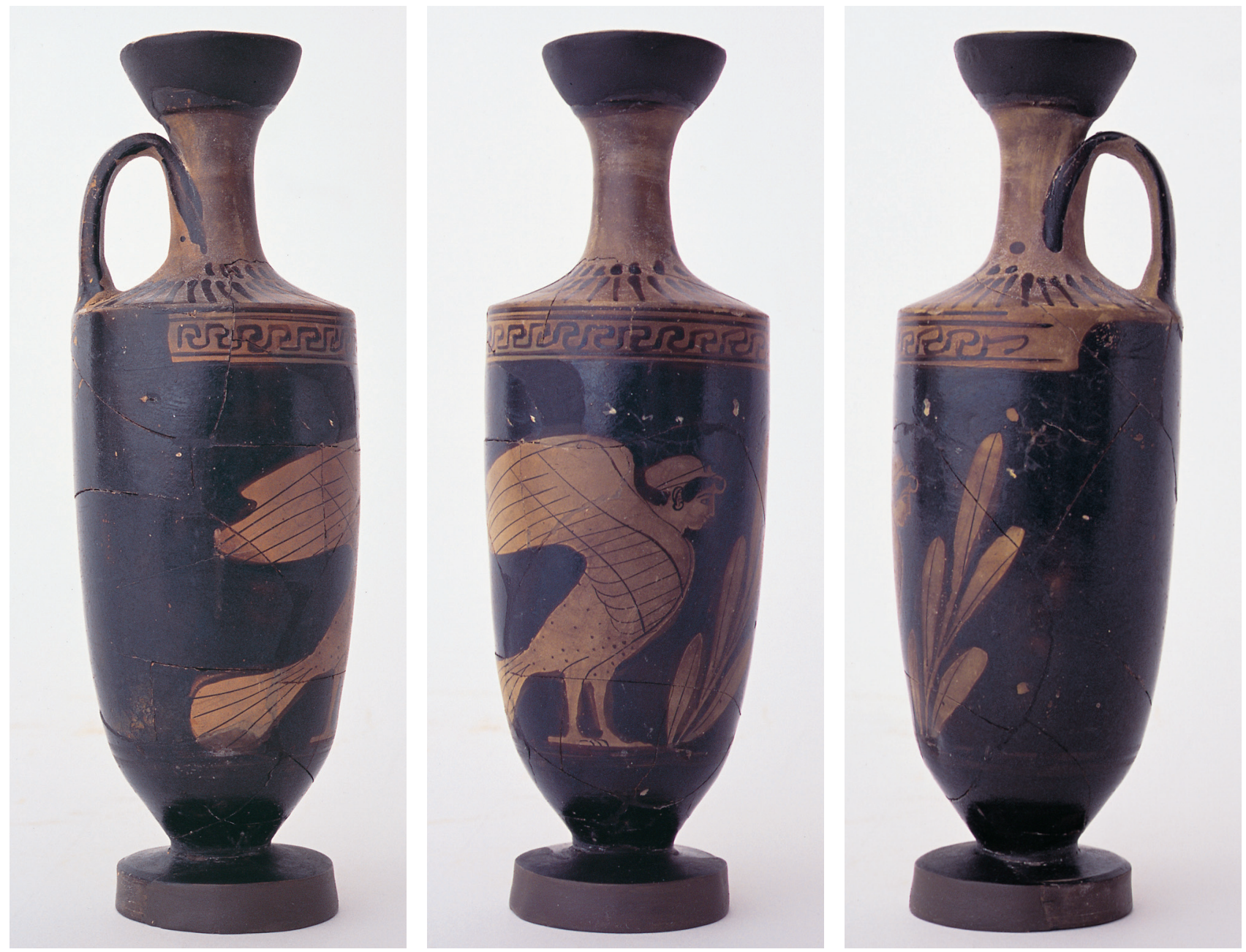

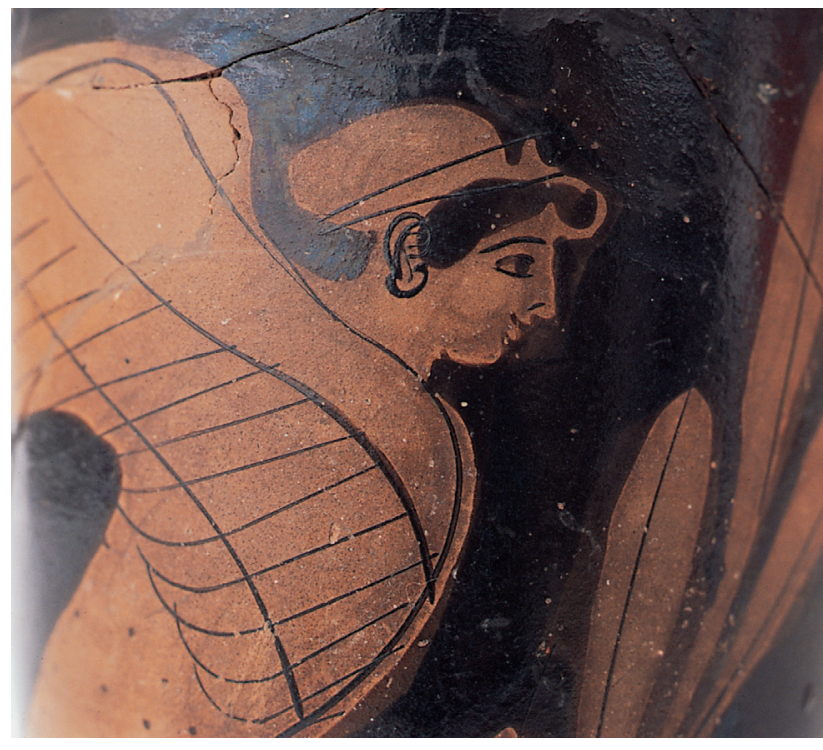

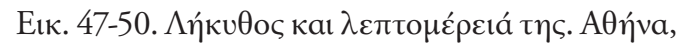

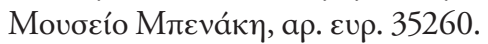

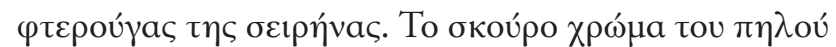

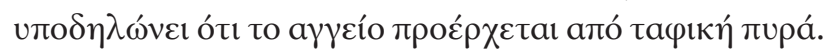

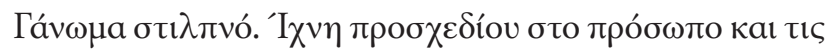

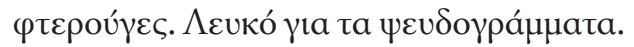

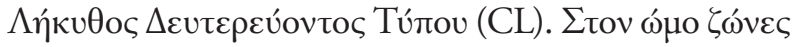

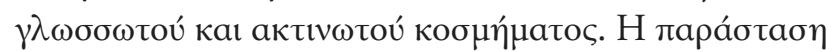

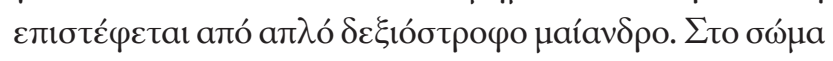

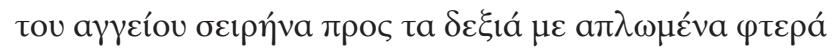
$\varepsilon \mu \pi \rho o ́ c$ a $\lambda$ lá Tov a

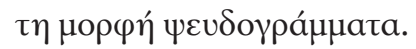

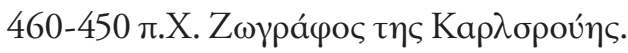

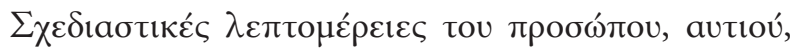

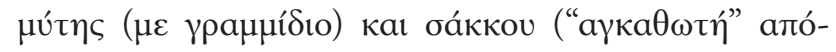

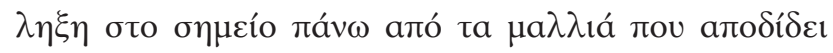

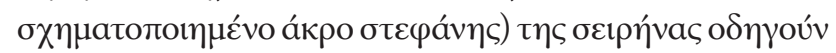

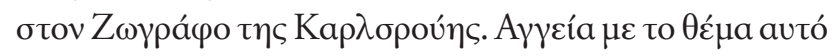

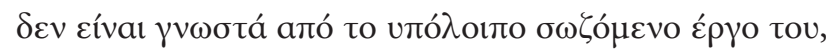




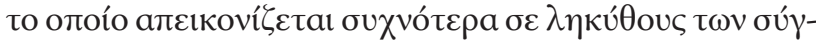

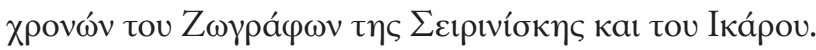

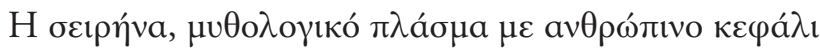

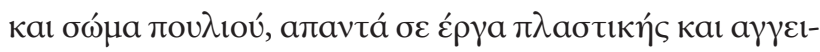

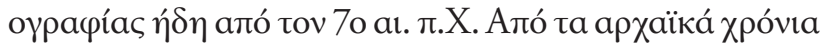

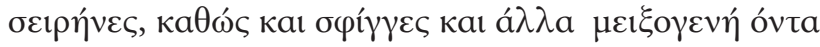

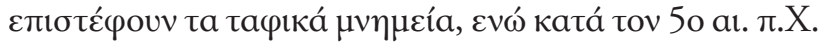

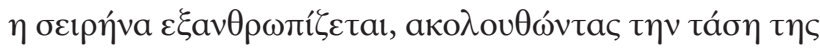

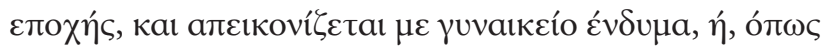

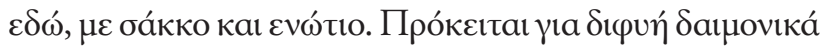

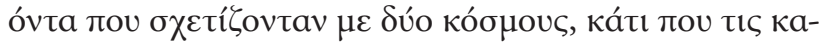

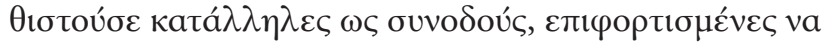

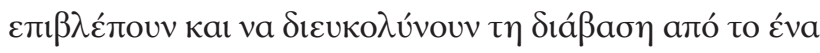

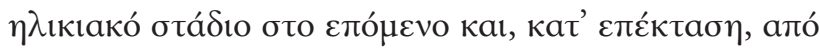

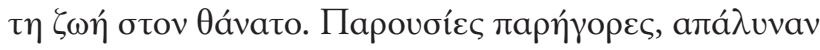

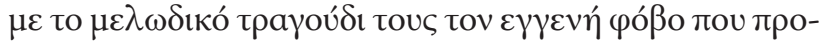

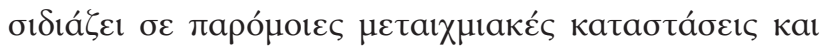

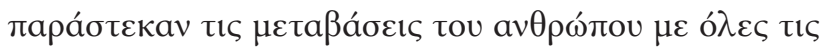

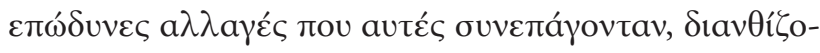

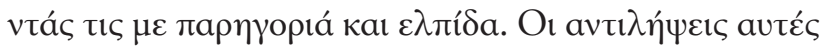

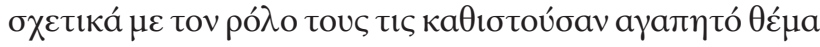

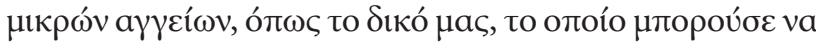

\section{¿YNTOMOГРАФIE $\Sigma$}

Add: T. H. Carpenter, Beazley Addenda (2nd ed., Oxford 1989).

Agora XXX: M. B. Moore, The Athenian Agora XXX, Attic Red-figured and White-ground Pottery (Princeton 1997).

ARV: J. D. Beazley, Attic Red-figure Vase-painters (2nd ed., Oxford 1963).

Banco Sicilia: F. Giudice - S. Tusa - V. Tusa, La collezione archeologica del Banco di Sicilia II (Palermo 1992).

Calame 1997: C. Calame, Choruses of Young Women in Ancient Greece (translated by D. Collins and J. Orion, Lanham 1997).

CVA: Corpus Vasorum Antiquorum.

Ferrari 2002: G. Ferrari, Figures of Speech (Chicago-London 2002).

Haspels, ABL: C. H. E. Haspels, Attic Black-figured Lekythoi (Paris 1936).

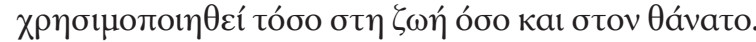

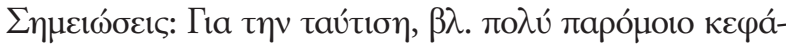

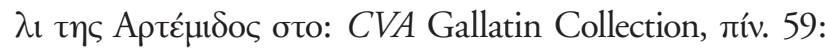

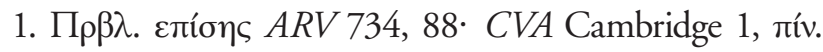

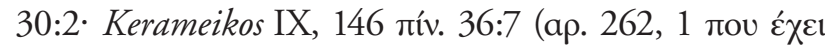

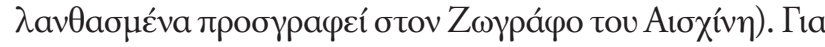
тоv Z

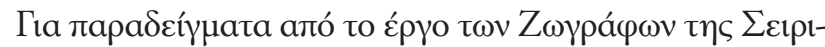

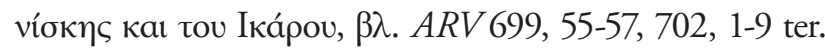
Tta to $\theta \varepsilon \dot{\mu a}, \beta \lambda$. E. Hofstetter, Sirenen im archaischen und klassischen Griechenland(Würzburg 1990) 186-95 каı үع-

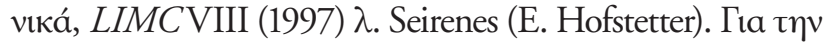

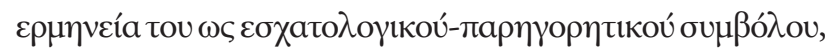
$\beta \lambda$. D. Tsiafakis, Life and Death at the Hands of a Siren, Studia Varia from The J. Paul Getty Museum 2 (2001) 18-21.

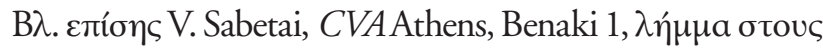

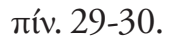

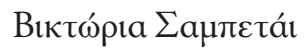

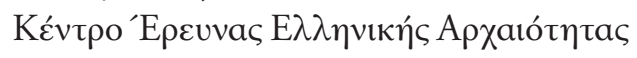

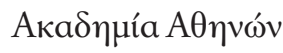

vsabetai@academyofathens.gr

Kerameikos IX: U. Knigge, Kerameikos: Ergebnisse der Ausgrabungen Bd. 9. Der Südhügel (Berlin 1976).

Kurtz, AWL: D. C. Kurtz, Athenian White Lekythoi: Patterns and Painters (Oxford 1975).

MuM: Kunstwerke der Antike, Münzen und Medaillen A.G., Basel.

Para: J. D. Beazley, Paralipomena (Oxford 1971).

Panvini 2003: R. Panvini, Ceramiche attiche figurate del Museo Archeologico di Gela : Selectio Vasorum (Venezia 2003)

ThesCRA: Thesaurus cultus et rituum antiquorum I (Los Angeles 2004)

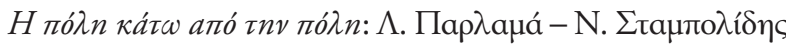

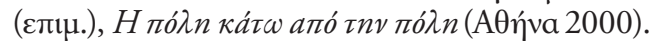




\section{$\sum$ HMEI $\Omega \Sigma E I \Sigma$}

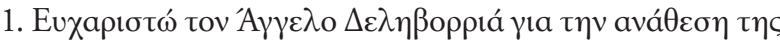

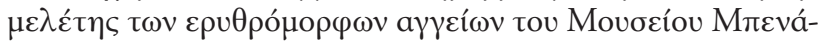

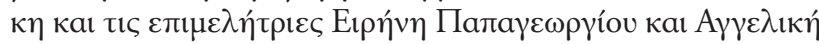

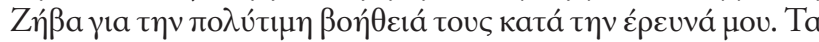

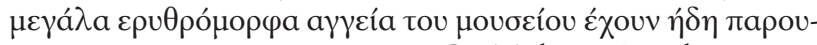

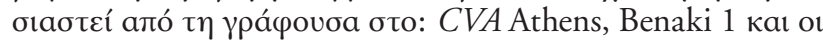
a

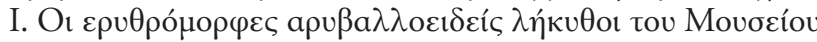

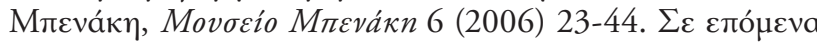

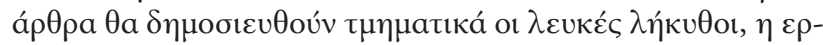

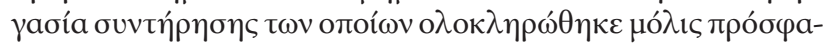

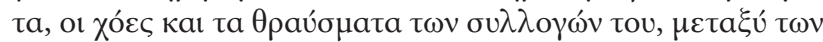

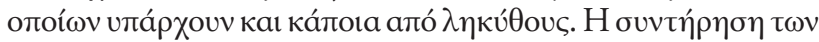

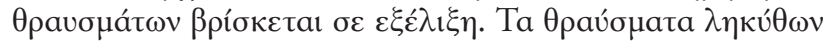

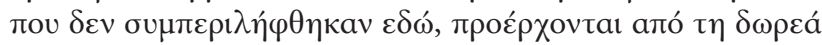

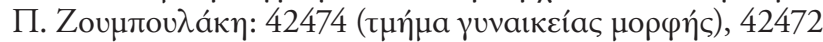

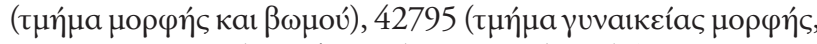

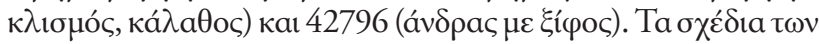

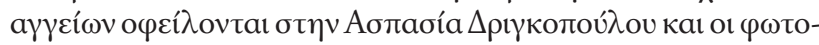

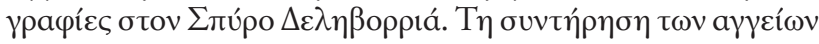

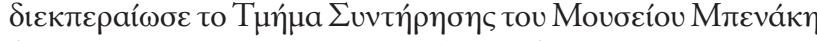

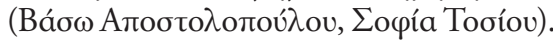

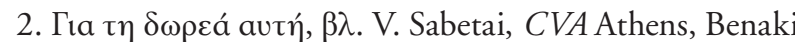
1, 9-11.

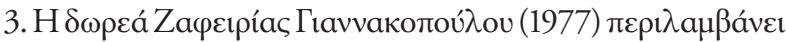

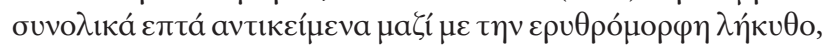

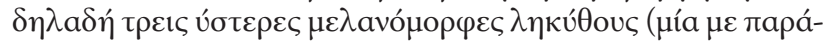

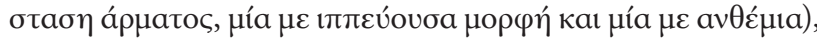

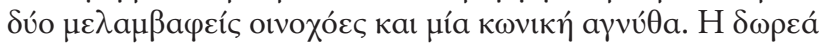

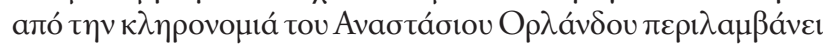

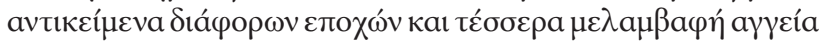
(

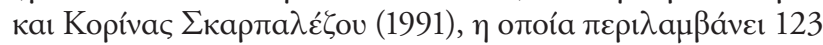

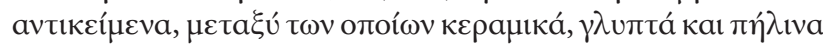

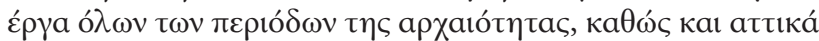

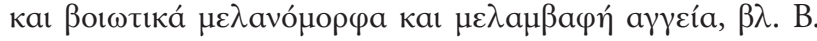

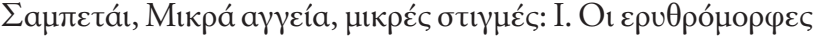
a

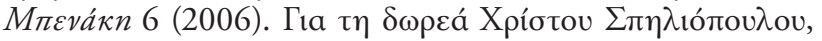

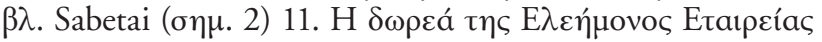

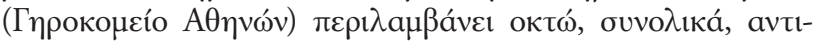

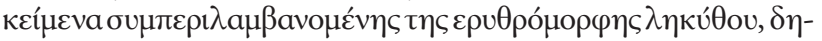

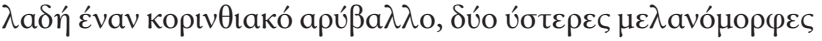

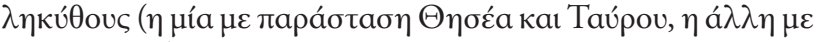

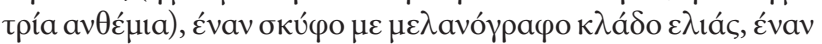

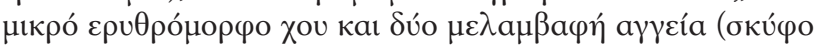
каı $\lambda \eta \kappa u ́ \theta t o)$.

4. S. Houby-Nielsen, The Archaeology of Ideology in the Kerameikos: New Interpretations of the "Opferrinnen", oto:

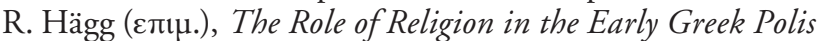

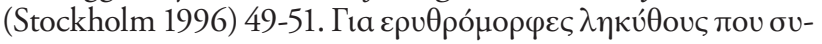

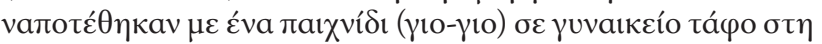
Bápๆ, $\beta \lambda$. M. Pipili, The Penthesilea Painter in the Attic Coun-

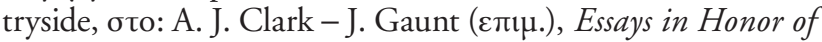

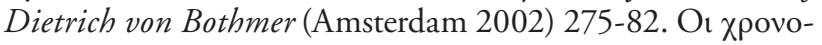

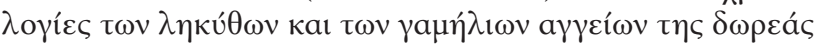

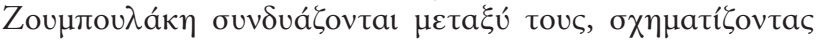

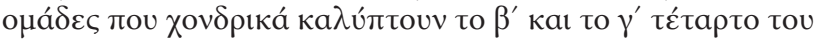

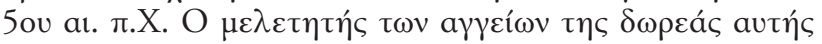

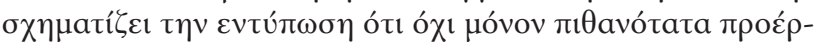

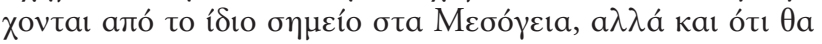

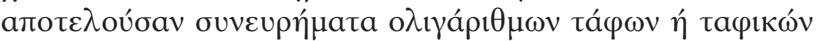

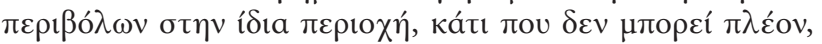
$\delta$

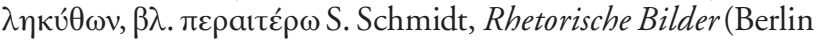
2005) 29-32.

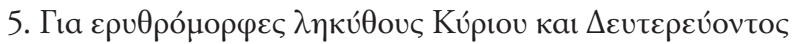

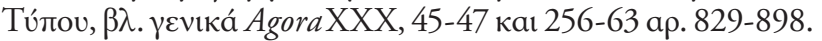

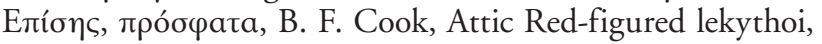
secondary types: Class 6L, OJA 10 (1991) 209-30.

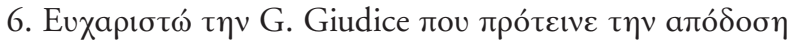
autท́. 


\section{VICTORIA SABETAI}

Small vases, small moments: II. The red-figured lekythoi from the Benaki Museum vase collection

This paper presents the red-figured lekythoi in the vase collection of the Benaki Museum. They date to the fifth century $\mathrm{BC}$ and must come from rural Attic cemeteries, and in particular from SE Attica; Boeotia is another possible provenance. The lekythoi are mainly decorated with emblematic, youthful figures, taken from larger compositions. The youths are represented as athletes, mantled citizens and jugglers, whereas females are pouring libations, carrying a thyrsos, fleeing some amorous pursuer or depicted as nuptial attendants or as generic marriageable maidens in the women's quarters. A particularly rare example, an unattributed black-bodied lekythos, has a youthful exploit of Theseus (the encounter with Skiron) depicted on its shoulder. The lekythos by the Berlin
Painter, depicting a Nike decking a tripod with a festive fillet, is of exceptional artistic quality. Nikai and a siren are legendary and possibly intermediary figures, while owls are the only animals depicted. The visual language of the lekythoi is succinct and emblematic. Their repertory is suitable for such small, yet perhaps luxury vessels, which were intended to be used in life and/or death. Vase-painters identified on the Benaki Museum examples are: the Bowdoin Painter, the Berlin Painter, the Karlsruhe Painter, the Dessypri Painter, the Aischines Painter, and the Beth Pelet Painter. Moreover one lekythos recalls the Seireniske Painter, while two others are tentatively assigned to the Painter of Prague 774 and to the Group of Harvard 2685 respectively. 
